\title{
PERCEPCIÓN DE LA COMUNIDAD DEL MUNICIPIO DE SANTA MARÍA (BOYACÁ) ANTE POSIBLES IMPACTOS AMBIENTALES ASOCIADOS A LA ADJUDICACIÓN DEL BLOQUE PETROLERO COR 60.
}

\author{
TESIS PARA OPTAR AL TÍTULO DE \\ MAGISTER EN PLANEACIÓN PARA EL DESARROLLO
}

AUTOR: FABIO ANTONIO GUERRERO AMAYA

\author{
ASESOR: MIGUEL URRÁ CANALES \\ DECANO FACULTAD DE SOCIOLOGIA
}

\author{
UNIVERSIDAD SANTO TOMÁS \\ FACULTAD DE SOCIOLOGÍA \\ MAESTRÍA EN PLANEACIÓN PARA EL DESARROLLO \\ BOGOTÁ D.C. \\ OCTUBRE DE 2016
}




\section{TABLA DE CONTENIDO}

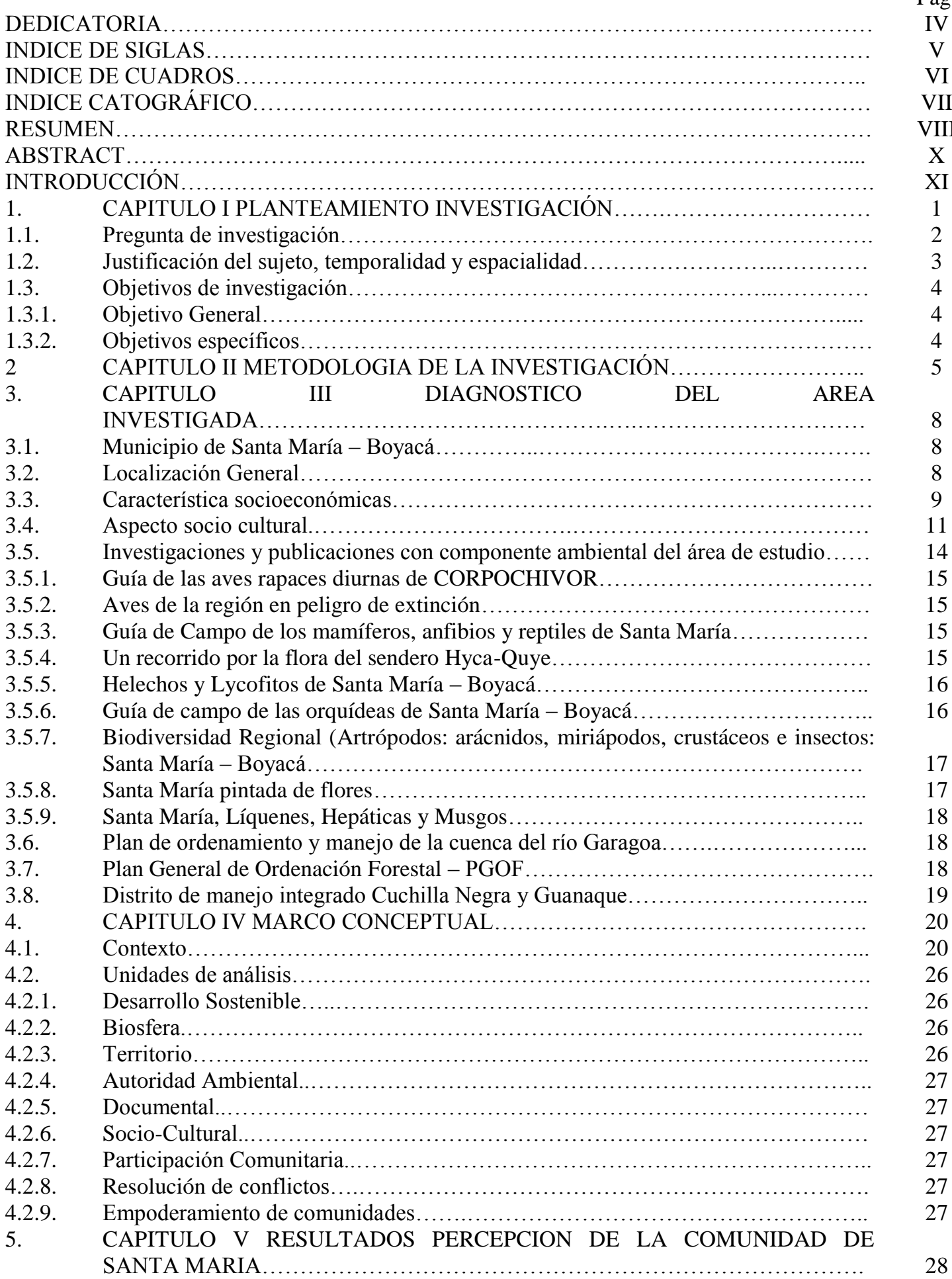




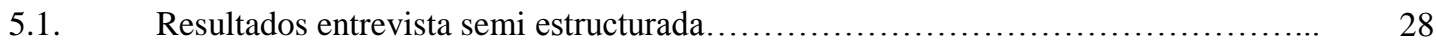

5.2. Resultados taller de cartografía social..................................... 34

5.3. Cartografía de estudios relacionada con la investigación........................ 40

5.4. Priorización de categorías.......................................... 53

5.5. Síntesis de los resultados de la aplicación de entrevista semiestructuradas y cartografía social a integrantes de la población objetivo para determinar la percepción respecto a la eventual aprobación del bloque petrolero COR-

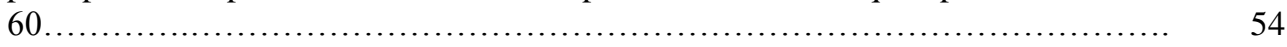

5.6. Recomendaciones o sugerencias a la autoridades ambientales................... 59

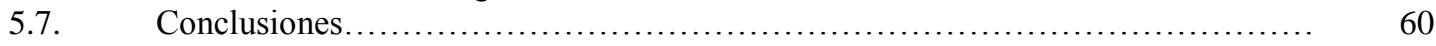

Bibliográficas y Web grafía.............................................. 63

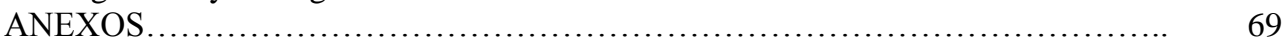

Anexo 1: Entrevista Semiestructurada ...................................... 69

Anexo 2: Guía para el desarrollo de cartografía social para determinar la percepción de la comunidad del municipio de Santa María (Boyacá) ante posibles impactos ambientales asociados a la adjudicación del bloque petrolero COR-

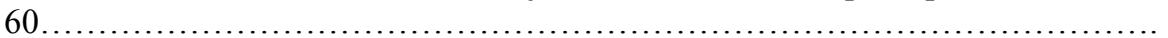

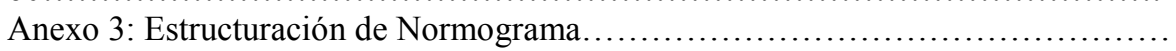

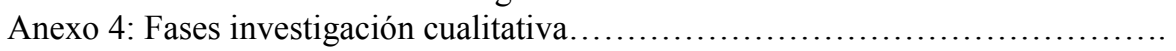

Anexo 5: Participantes herramientas de investigación.......................... 82

Anexo 6: Evidencias realización de taller cartografía social..................... 83

Anexo 7: Características ecológicas estructurales de los bosques existentes en el municipio de Santa María - Boyacá........................................ 


\section{DEDICATORIA}

A la memoria de mi hermano Carlos Armando, en los 50 años de su fallecimiento y a todos mis mayores quienes se marcharon a la gloria de Dios, entre ellos: Manuelito, Cecilita, Numita, Isabelita y Margarita, gracias por su ejemplo, por siempre en nuestros corazones.

A Camilo Andrés, mi hijo por ser la inspiración de mi vida, a Herminda por su dedicación y apoyo continuo, a todos mis sobrinos por ser las bases del futuro y a toda la familia en general, gracias por ser como son, mi familia. 


\section{INDICE DE SIGLAS}

AES

ANH

ANLA

APA

$\mathrm{CO}_{2}$

COR

CORPOBOYACÁ

CORPOCHIVOR

DRMI

EIAS

ICFES

MADS

ONGs

PBC

PGOF

PIGA

PNN

POMCAS

PNUD

RSE

SINA

UICN
Applied Energy Services.

Agencia Nacional de Hidrocarburos.

Agencia Nacional de Licencias Ambientales.

Conjunto de estándares o reglas que ayudan a codificar varios componentes de la escritura científica.

Dióxido de Carbono.

Área disponible.

Corporación Autónoma Regional de Boyacá

Corporación Autónoma Regional de Chivor

Distrito regional de manejo integrado

Evaluaciones de impacto ambiental y social.

Instituto Colombiano para el fomento de la educación superior.

Ministerio de Ambiente y Desarrollo Sostenible.

Organizaciones no gubernamentales.

Programa de beneficio de las comunidades

Plan General de Ordenación Forestal.

Plan institucional de gestión ambiental.

Parques Nacionales Naturales

Plan de ordenamiento y manejo de las cuencas

Programa de las naciones unidas para el desarrollo.

Responsabilidad social empresarial.

Sistema Nacional Ambiental

Unión internacional para la conservación de la naturaleza. 


\section{INDICE DE TABLAS}

Pág.

Aspectos y categorías identificadas................................ 53

$2 \quad$ Niveles de la problemática....................................... 54

$3 \quad$ Niveles de los impactos positivos identificados..................... 56

$4 \quad$ Niveles de los impactos positivos identificados .................... 57

$5 \quad$ Planilla asistencia a taller cartografía social....................... $\quad 72$

$6 \quad$ Identificación de convenciones................................... 73

$7 \quad$ Normograma tema petróleo...................................... $\quad 76$

$8 \quad$ Fases de la investigación cualitativa................................ 81

$9 \quad$ Participantes taller cartografía social............................. 82

10 Participante entrevista semi estructurada.......................... 82 


\section{INDICE CARTOGRAFICO}

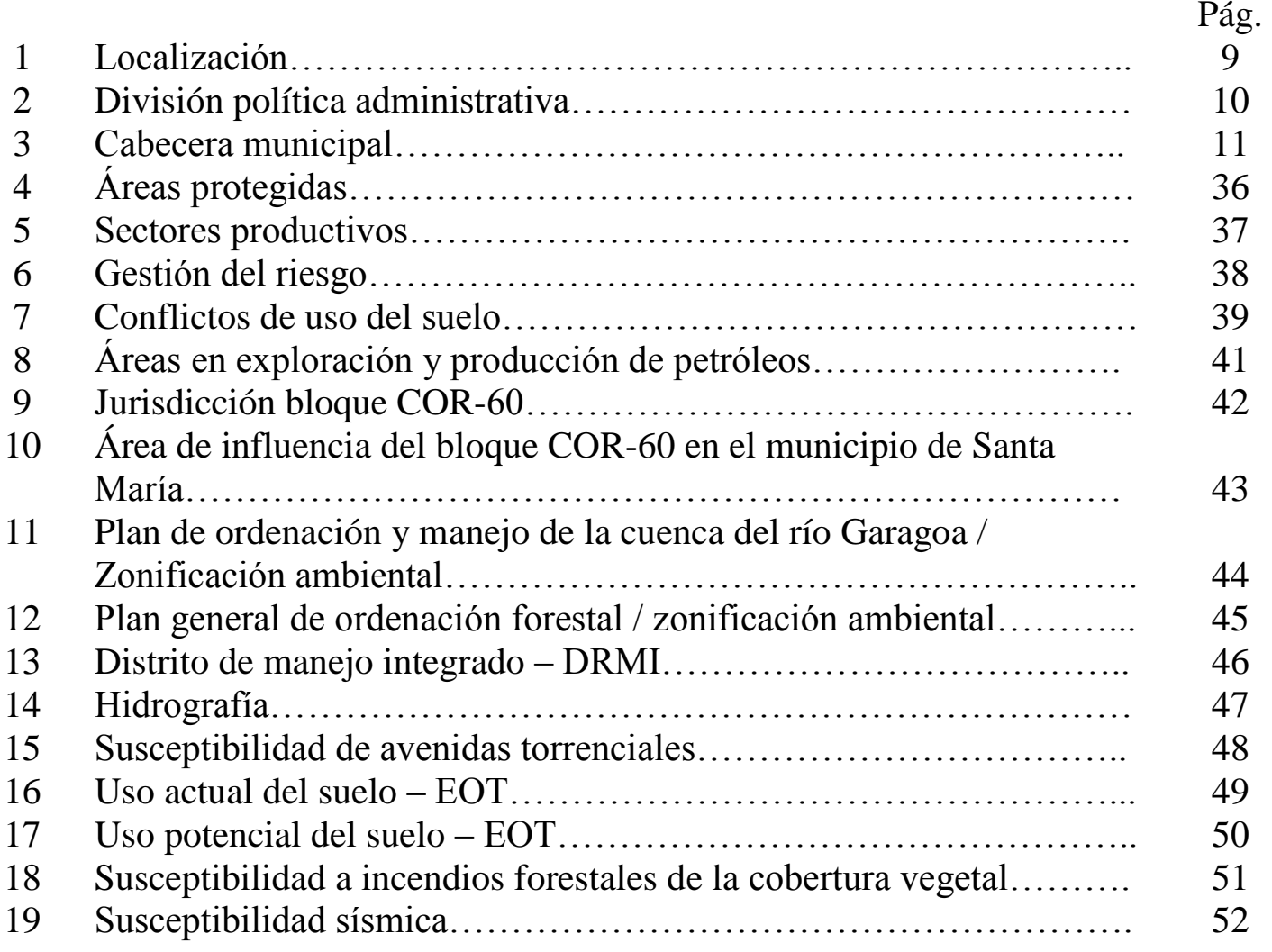




\section{RESUMEN}

El trabajo se realizó en el marco del trabajo de grado de la maestría en Planeación para el desarrollo, titulado: Percepción de la comunidad del municipio de Santa María (Boyacá) ante posibles impactos ambientales asociados a la adjudicación del bloque petrolero, se desarrolló durante el periodo 2014-2016. Identifica los principales aspectos (social, Recursos Naturales renovables y no renovables, Instrumentos de planificación y Riesgos) ambientales que le preocupa a la comunidad si el proyecto se llega a desarrollar, al igual identifica los impactos ambientales positivos en el campo Social, Económico, Institucional y Tecnológico, también identifica los impactos ambientales negativos a los recursos naturales (Agua, Suelo, Ruido, Fauna, Flora y Comunidad).

Dentro de las Recomendaciones y sugerencias, la comunidad enfatiza en que se exijan estudios de la zona para mitigar los impactos que se generen, acatar las directrices de la autoridad ambiental, respetar las áreas que han sido declaras como protegidas y que se realice seguimiento y acompañamiento para todo lo relacionado con el plan de manejo ambiental.

Finalmente se concluye que el municipio de Santa María - Boyacá es muy biodiverso por las condiciones ambientales de clima, geomorfología y biodiversidad, está ubicado en una zona de transición entre la región de la Orinoquía y la Región Andina, formando un corredor biológico, haciendo que las condiciones ambientales sean propias para el hábitat de especies silvestres, que el territorio ha sido altamente valorado y estudiado por la academia y las instituciones, los habitantes sienten temor por los impactos ambientales negativos que se presenten por la experiencia vivida con la construcción del embalse la Esmeralda, se imaginan que se podría presentar una burbuja dentro de la economía del municipio por el aumento de la población y por consiguiente la demanda de bienes y servicios de manera temporal, ocasionando problemas de carácter social 
principalmente, manifiestan que se debe diferenciar el tema de responsabilidad social empresarial y las medidas de compensación.

Palabras clave: desarrollo sostenible, impactos ambientales, ecosistemas, biósfera, petróleo, Santa María-Boyacá. 


\begin{abstract}
ABTRACT
The work was conducted under the work degree of expertise in planning for development, entitled Perceptions community in the municipality of Santa María (Boyacá) for possible environmental impacts associated with the award of the oil block, developed during the 2014-2016. Identifies the main aspects (social, Natural Resources, Planning instruments and Risks) environmental that concerns the community if the project comes to develop, as identifies the positive environmental impacts in the Economic Social field, Institutional and Technological also identifies the negative environmental impacts to natural resources (water, soil, noise, Fauna, Flora and Human (Community).

Among the recommendations and suggestions, the community emphasizes that studies of the area are required to mitigate the impacts generated, abide by the guidelines of the environmental authority, respect areas that have been declare as protected and that monitoring is made and accompanying for everything related to the environmental management plan.

Finally it is concluded that the municipality of Santa Maria - Boyacá is very biodiverse by environmental conditions of climate, geomorphology and biodiversity, is located in a transition zone between the region of the Orinoco and the Andean region, forming a biological corridor, making environmental conditions are proper for wildlife habitat, the territory has been highly valued and studied by academia and institutions, people feel fear about the negative environmental impacts that arise from the experience with the construction of the dam the Esmeralda, imagine that they could present a bubble within the town's economy by increasing the population and therefore the demand for goods and services temporarily, causing social problems mainly character, show that one must differentiate theme corporate social responsibility and compensation measures.
\end{abstract}

Keywords: sustainable development, environmental impacts, ecosystem, biosphere, petroleum, Santa Maria - Boyacá. 


\section{INTRODUCCIÓN}

El tema ambiental ha sido una de las preocupaciones de los gobernantes y es así como se incluye dentro de los diferentes instrumentos de planificación, enfocados hacia el desarrollo sostenible, previendo que las futuras generaciones tengan condiciones dignas en cuanto a la oferta y demanda de recursos naturales renovables y no renovables.

La Constitución Política tiene el carácter ambientalista y las normas que la han reglamentado abogan por que los derechos y deberes de los ciudadanos se enfoquen en las conductas ciudadanas para no derrochar e impactar los recursos naturales desmedidamente.

Los ciudadanos han entendido que tienen mecanismos de participación para manifestar su conformidad o inconformidad frente a proyectos de carácter macro que impactan de manera positiva o negativa el ambiente, entendiendo que las comunidades son muy importantes porque conocen los contextos regionales y generan información importante al momento de realizar un diagnóstico.

En el caso del municipio de Santa María, se aplicaron una serie de herramientas que permitieron recoger información de carácter primario constituyéndose en la línea base de la investigación, es de anotar que la realización del proyecto construcción del embalse la Esmeralda ha sido fundamental porque las comunidades entienden el concepto de macro proyecto y lo que se desencadena en el campo ambiental, social, cultural, económico y tecnológico.

Con la implementación de la investigación para determinar la percepción de la comunidad del municipio de Santa María (Boyacá) ante posibles impactos ambientales asociados a la adjudicación del bloque petrolero COR-60, fue necesario acudir a profesionales que fuesen del municipio de Santa María o que hubiesen participado en algún trabajo de carácter ambiental, para que la información aportada se ajustara a la realidad y se considerara confiable.

La investigación fue de carácter cualitativo, fue necesario recolectar la información de manera detallada para agruparla por categorías y determinar el orden en función de interpretar la 
percepción respecto a los aspectos que le preocupan a la comunidad, la identificación de impactos positivos y negativos si el bloque petrolero COR-60 es adjudicado.

Respecto a la priorización de categorías, se concluye que a los habitantes del Municipio de San María - Boyacá les preocupa el agotamiento de los recursos naturales, la descomposición social y familiar, la armonización de los instrumentos de planificación del orden regional y local, y el tema de riegos de carácter natural y antrópico.

Respecto a los impactos positivos destacan el apoyo interinstitucional para el tema ambiental, la destinación de recursos para el tema ambiental, la dinamización de la economía regional y local, la oferta de trabajo y el tema de compensaciones, además el tema tecnológico es considerado como trascendental porque demanda de capacitación para la mano de obra calificada.

En lo relacionado a impactos negativos es liderado por el aspecto comunitario porque creen que se formará una burbuja de especulación mientras el proyecto se esté realizando, lo que conlleva a desordenes de tipo social que a largo plazo se convierte en pobreza, además creen que se impactaran drásticamente el recurso agua, flora, aire, fauna y suelo.

Entender el tema del desarrollo sostenible y las políticas que tiene el estado en torno al manejo y dinamización de la economía a través uso responsable de los recursos naturales renovables y no renovables con tecnologías de punta para mitigar los impactos generados, donde las instituciones con funciones ambientalistas sean autoridad aplicando la normatividad vigente, sin desconocer la percepción de las comunidades respecto a la viabilizarían o no de los proyectos en sus contextos. 


\section{CAPitulo I}

\section{PLANTEAMIENTO DE LA INVESTIGACIÓN.}

Los bloques de exploración petrolera son adjudicados a las diferentes compañías interesadas, por la Agencia nacional de hidrocarburos - ANH, antes de la adjudicación de dichos bloques son analizados aspectos técnicos de orden social, ambiental y económico, en algunos casos es adjudicado con condicionamientos de carácter social y ambiental, los cuales deben ser analizados en detalle e incluirlos en los estudios de impacto ambiental previo a la aprobación ante la agencia nacional de licencias ambientales - ANLA y luego estructurar el plan de manejo ambiental. Lo anterior define la pertinencia o no del otorgamiento de licencia para exploración y explotación del bloque ofertado.

El aporte de la investigación es determinar las impresiones o preocupación de los residentes respecto al manejo o protección ambiental y determinar los impactos que se generen por la actividad petrolera y que sean tenidos en cuenta por las instituciones que son autoridad ambiental en el momento de la adjudicación a las compañías interesadas en el bloque petrolero.

La investigación permitirá identificar las diferentes categorías de carácter ambiental, social, tecnológico y económico con el objeto de determinar los posibles condicionamientos a quien se otorgó el licenciamiento del bloque y manejados en función de mitigar los aspectos e impactos en lo relacionado a costumbres ancestrales, productivas e históricas de las comunidades asentadas, declaratorias adoptadas para el área, acorde con los condicionamientos ambientales de las áreas estratégicas objeto de estudio. 


\subsection{Pregunta de investigación.}

En la actualidad no está adjudicado el bloque petrolero COR-60, sin embargo la Agencia Nacional de Hidrocarburos - ANH cada dos años oferta las áreas que están si adjudicar, el Municipio de Santa María posee 10.066 Ha. de bosque natural denso y 3.646 Ha. de bosque fragmentado, donde se encuentra gran biodiversidad, la cual ha sido estudiada y publicada a través de convenios entre instituciones como AES Chivor, CORPOCHIVOR, Universidad Nacional de Colombia, Universidad Francisco José Caldas y Administración Municipal, como antecedente relevante está la construcción de la hidroeléctrica, macro proyecto denominado Embalse la Esmeralda, la cual generó muchas expectativas positivas y negativas al igual que impactos positivos y negativos en el componente ambiental, relacionados con el clima, pérdida de biodiversidad, cambio de uso del suelo, generación de ruido y partículas, el deterioro de las vías por el desplazamiento de maquinaria pesada y la descomposición social entre otros, teniendo en cuenta los atenuantes anteriores, se revisó la cartografía generada por la ANH, titulada "Actividad Hidrocarburifera en la jurisdicción de Corpochivor", encontrando disponible de adjudicación el bloque COR - 60, dentro de esa área se encuentra el municipio de Santa María, el cual está incluido dentro del Plan General de Ordenación Forestal, declarado el Distrito Regional de manejo integrado de la cuchilla Negra y Guanaque y con Esquema de Ordenamiento Territorial.

Ante la amalgama de factores se formuló la siguiente pregunta ¿Cuál es la percepción de la población en la cabecera municipal de Santa María (Boyacá) ante posibles impactos ambientales asociados a la adjudicación del bloque petrolero COR-60, por la Agencia Nacional de Hidrocarburos - ANH?, siendo esta el insumo para la investigación, de tal manera que los resultados ambientales generados sean el atenuante preventivo para que las autoridades ambientales y administrativas exijan el cumplimiento de la normatividad ambiental y los aspectos que le preocupan a los habitantes del Municipio de Santa María. 


\subsection{Justificación del SUJETO, temporalidad y espacialidad.}

Es importante realizar la investigación porque al identificar los aspectos ambientales que influyen o impactan en los ecosistemas y en las comunidades de base, se convierten en la línea base a tener en cuenta por las autoridades institucionales que autorizan la explotación de hidrocarburos.

El trabajo pre, con las comunidades de base e interinstitucional es fundamental para realizar un diagnóstico donde se identifican los impactos y herramientas que se tienen a disposición para mitigar las acciones que generan malestar al implementar la explotación de hidrocarburos, teniendo en cuenta la normatividad vigente.

La ubicación geográfica del bloque petrolero COR-60, es estratégica por la diversidad de ecosistemas que se deben proteger y por el manejo social que se debe dar porque el área rural es extensa y los usos del suelo deben ser tenidos en cuenta por el tema del ordenamiento ambiental territorial.

La población objetivo a estudiar es la población del área urbana del municipio de Santa María porque allí residen la mayoría de presidentes de Juntas de acción comunal, Juntas de acueductos, docentes que laboran en el área rural, Ingenieros, personas que vivenciaron la realización de un macro proyecto en la zona, como fue la construcción y operación del embalse La Esmeralda, generadora de energía, dentro de la población residente se encuentran técnicos, tecnólogos, profesionales, especialistas que por la experiencia aportaran información relevante para la investigación.

Santa María pertenece al pie de monte llanero, las investigaciones realizadas lo han considerado como una zona de transición ecológica que contiene gran diversidad de 
especies de diferentes zonas de vida, la riqueza natural en un área tan pequeña atrae a la academia para investigar y a sus moradores a valorar el patrimonio ambiental existente.

A nivel institucional, se han protocolizado alianzas estratégicas para investigar y publicar la gran riqueza natural, han apoyado a investigadores las siguientes instituciones: AES Chivor, Universidad Nacional de Colombia, Corporación Autónoma Regional de Chivor, Instituto Alexander Von Humboldt y Alcaldía

\subsection{Objetivos de la investigación.}

\subsubsection{Objetivo General:}

Determinar la percepción de la población urbana del municipio de Santa María (Boyacá), respecto a posibles impactos ambientales en áreas estratégicas, asociado a la adjudicación del bloque petrolero COR-60 por la Agencia nacional de hidrocarburos ANH, Sur oriente de Boyacá.

\subsubsection{Objetivos Específicos:}

- Diagnosticar el conocimiento que tiene la población de Santa María, sobre áreas estratégicas ambientales en su municipio.

- Identificar posibles impactos ambientales generados por la actividad petrolera en el municipio de Santa María - Boyacá 


\section{CAPITULO II. METODOLOGIA DE LA INVESTIGACIÓN.}

Se aplicó el método de carácter cualitativo, porque las fases se ajustaban a la temática, a las circunstancias de contexto y al aspecto social porque tiene el carácter de flexibilidad al momento de interactuar con el investigado, acorde con la tabla 8, "Se busca examinar la realidad tal como otros la experimentan, a partir de la interpretación de sus propios significados, sentimientos, creencias y valores" (Rodríguez, 2011, p. 17), entablando un

proceso de comunicación permanente y de manera directa, acorde con los momentos e imprevistos que se presenten, lo que permite al investigador replantear el cuestionario o encausar la temática abordada, ampliar las preguntas y profundizar en aspectos que permitan concluir en la investigación.

La recolección de la información se basó inicialmente en consultar las fuentes secundarias como la Agencia Nacional de Hidrocarburos - ANH, Corporación Autónoma Regional de Chivor, Universidad Nacional de Colombia, AES Chivor y la Alcaldía de Santa María, se consultaron las normas de carácter ambiental, relacionadas con el tema de exploración y explotación de petróleo, lo que se sintetizó en el Normograma, incluido en la tabla 7, determinando la línea base de la información a manera de diagnóstico y el diseño de otras herramientas, para alcanzar los objetivos propuestos, encontrándose las siguientes herramienta: entrevista semi estructurada para comunidades de la cabecera municipal de Santa María y la cartografía social, para determinar la percepción de la comunidad del municipio de Santa María (Boyacá) ante posibles impactos ambientales asociados a la adjudicación del bloque petrolero COR-60, referenciado los participantes en las tablas 9 y 10. En esta fase "el investigador se focaliza en aprender el significado que los participantes otorgan al problema o fenómeno en cuestión” (Alesina Et al., 2011, p. 78), el papel que 
cumple va enfocado a ser perceptivo, facilitador, orientador e intérprete del lenguaje, verbal, escrito y no verbal.

Los datos de la entrevista semi estructurada se encuentran en grabaciones de audio, lo que conllevó a escuchar y pasar la información relevante a un archivo de texto para poder analizar los datos, al igual se realizó con la cartografía social de cada una de la mesas, a saber: Biodiversidad, Ecosistemas y Recurso Hídrico, Sectores Productivos, Gestión del Riesgo y Conflictos socio-ambientales. Fue necesario resaltar la información que se consideró clave, teniendo en cuenta las siguientes unidades análisis: desarrollo sostenible, biósfera, territorio, autoridad ambiental, documental, sociocultural, Participación Comunitaria, resolución de conflictos ambientales y empoderamiento de las comunidades de base.

La identificación de Impactos ambientales por fenómenos antrópicos, es fundamental en la fase pre de un proyecto y partir del postulado "Las evaluaciones de impacto ambiental son herramientas de predicción, y como tales adquieren sentido sólo si pueden influir en el desarrollo futuro de un proyecto". (Espinoza, 2002, p. 39) por tal motivo la investigación adquiere realce porque los habitantes del municipio entregan información en base a la oferta de recursos naturales y la prospección de manejo al realizarse la exploración y explotación de petróleo en el territorio.

En el trabajo de campo el investigador se encuentra con situaciones imprevistas porque las fuentes son diversas e interpretan la temática desde su punto de vista y contexto, en ocasiones no encaja, haciendo que investigador amplíe los datos y replantee la pregunta, lo que conlleva a asimilar que las técnicas "cualitativas permiten profundizar en determinados aspectos que quizá ni se tenían en cuenta inicialmente”. (Hueso González, A., i Sempere, C., \& Josep, M., 2012. p. 8), no quiere decir que la planificación fuese incompleta, simplemente aparecen aspectos o componentes complementarios que son importantes tenerlos en cuenta e 
incluirlos dentro de la investigación, es fundamental entender que la planificación de un proyecto es dinámica y permite ser complementada en la fase de implementación.

La información obtenida fue necesario clasificarla por categorías en cada una de las herramientas aplicadas plasmadas en la tabla 1, para el caso de lo que le preocupa en su orden se encuentran los recursos naturales, el aspecto social, los instrumentos de planificación y los riesgos que se generan identificado en la tabla 2; respecto a los impactos positivos en su orden identifican el institucional, económico, social y tecnológico visualizado en la tabla 3 y los impactos negativos en su orden identifican lo relacionado con la comunidad, recurso agua, flora, aire, fauna y suelo, sintetizados en la tabla 4.

Se destaca que la observación del comportamiento por parte del investigador es fundamental porque le permite complementar y contextualizar la temática, generalmente se adopta el método inductivo porque al consultar fuentes secundarias y primarias llega a categorías y unidades de información que permite al investigador analizar y develar la información de lo que observó, escuchó y sintetizó.

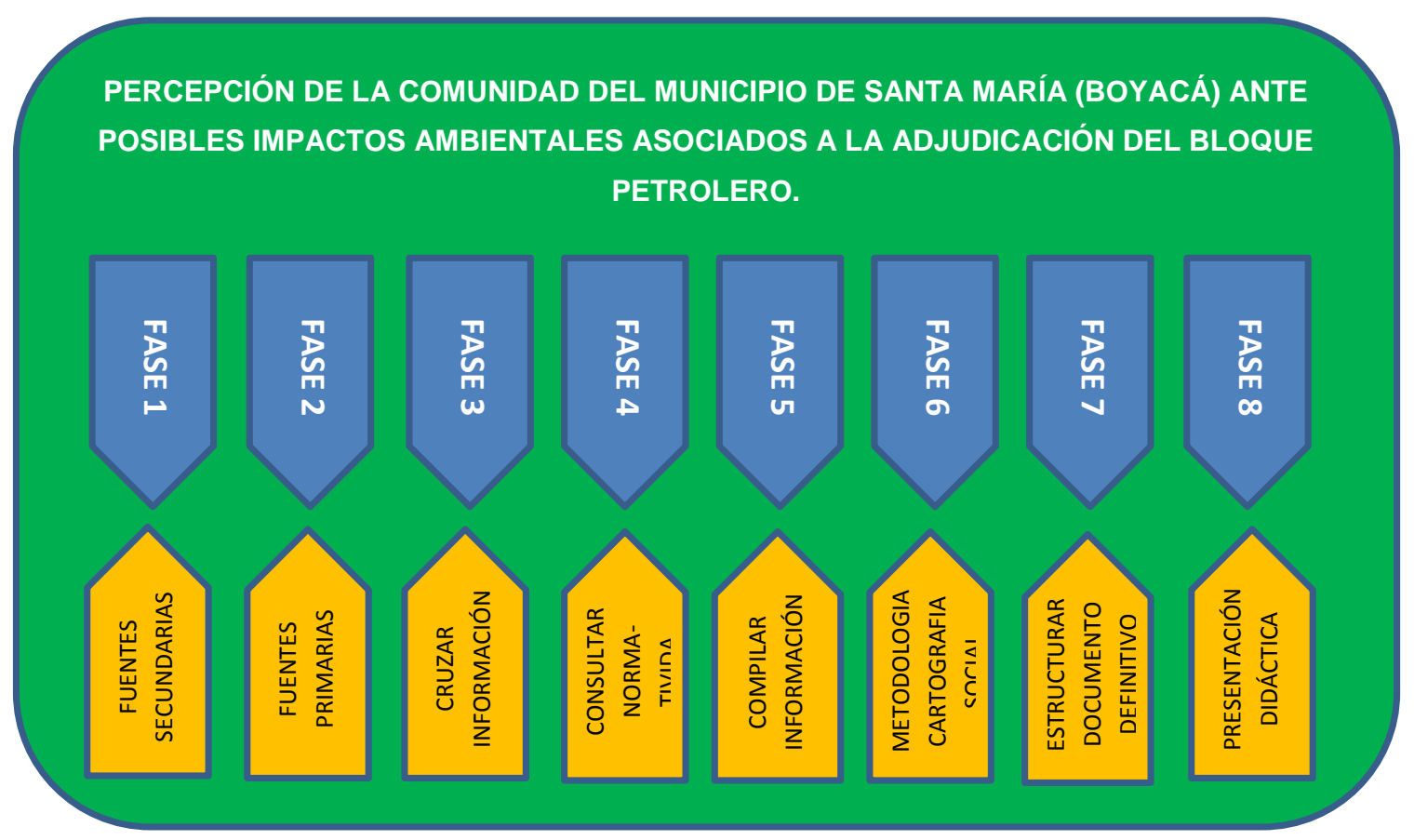

Figura 1: Fases aplicadas a la investigación. 


\section{CAPITULO III DIAGNOSTICO DEL AREA INVESTIGADA.}

Los diferentes aspectos que mencionan a continuación permiten contextualizar el territorio y a la vez tener un inventario que se convierte en línea base de los principales factores (social, cultural y económico) que han influido en el desarrollo de los habitantes del municipio de Santa María.

\subsection{Municipio de Santa María - Boyacá.}

Los diferentes aspectos que se esbozan a continuación permitirán la trazabilidad de aspectos que confluyen e influyen en la comunidad por experiencias vividas con macro proyectos y que de alguna manera están latentes ante posibles intervenciones en el campo ambiental, social, cultural y económico.

\subsection{Localización General.}

Santa María está ubicado en el piedemonte llanero. Pertenece a la Provincia de Neira, al sur oriente del Departamento de Boyacá y limita por el norte con los municipios de Macanal y Campohermoso, por el oriente con San Luis de Gaceno, por el sur con Ubalá (Cundinamarca) y por el oeste con Chivor, cuenta actualmente con 4.498 habitantes de los cuales 2025 son urbanos y tiene una temperatura de 24 grados centígrados. 


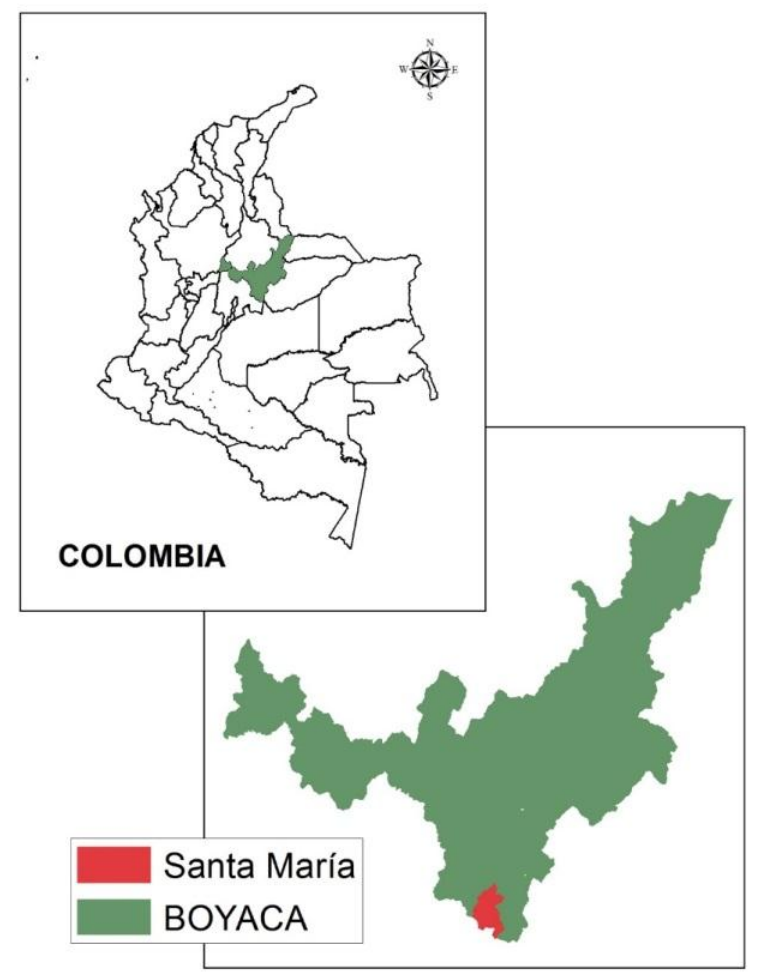

Mapa No. 1. Localización.

\subsection{Características socioeconómicas.}

El 55 por ciento de la población (2.473 habitantes), reside en el sector rural comprendido por 20 veredas, (mapa No.2) se dedican a la actividad agropecuaria, siendo este el principal renglón productivo de la economía del municipio (sector primario); la producción de energía es el sector secundario y el área urbana (mapa No. 3) comprendida por ocho barrios donde se desarrolla actividades de comercio en general, hotelería, restaurantes, discotecas y estaciones de servicio conforman el renglón terciario. 


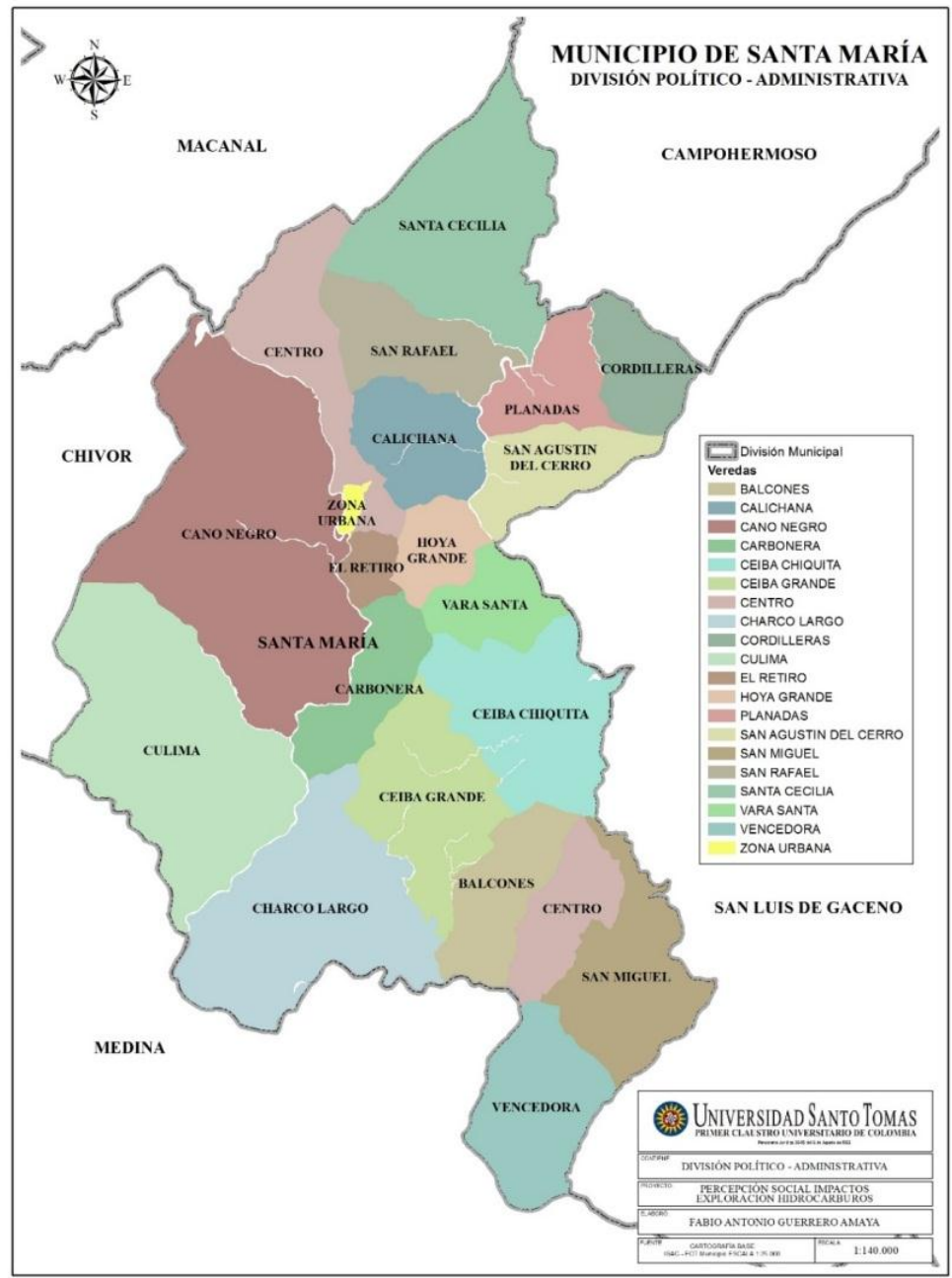

Mapa No. 2: División Político - Administrativa / SIG - CORPOCHIVOR, 2015. 


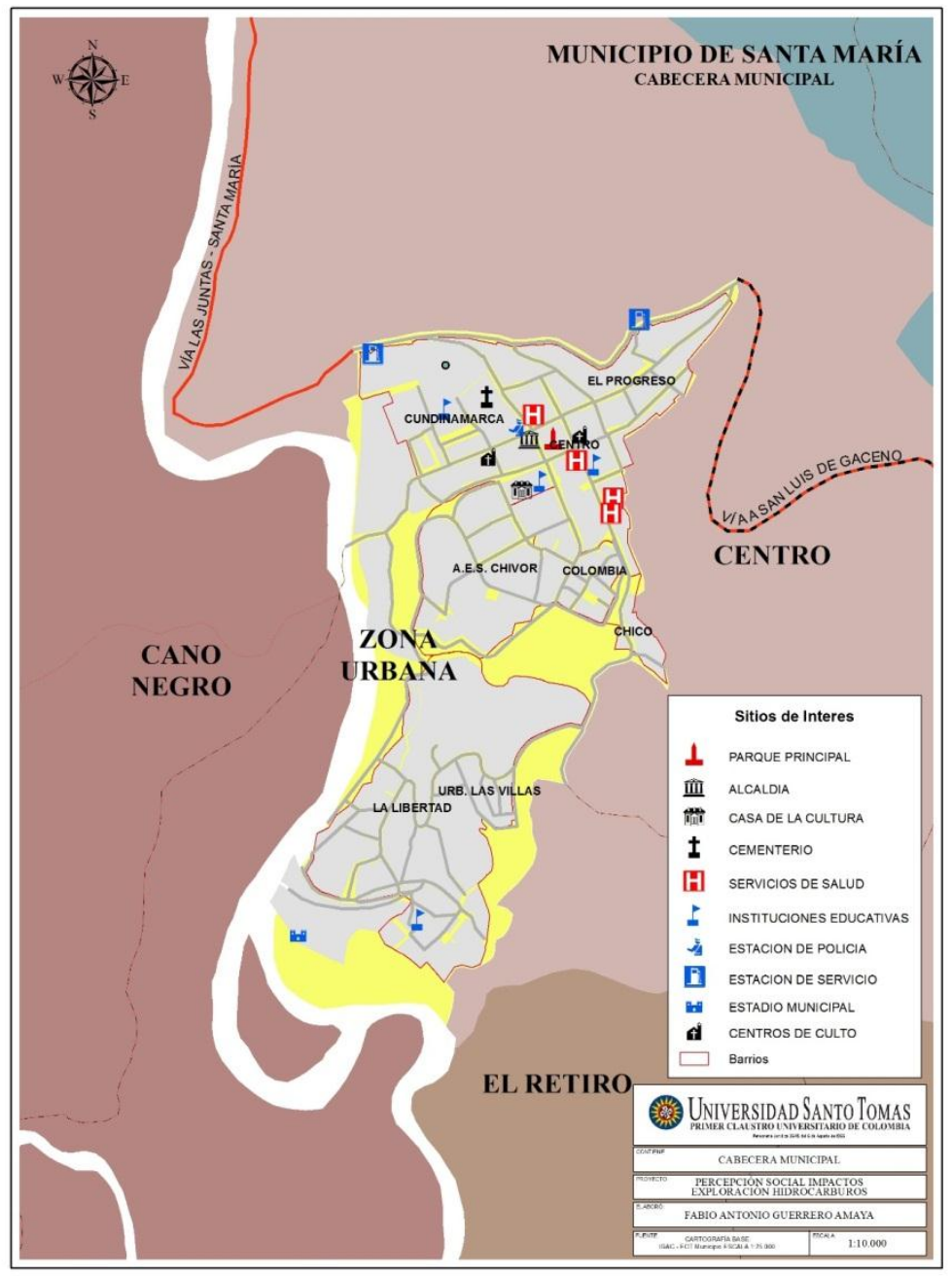

Mapa No. 3: Cabecera Municipal / SIG - CORPOCHIVOR, 2015.

\subsection{Aspecto socio culturales.}

En el municipio de Santa María se llevó a cabo un macro proyecto relacionado con la generación de energía hidráulica denominado "Construcción del Embalse La Esmeralda", macro proyecto realizado a final de los años 60, fue una época próspera porque se generó trabajo de mano de obra no calificada para los redientes del Valle de Tenza e ingresando gran cantidad de trabajadores calificados y profesionales, en algunos casos con sus familias, el municipio y la región no estaba preparada para recibir y 
atender las necesidades de los nuevos habitantes, se elevó el costo de vida porque la oferta de infraestructura, bienes, servicios era escasa o limitada y la demanda era superior, presentándose especulación.

En cuanto a las costumbres el cambio fue radical, se encontraron personas de diferentes regiones de Colombia e incluso de otros países, se asentaron y empezaron a intercambiar, notándose cambios en la preparación de las comidas, en los lenguajes, en el vestuario y en la forma de concebir el mundo, lo cual genero con choque con la cultura existente en zona.

En la composición familiar, se notó descomposición social, algunos matrimonios se acabaron por infidelidad, se encontraron sitios de diversión y prostitución, se identificaron madres o padres cabeza de familia.

Se evidenció que los campesinos se desplazaron al pueblo abandonando sus tierras, en búsqueda de mejores condiciones de vida, querían trabajar como obreros, ayudantes y empleadas de servicios generales porque tenían un salario fijo y estable.

Las vías fueron destruidas por el tráfico pesado de manera permanente, al desplazar maquinaria, herramientas y materiales para la construcción de 14 túneles porque las condiciones topográficas de gran pendiente, no permitieron el trazado de vías alternas.

Los riesgos naturales han sido latentes por la gran pendiente del terreno, la abundancia de agua sin control, la composición del suelo cascajosa, la presencia de fallas geológicas y las acciones antrópicas para escavar las montañas y construir túneles, generó gran presencia de derrumbes y en algunos casos accidentes que cobraron vidas de los habitantes del lugar o de trabajadores. 
El clima fue otro factor que cambió, al represar el agua y llegar al límite de llenado hace que baje la temperatura de la zona y por consiguiente afectó la producción de papaya, naranja, mandarina, chirimoya, guayaba y mango.

El paisaje fue transformado, de unos ríos con sus cuencas y microcuencas, con montañas y especies nativas, se pasa a un espejo de agua inmenso en la época de invierno a ver una sedimentación del embalse en época de verano, donde las mejores tierras han sido llevadas por el agua al fondo del embalse, colmatándolo y bajando la vida útil del mismo.

Terminado el proyecto y puesto en funcionamiento, la mano de obra no calificada fue despedida, se redujo el número de profesionales, haciendo que algunas familias buscaran horizontes en otras regiones, los que se quedaron no regresaron al campo porque los ingresos eran mínimos y el trabajo arduo, se desaceleró la economía regional y el comercio bajo sus ventas.

Se destaca la red hídrica como riqueza del municipio; está comprendida por los ríos Batá, Lengupá, Guavio, Tunjita y Bocachico, que son afluentes del río Upía. Las microcuencas y sus principales tributarios son: microcuenca río Batá, tributario de las quebradas Pluma de Agua, la Cascada, el Chorro, la Colorada, Cristalina y Honda. El río Lengupá con sus quebradas tributarias: la Vara Santa, los Encenillos, la Cristalina, Saldaña, Planadas, la Rubia, Cantonera, Monte Negro, Cachipay y Negra. El río Guavio, con sus principales afluentes que son: las quebradas las Pavas, Montecillo, Doradas, Colorada, la Corneta, la Yacoreña, los Azulejos y Nariguera. El río Tunjita, con su principal afluente la quebrada Blanca.

Un atractivo turístico corresponde al recorrido por catorce túneles en roca viva, bordeando el embalse La Esmeralda, por la vía alterna al llano, que conduce al 
municipio de Santa María. Además cuenta con un gran potencial turístico originado por su biodiversidad, riqueza hídrica e infraestructura energética.

Respecto al ecoturismo sobresalen los humedales ubicados en la vereda San Agustín, la cascada Curva del Indio, cascada la Clarita, Piedra Campana, laguna el Placer ubicada en la vereda Charco Largo, Cuchilla Guaneque y Cuchilla Negra a 2.600 msnm., la Cuchilla Calichana, cerro La Vieja en San Agustín, las Bocas del Tunjita, laguna Planadas, Salto del Cristo en la vía a Chivor, los Farallones, el Alto del Vegón, las cuevas en Caño Negro, las cuevas en cercanías de Nazaret, los Miráculos y vestigios de los indígenas Teguas en "El Hotel”.

Existen los senderos ecológicos las Cabras, la Almenara, Portones, Hyca Quye, caserío de Nazaret y la Mina en Caño Negro. Aguas abajo del embalse La Esmeralda, sobre el río Batá, existe un gran número de pozos y balnearios naturales aprovechados como sitios turísticos y de recreación entre los que se destacan: las Bocas del río Tunjita, las quebradas la Cristalina en Caño Negro y la Cristalina en San Rafael, quebrada la Vara Santa, Quebrada Blanca, quebrada Honda; sobre el río Bocachico existen pozos, utilizados por los habitantes de las veredas Nazareth y San Miguel, el Salto del Cristo, ubicado en la vereda Caño Negro y Monserrate, en la vereda San Agustín.

\subsection{Investigaciones y publicaciones con componente ambiental del área de estudio.}

El área objeto de estudio es biodiversa, por tal motivo la academia e instituciones se han interesado en realizar investigaciones en aves, mamíferos, anfibios, reptiles, mariposas, helechos y Lycofitos, orquídeas, artrópodos, flores, líquenes, hepáticas y musgos, constituyéndose en la línea base para determinar la riqueza ecosistémica por las condiciones de clima, topografía y variedad de especies, lo que se ha constituido en factor clave para que la comunidad valore su hábitat como patrimonio natural y cultural único. 
3.5.1. Guía de las aves rapaces diurnas de CORPOCHIVOR (Municipios de San Luis de Gaceno y Santa María)

"Hace una descripción inicial sobre qué es una ave rapaz, la composición de la diversidad de especies encontradas en el área de influencia de los municipios de Santa María y San Luis de Gaceno. Igualmente se hace una presentación acerca de la ecología, estado actual de conservación y principales especies que se encuentran en algún estado de amenaza a desaparecer”. (Márquez Reyes, C y Vanegas V. H. 2008, p. 5).

\subsubsection{Aves de la región en peligro de extinción.}

"Recopila los registros de fauna que han sido reportados en los diferentes estudios y planes de manejo realizados a través de la historia de Corpochivor, y destaca las especies de aves que se encuentran en peligro de desaparecer ubicadas sobre los ecosistemas estratégicos regionales, propios de la vertiente oriental de la cordillera oriental". (Corporación Autónoma Regional de Chivor, 2012, p. 4).

\subsubsection{Guía de Campo de los mamíferos, anfibios y reptiles de Santa María (Boyacá)}

"Presenta información detallada sobre la ecología, hábitat y preferencias alimentarias de las especies estudiadas, así como su grado de vulnerabilidad ante las amenazas a las que están sometidas, lo cual nos permite comprender la riqueza de la zona en términos de diversidad". (Aguirre Ceballos, J. 2011, p. 17).

\subsubsection{Un recorrido por la flora del sendero Hyca-Quye.}

"Presenta el tratamiento florístico para las plantas con flores que crecen en el sendero ecológico Hyca-Quye, a modo de guía de campo. Este sendero está ubicado en la 
vertiente oriental de la Cordillera Oriental Colombiana, aproximadamente a $900 \mathrm{~m}$ de altitud, en el municipio de Santa María (Boyacá). Se estudiaron 345 especies, agrupadas en 250 géneros y 94 familias, entre las que se encuentran ocho especies naturalizadas y cuatro vulnerables o casi amenazadas, según las categorías de la UICN". (González F. M. y Betancur J. 2013, p. 10).

\subsubsection{Helechos y Lycofitos de Santa María - Boyacá.}

"El área investigada corresponde a 1750 hectáreas que hacen parte de una zona protegida de AES Chivor y algunos predios adicionales vecinos a la cabecera municipal. Los resultados obtenidos son sorprendentes, se registró un total de 183 especies de 64 géneros y 23 familias. Con una perspectiva meramente cuantitativa tal cantidad significa que en esta pequeña área se halla alrededor del 11\% de la diversidad de estas plantas en Colombia y se comprueba nuevamente la importancia que tiene el Pie de Monte Llanero, donde están localizados los predios investigados, como zona de transición ecológica que alberga especies de diferentes zonas de vida y donde la riqueza natural nos reta todos los días a investigar y con seguridad a encontrar elementos nuevos dentro del conocimiento científico". (Méndez Arce C. M. y Murillo J. 2014, p. 8)

\subsubsection{Guía de campo de las orquídeas de Santa María - Boyacá.}

"Presenta la sinopsis de la familia Orchidaceae para el municipio de Santa María (Boyacá, Colombia) ubicado hacia la vertiente oriental de la Cordillera Oriental andina, aproximadamente 400 y $2000 \mathrm{~m}$. de altitud, se incluyen descripciones morfológicas y claves para identificar los géneros los géneros y las especies. Se encontraron 121 especies y 64 géneros... Para cada especie se incluye los sinónimos relevantes, su distribución geográfica general y local, las preferencias de hábitat y fotografías que ilustran diferentes de la planta". (Giraldo Caro G. y Betancur J. 2011, p. 10). 
3.5.7. Biodiversidad Regional (Artrópodos: arácnidos, miriápodos, crustáceos e insectos: Santa María, Boyacá.

"En la región de Santa María se conocen unas 400 especies de Artrópoda, de las cuales se tratan, de manera representativa, 106 especies incluidas en 55 familias. Los lugares más ricos en especies corresponden a las zonas de la Almenara, El Sendero Ecológico y La Cristalina. Sobre los grupos mencionados se proporciona información relacionada con aspectos morfológicos, ecológicos, geográficos y rangos de distribución para algunas especies; la información se complementa, además, con descripciones de los tipos de hábitats, aspectos del ciclo de vida, preferencias alimentarias y comportamiento, entre otros". (Amat-García G. 2009, p. 7).

\subsubsection{Santa María pintada de flores.}

"Da a conocer el maravilloso universo de diferentes grupos de plantas, y animales presentes en la zona, tales como ranas, mariposas, aves, mamíferos, insectos, musgos, líquenes, hepáticas, helechos, plantas medicinales y maderables, entre otros, muy importantes para el conocimiento biótico de Colombia. La valiosa información generada por ésta serie de guías contribuirá a dar respuesta a uno de los grandes retos que enfrentamos en épocas recientes, y es la de poder llegar a comprender y entender esa inmensa diversidad biológica que alberga nuestro territorio antes de que desaparezca, ya que la mayor parte de nuestro capital natural está siendo diezmado como producto de prácticas agropecuarias no sostenibles, la deforestación, el crecimiento de la población y el establecimiento de obras civiles no planificadas y sin estudios de impacto ambiental, entre muchos otros factores". (Betancur, Zuluaga, Clavijo, Cordero y Salinas, 2007, p. $5)$. 


\subsubsection{Santa María, Líquenes, Hepáticas y Musgos.}

"En las altas montañas que rodean a Santa María aún conservan parches de bosque en donde es posible encontrar gran diversidad de especies de líquenes y briófitos, grupo de organismos que hoy nos ocupa en esta nueva guía; de los cuales presentamos fotografías y descripciones, que esperamos sean útiles para las personas interesadas en la diversidad". (Campos S., Uribe M. y Aguirre C., 2008 p. 9).

\subsection{Plan de ordenamiento y manejo de la cuenca del río Garagoa.}

La cuenca se conforma por el área de 33 municipios de los cuales 5 corresponden a la jurisdicción de CORPOBOYACÁ (Samacá, Siachoque, Soracá y Tunja), 5 a la jurisdicción de la CAR (Chocontá, Machetá, Manta, Tibirita y Villapinzón) y 23 a la jurisdicción de CORPOCHIVOR (Ventaquemada, Boyacá, Viracachá, Ciénega, Jenesano, Nuevo Colón, Turmequé, Tibaná, Ramiriquí, Úmbita, Chinavita, Pachavita, La Capilla, Tenza, Garagoa, Guayatá, Macanal, Sutatenza, Guateque, Somondoco, Almeida, Chivor y Santa María).

\subsection{Plan General de Ordenación Forestal - PGOF.}

La Corporación Autónoma Regional de Chivor - CORPOCHIVOR, mediante Acuerdo del Consejo Directivo No. 016 del 27 de noviembre de 2013, adoptó el "Plan General de Ordenación Forestal, PGOF”, un instrumento de planificación de responsabilidades compartidas, que busca la conservación y protección de los bosques naturales en cuanto a su función, extensión, composición y estructura. Como logros sobresalientes del PGOF, se resalta, la ordenación de 288 mil hectáreas de las 311 mil que tiene la jurisdicción, incluido el municipio de Santa María, el restante, hace parte de las áreas estratégicas y áreas de páramo que han sido declaradas dentro del proceso de ordenamiento y zonificación del territorio. La implementación de estas actividades, 
pondera el manejo apropiado de las tierras forestales integrando principios de la silvicultura en el contexto administrativo, técnico, científico, jurídico, biofísico, económico, cultural y social.

\subsection{Distrito de Manejo Integrado Cuchillas Negra y Guanaque - DRMI.}

Ubicado en los Municipios de Santa María, Chivor, Macanal y Campohermoso, con una extensión de 19.304 hectáreas).

"Las cuchillas Negra y Guanaque ocupan el 28\% aproximadamente de bosque natural, el $11 \%$ de bosque fragmentado con pastos y cultivos, y el $11 \%$ de bosque fragmentado con vegetación secundaria de la totalidad de los bosques de la jurisdicción de CORPOCHIVOR, y representa el $21.9 \%$ de los bosques para preservar y restaurar... Es decir, la declaración de las cuchillas busca preservar la zona mayormente boscosa en la jurisdicción de Corpochivor, con coberturas de bosque natural de forma continuas rodeadas por bosques fragmentados, lo que genera la oportunidad de establecer un corredor biológico entre 30.9 y 20.3 km, lineales" (Corpochivor, 2015, p 14.) 


\section{CAPITUlO IV}

\section{MARCO CONCEPTUAL.}

\subsection{Contexto.}

El trabajo investigativo parte del interrogante ¿Cuál es la percepción (Preocupación) de la población en la cabecera municipal de Santa María (Boyacá) ante posibles impactos ambientales asociados a la adjudicación del bloque petrolero COR-60, por la Agencia Nacional de Hidrocarburos - ANH?, por los aspectos ambientales y sociales que inciden al explotar un recurso natural no renovable, se enmarca dentro del concepto de territorio, como una instancia que incide en las personas y en el contexto en el cual desarrolla sus actividades, los seres humanos existen y por consiguiente habitan en lugar determinado, al cual pertenecen e identifican. No se trata solamente del espacio físico donde desarrolla la vida, se refiere al resultado de las múltiples interacciones tangibles e intangibles, materiales y simbólicas, de carácter natural y sociocultural. En concordancia con lo expresado por (Llanos-Hernández, 2010, p. 208) "Como todo concepto, el territorio ayuda en la interpretación y comprensión de las relaciones sociales vinculadas con la dimensión espacial; va a contener las prácticas sociales y los sentidos simbólicos que los seres humanos desarrollan en la sociedad en su íntima relación con la naturaleza, algunas de las cuales cambian de manera fugaz, pero otras se conservan adheridas en el tiempo y el espacio de una sociedad."

Las actividades que realiza el ser humano sobre los recursos naturales, lo que comúnmente llamamos efectos antrópicos, generan los impactos ambientales, entendiéndolos como el "estimativo de valor del efecto ambiental para los receptores natural, socioeconómico y humano" (Millán J. 2005, p. 47), los cuales influyen de manera directa en el paisaje, la producción y en las condiciones de vida de las personas, dependiendo de la clasificación (leves, moderados o graves), es importante entender el 
concepto de efecto ambiental como "una alteración mesurable de los sistemas naturales y de la cualidad ambiental"' (Maya A., 1997, p. 47)

Se tiene el concepto que la naturaleza es sabia y que por ende se recupera con facilidad, en el caso de los ecosistemas al ser intervenidos o transformados, efectivamente ellos tienen la capacidad de recuperarse nuevamente, lo cual dura mucho tiempo en algunas especias, lo que conlleva a manejar diferentes variables de orden trófico, haciéndonos entender que la "solución al problema ambiental depende en gran parte del conocimiento que se adquiera sobre los límites de resiliencia de los ecosistemas, por una parte, y del establecimiento de los límites tecnológicos que permitan la continuidad de los sistemas vivos, por otra”. (Maya A., 1997, p. 99).

El desarrollo conlleva a ser creativos, propositivos y a planificar las diferentes actividades que se realizarán para solucionar problemática de diferente índole, es así como "los asentamientos humanos - poblados, ciudades pequeñas y medianas, metrópolis y megalópolis- se construyen y se configuran modificando o transformando la naturaleza: la tierra, el aire, el agua, la flora y la fauna, sirven de soporte a estas transformaciones y son, en sí, transformados por ellas" (Lavell A., 1996, p. 12), lo que nos conlleva a romper paradigmas dentro de la mesura para mitigar los impactos generados.

Los factores ambiental, social y económico nos inducen a pensar en desarrollo, bienestar y crecimiento, dentro del contexto de la ecología humana, entendida como todas las interrelaciones entre la población con los ecosistemas, como lo expone (Sunkel, 1980, p. 22), "Puesto que la vida humana depende por entero de la disponibilidad de numerosos elementos extraídos de la naturaleza, uno de los aspectos clave de la organización sociales precisamente el modo de apropiación social de los elementos de la biosfera esenciales para la supervivencia de la sociedad en su conjunto..." y el desarrollo que propende por realizar investigación y generar conocimiento constructivo 
con el uso o generación de herramientas tecnológicas de punta, de tal manera que las estrategias del gobierno se reviertan en solución de las necesidades básicas insatisfechas de los ciudadanos, el bienestar que se genera por la equidad en el cubrimiento de los planes, programas y proyectos que las instituciones ejecutan para erradicar la pobreza y el crecimiento del aparato productivo y de la persona como dinamizador del sistema democrático, al participar en el diagnóstico, prospectiva, ejecución y evaluación de los instrumentos de planificación de carácter, local, regional y nacional.

El tema de desarrollo sostenible ha cobrado vital importancia debido a que existe desequilibrio en la biosfera, haciendo que se presente situaciones extremas en el clima, en la regulación del recurso hídrico, especies en vía de extinción, generación de incendios forestales y emisión de gases de efecto invernadero, lo que nos conlleva a entender que "La sustentabilidad no es "simplemente" un asunto del ambiente, de justicia social y de desarrollo. También se trata de la gente y de nuestra supervivencia como individuos y culturas" (Barkin, D., 2012, p. 67).

Al implementar iniciativas de producción, conllevan necesariamente a la utilización de materias primas provenientes de los recursos naturales renovables y no renovables, lo que conlleva a generar bienestar a quien explota porque es fuente de ingresos, genera trabajo y estatus de poder, sin embargo para los residentes de la zona le genera zozobra porque identifica riesgos, le afecta los aspectos ambientales, convirtiéndose en una situación incómoda que conlleva a asimilar que "El conflicto ambiental presupone la existencia de un problema ambiental”. (ECOFONDO, 2004, p. 13)

En la actualidad el tema de participación ha cobrado mucha importancia, las comunidades han entendido que es importante pronunciarse de manera oportuna ante las instancias correspondientes de situaciones positivas o negativas que sucedan para que no les vulneren el derecho a disfrutar de un ambiente sano, como lo estipula la Constitución Política de Colombia de 1991, en el artículo 79 donde también expresa que "La ley 
garantizará la participación de la comunidad en las decisiones que puedan afectarlo" lo que se complementa con el siguiente postulado "la participación ciudadana en material ambiental también puede consistir en el control que se ejerza sobre las decisiones ya adoptadas y en general sobre la actividad de la administración y los particulares, para que dicha con actividad no se vulnere el medio ambiente". (Riveros H. y León L., 1997, p. 82)

Existen políticas en torno al manejo del recurso hídrico, biodiversidad, educación ambiental, manejo de residuos, producción limpia entre otras, las cuales están plasmadas en los instrumentos de planificación y es así como el Gobierno Nacional ha fomentado el uso sostenible del suelo y el subsuelo con el impulso a iniciativas de exploración y explotación de minerales y derivados del petróleo, lo que ha conllevado a las autoridades ambientales a exigir diagnósticos de alternativas y planes de manejo para mitigar los riesgos generados, presentándose preocupación por el deterioro ambiental y entender que "lo que causa la extinción de especies no son las comunidades, sino las fuerzas económicas que presionan sobre ellas para extraer rápidas ganancias ocasionales y cubrir mercados más amplios a nivel nacional, regional o mundial”. (Maya, A., 1997, p. 10)

La investigación a través de la ciencia y la tecnología avanza rápidamente, haciendo que las personas se atrevan a utilizar herramientas tecnológicas que faciliten los procesos, se utilicen al máximo las materias primas, la producción sea limpia, encaminada a ofrecer productos competitivos en el mercado con los correspondientes sellos de calidad, ante lo cual el comprador debe actuar responsablemente para incentivar a los productores que trabajan por entregar un producto que genera bienestar lo que se traduce en la administración ambiental, la cual se encamina "en lograr los límites de equilibrio tecnobiológico que permita, la continuidad de los sistemas vivos”. (Maya, A., 1997, p. 258). 
El tema de responsabilidad social empresarial, es atinente al desempeño de las empresas en relación con el entorno y las comunidades aledañas, se trata de mejorar las relaciones entre los diferentes actores del proceso productivo, procurando mejores condiciones de vida y la forma como se retribuyen a las comunidades los excedentes generados por la exploración, explotación, conducción y comercialización de bienes y servicios ambientales.

Respecto a las autoridades ambientales, en Colombia existen: el ministerio de ambiente y desarrollo sostenible - MADS, la agencia nacional de licencias ambientales - ANLA, las corporaciones autónomas regionales - CAR y parques nacionales naturales - PNN, cada una tiene sus competencias y en momentos se coadyuvan, facilitando información y protocolizando convenios para realizar acciones en ecosistemas compartidos de acuerdo los planes de ordenación y manejo de la cuenca hidrográficas, en función de ordenar el territorio. Respecto al manejo de los recursos naturales no renovables (petróleo), generalmente son proyectos de gran magnitud, la competencia directa de licenciamiento la tiene el ANLA y el ministerio de Ambiente y Desarrollo Sostenible, respecto al otorgamiento del área la competencia es del ministerio de Minas y Energía, las Corporaciones Autónomas Regionales proporcionan información de estudios y geográfica, expiden las autorizaciones y permisos a que haya lugar en la ecorregión que será licenciada y en algunos casos le delegan el seguimiento puntual a algunos proyectos, dependiendo del actor, el proyecto tiene una significación según el actor “...el proyecto del estado es ordenar el territorio nacional, mientras el de las empresas es realizar ganancias, el de los ambientalistas es defender el medio ambiente y el de los indígenas defender la identidad colectiva." (Fontaine, 2004, p. 527).

En lo relacionado a la normatividad aplicable a lo ambiental, "la acción del estado valoriza el derecho público nacional y el marco legislativo definido por la Constitución, las leyes de protección del medio ambiente y las leyes de hidrocarburos. La acción de las empresas valoriza el derecho privado y la libertad de empresa como tal. Las 
organizaciones ambientalistas e indígenas valorizan, por su lado, el derecho internacional y los derechos colectivos", (Fontaine, 2004, p. 526) sin embargo se hace alusión a la Constitución Política de Colombia del año 1991, que es eminentemente ambiental, Decreto 2811 de 1974, por el cual se dicta el Código Nacional de Recursos Naturales Renovables y de Protección al Medio Ambiente, la ley 99 de 1993, por la cual se crea el ministerio del medio ambiente, se reordena el sector público encargado de la gestión y conservación del medio ambiente y los recursos naturales renovables, se organiza el sistema nacional ambiental, SINA, y se dictan otras disposiciones, Ley 1333 de 2009, establece el procedimiento sancionatorio ambiental, las anteriores son algunas de las normas porque en muchos casos se han expedido más actos administrativos donde reglamentan algunos aspectos de las leyes aprobadas.

El gobierno nacional a través del plan nacional de desarrollo, (Todos por un nuevo país, 2014 - 2018, p. 7) fijo como objetivos los siguientes para alcanzar el crecimiento verde: 1) Avanzar hacia un crecimiento sostenible y bajo en carbono. 2) Proteger y asegurar el uso sostenible del capital natural y mejorar la calidad y la gobernanza ambiental. 3) lograr un crecimiento resiliente y reducir la vulnerabilidad frente a los riesgos de desastres y al cambio climático. Con la implementación del plan se ha intensificado el tema de autoridad ambiental, al identificar, requerir y sancionar la minería ilegal, siempre se excusan en el derecho al trabajo pero la verdad es que muchas veces es muy artesanal y no se tienen o implementan los protocolos de seguridad

El tema de análisis documental "es conocido como transformación o conversión de la información documental, ...se encarga de las partes más externas del documento, se orienta básicamente hacia la representación, organización y localización de la información; su resultado es para buscar y recuperar" (Guimarães, J. A. C., de Moraes, J. B. E., \& Guarido, 2007, p. 97), es de vital importancia para la investigación, se trata de inventariar todos los estudios e investigaciones que tienen alguna relación con la identificación de impactos ambientales a tener en cuenta si se adjudica el bloque 
petrolero COR-60, Municipio de Santa María - Boyacá, en entes como ministerio de minas y energía, ministerio de agricultura, ministerio de ambiente y desarrollo sostenible, corporación autónoma regional de Chivor, Instituto Alexander Von Humboldt y municipios. Además cruzar información geográfica para concluir y direccionar el estudio.

\subsection{Unidades de análisis.}

4.2.1. Unidad de análisis enfocada hacia el desarrollo sostenible, entendido como "el desarrollo que conduzca al crecimiento económico, a la elevación de la calidad de vida y al bienestar social, sin agotar la base de recursos naturales renovables en que se sustenta, ni deteriorar el medio ambiente o el derecho de las generaciones futuras a utilizarlo para la satisfacción de sus propias necesidades”. (Santos Calderón, 2012, p. 16).

4.2.2. Unidad de análisis de la biósfera enfocado hacia el sistema formado por el conjunto de los seres vivos del planeta Tierra y sus relaciones (ecosistemas, recursos naturales y seres humanos). Entender el concepto de resiliencia relacionado con los ecosistemas que al ser intervenidos o transformados, tienen la capacidad de recuperarse nuevamente si las condiciones ambientales son complementarias. Respecto a la extracción y aprovechamiento de los recursos naturales renovables y no renovables, en ocasiones se piensa que son infinitos y que por consiguiente los podemos derrochar a libre albedrío.

4.2.3. Unidad de análisis de territorio, enfocado al ordenamiento ambiental territorial, la interacción tangible e intangible de los actores de una región y la reglamentación de los usos del suelo. El territorio virtual, relacionado con la realidad simulada para modelar situaciones que permitan proyectar y realizar acciones que impacten de manera leve los ecosistemas. 
4.2.4. Unidad de análisis de autoridad ambiental, enfocada a la gobernabilidad y aplicación de políticas públicas, identificando las competencias de las instituciones y la normatividad emitida y aplicada para el manejo de los recursos naturales renovables y no renovables (proceso sancionatorio ambiental).

4.2.5. Unidad de análisis documental para la consulta y organización de la información de fuentes primarias y secundarias en función de estructurar los datos para que permitan tomar decisiones oportunas o direccionar la investigación.

4.2.6. Unidad de análisis sociocultural para entender el comportamiento de los habitantes de la región, respecto al manejo de megaproyectos, los imaginarios que desarrolla, los valores que predominan, la semiótica que maneja y las creencias que influyen en el comportamiento.

4.2.7. Unidad de análisis relacionada con Participación Comunitaria, entendida como hacerse parte de los procesos, exigir sus derechos y actuar en consonancia con los deberes como ciudadano que forma parte activa de una comunidad y que trabaja por el bien común y el empoderamiento para valorarse y ser propositivo en proyectos productivos que mejoren las condiciones de vida de los habitantes de la región.

4.2.8. Unidad de análisis relativas a la resolución de conflictos ambientales, representada en situaciones de malestar por la comunidad cuando se vulneran derechos, malos entendidos por fallas en la comunicación o por apuestas radicales ante una situación dada, lo que afecta de manera significativa el tejido social.

4.2.9. Unidad de análisis de empoderamiento de las comunidades de base, para que utilicen de manera efectiva ante situaciones concretas herramientas como: derecho de petición, tutela, acciones populares, veedurías y la consulta de sentencias que les permitan exigir sus derechos como ciudadanos. 


\section{CAPITULO V \\ RESULTADOS PERCEPCION DE LA COMUNIDAD DE SANTA MARIA.}

A continuación se encuentran los resultados de la aplicación de la entrevista semi estructurada y el taller de cartografía social, para determinar la percepción de la comunidad del municipio de Santa María - Boyacá, ante posibles impactos ambientales asociados a la adjudicación del bloque petrolero COR-60.

Es de resaltar que el proceso de investigación fue planeado y llevado a cabo con un cronograma de actividades que fue estructurado desde el comienzo del año 2014, convirtiéndose en el soporte para la ejecución de las actividades en cada una de las fases de la investigación, se presentaron imprevistos pero fueron abordados y asumidos para que los resultados fueran consolidados y presentados en el segundo trimestre del año 2016.

5.1. Resultados de Entrevista semi estructurada.

5.1.1. Las instituciones que han determinado la importancia ambiental según los encuestados son: Corporación Autónoma Regional de Chivor - CORPOCHIVOR, Empresa AES Chivor - Hidroeléctrica, Universidad Nacional de Colombia y de Manizales, Administración Municipal y Universidad Nacional asociada con AES Chivor.

5.1.2. Reconocen que Cuchilla Negra y Guaneque es considerado como un ecosistema estratégico por la existencia de bosque nativo que es generador del recurso agua y que las precipitaciones que vienen de la Orinoquía se encuentran con el sistema montañoso existente en San María, haciendo que llueva más de 4.000 m.m. al año, convirtiéndose en zona propicia para el desarrollo de ecosistemas y especies. 
5.1.3. También porque el $85 \%$ de la jurisdicción del municipio de Santa María es un sistema boscoso, que posee área forestal protectora que contiene gran biodiversidad comparada con otros ecosistemas de la región y del país, en la actualidad existen restricciones y directrices para el uso del suelo con el fin de garantizar la existencia de la riqueza forestal en el territorio, consideran que la riqueza natural existente se debe cuidar como legado para las próximas generaciones y que el futuro es promisorio si se cuenta con recursos naturales.

5.1.4. Los encuestados no tienen claridad cuál es la misión de la Agencia Nacional de Hidrocarburos - ANH.

5.1.5. Recuerdan que SISMOCOL hace 20 años estuvo realizado estudios en el municipio para exploración de petróleo, en el año 2004 se realizaron algunas perforaciones o sondeos, no se supo que pretendían y no han presentado informe de resultados.

5.1.6. Los participantes tienen poco conocimiento de la existencia del bloque petrolero COR 60, sin embargo manifiestan que han participado en mesas técnicas de trabajo con la Unidad de Planificación Minero Energética (UPME), han discutido temáticas de minería, hidrocarburos y gas. La Corporación Autónoma Regional de Chivor, ha participado y socializado los planes y políticas de conservación de los recursos naturales, ha cruzado la información y han relacionado los títulos que se han otorgado para la explotación de los Recursos Naturales no renovables. 


\subsubsection{A los habitantes del municipio de Santa María les preocupa:}

- Que no se maneje adecuadamente el agua, los bosques y corredores biológicos naturales de la fauna silvestre.

- Que no se controlen los métodos de explotación.

- Que se intensifique la intervención antrópica sobre los bosques jóvenes que están en proceso de crecimiento, generando riesgos potencialmente altos.

- El cambio en el uso del suelo para los sitios de operación (torres, sitios donde pasa la infraestructura)

- El municipio tiene fallas geológicas que ocasionan deslizamientos y avalanchas en la parte alta y por la cercanía a la presa del Embalse la Esmeralda, consideran que están ante un inminente riesgo si se ejecuta el proyecto petrolero.

- Afectación a las especies vivientes por el derrame de crudo y gas.

- Que no se realice técnicamente el diagnóstico ambiental de alternativas.

- Aumento en la generación de residuos sólidos.

- Abandono de las actividades productivas tradicionales. (Agrícola, en menor proporción la Ganadería).

- Afectación negativa por el desarrollo del turismo (presión a recursos naturales renovables).

- A nivel social se podría generar una mal llamada bonanza, al presentarse una burbuja dentro de la economía del municipio, se elevarían los precios en los artículos de primera necesidad y en los costos de manutención, presentándose especulación y generando un mayor costo de vida.

- Que los intereses nacionales primen más sobre los intereses regionales, existe instrumentos (Plan de Ordenamiento y Manejo de la Cuenca Hidrográfica, Plan de Ordenación Forestal, Distrito de manejo regional integrado y Esquemas de Ordenamiento Territorial) de reglamentación de la autoridad ambiental y municipal, no se sabría hasta qué punto podría pasar por encima de las restricciones identificadas. 
5.1.8. Impactos Negativos identificados si es adjudicado el bloque petrolero COR-60.

\begin{tabular}{|c|c|c|}
\hline \multirow{4}{*}{ 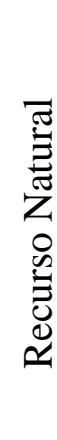 } & \multirow{4}{*}{ 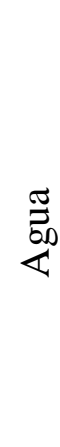 } & e agua. \\
\hline & & $\begin{array}{l}\text { Contaminación con residuos químicos generados, metales pesados y sustancias } \\
\text { peligrosas que alterarían la calidad del agua o composición fisicoquímica en las } \\
\text { fuentes superficiales del municipio. }\end{array}$ \\
\hline & & Cont \\
\hline & & $\begin{array}{l}\text { Derrames de crudo, derrames de aceites quemados por el uso de las maquinarias, } \\
\text { remoción del suelo descubierto hacia las fuentes hídricas. }\end{array}$ \\
\hline
\end{tabular}

\begin{tabular}{|c|c|c|}
\hline \multirow{3}{*}{\multicolumn{2}{|c|}{ 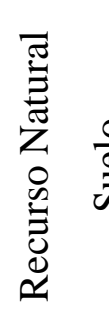 }} & Vertimientos líquidos que alteran la composición del suelo. \\
\hline & & Cambio en el uso del suelo \\
\hline & & $\begin{array}{l}\text { Descapote para perforaciones y para construcción de infraestructura, uso de } \\
\text { maquinaria pesada, tránsito de vehículos y pisoteo por personas generaran procesos } \\
\text { dinámicos de inestabilidad y derrumbes }\end{array}$ \\
\hline
\end{tabular}

\begin{tabular}{|c|c|c|}
\hline \multirow{4}{*}{ 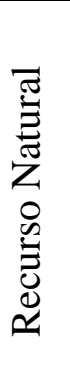 } & \multirow{4}{*}{$\stackrel{\circlearrowright}{Z}$} & Contaminación por fuentes fijas y móviles. \\
\hline & & La generación de ruido afecta la salud humana y genera estrés en los animales. \\
\hline & & $\begin{array}{l}\text { Contaminación permanente por altas temperaturas, afectan al aire con la emisión de } \\
\text { gases no aprovechables. }\end{array}$ \\
\hline & & $\begin{array}{l}\text { Aumento de emisiones atmosféricas, con la generación de partículas que contaminan } \\
\text { el aire y afectación a los habitantes aledaños. }\end{array}$ \\
\hline • & & \\
\hline 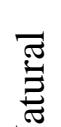 & & $\begin{array}{l}\text { Migración obligada de especies, desplazamiento de diferentes especies del } \\
\text { ecosistema, con amenaza de desaparición del entorno natural. }\end{array}$ \\
\hline L & $\Xi$ & El ruido hará que a la fauna se le altere el ecosistema. \\
\hline$\stackrel{\Xi}{\ddot{Z}}$ & H & $\begin{array}{l}\text { Desplazamiento de la fauna, se rompen los ciclos de la reproducción vegetal, se } \\
\text { pierde la dispersión de semillas. }\end{array}$ \\
\hline
\end{tabular}




\begin{tabular}{|c|c|c|}
\hline \multirow{4}{*}{\multicolumn{2}{|c|}{ 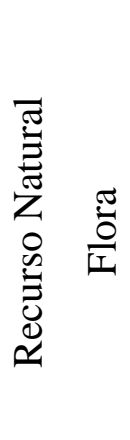 }} & $\begin{array}{l}\text { La riqueza (especies promisorias, semillas, resinas, briofitas, líquenes y musgos) del } \\
\text { bosque se pierde por la ampliación de la frontera para la realización del proyecto }\end{array}$ \\
\hline & & $\begin{array}{l}\text { Intervención en zonas de gran valor ambiental donde la vegetación es diversa y } \\
\text { promisoria. }\end{array}$ \\
\hline & & $\begin{array}{l}\text { Incremento de la explotación de madera a través del aprovechamiento forestal, } \\
\text { incremento de la deforestación. }\end{array}$ \\
\hline & & ua. \\
\hline
\end{tabular}

\begin{tabular}{|c|c|c|}
\hline \multirow{7}{*}{\multicolumn{2}{|c|}{ 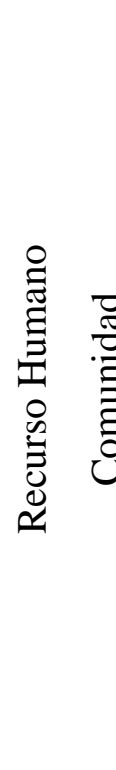 }} & $\begin{array}{l}\text { El proyecto es asumido por la comunidad como una imposición por parte de ANH y } \\
\text { Ministerio de Minas. }\end{array}$ \\
\hline & & $\begin{array}{l}\text { Aceptado por el comercio o los que ven una oportunidad de trabajo, la comunidad lo } \\
\text { ve como una amenaza, no tendría una acogida masiva. }\end{array}$ \\
\hline & & Desplazamiento de personas que habitan el lugar del proyecto. \\
\hline & & $\begin{array}{l}\text { Descomposición familiar, generación de madres o padres cabeza de familia por la } \\
\text { transitoriedad del personal que trabaja en ese sector. }\end{array}$ \\
\hline & & $\begin{array}{l}\text { La comunidad está interesada en el pago por servicios ambientales, que se generen } \\
\text { más benéficos sociales. }\end{array}$ \\
\hline & & Demanda de mano de obra no calificada, se ve como una oportunidad de empleo. \\
\hline & & Cambio en tradiciones y cultura, al confluir personal de otras regiones o países. \\
\hline
\end{tabular}

5.1.9. Impactos positivos identificados si el bloque petrolero COR-60 es adjudicado.

\begin{tabular}{|c|c|}
\hline $\mathcal{Q}$ & $\begin{array}{l}\text { Impulso de la política relacionada con el uso y aprovechamiento sostenible de los } \\
\text { recursos naturales no renovables. }\end{array}$ \\
\hline 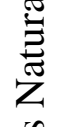 & $\begin{array}{l}\text { Las medidas de compensación ambiental mitigaran los efectos de la intervención a los } \\
\text { recursos naturales renovables, siempre y cuando se respete el uso del suelo. }\end{array}$ \\
\hline 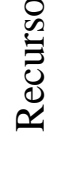 & $\begin{array}{l}\text { La Inversión en la responsabilidad social empresarial (pavimentar vías, mejoramiento } \\
\text { de viviendas, mejoramiento de escuelas y de escenarios deportivos), eventualmente } \\
\text { mejorarían las condiciones de vida de los habitantes. }\end{array}$ \\
\hline
\end{tabular}


Capacitación del recurso humano, se pasa de un contexto agrícola a uno más técnico. Colombia es un país que exporta petróleo y dentro del PIB es un ingreso por la venta de petróleo.

5.1.10. Identifican que se ha generado cartografía ambiental para el municipio por parte de la Corporación Autónoma Regional de Chivor - CORPOCHIVOR, a través del PGOF, DRMI, Zonificación ambiental 2014, Atlas Ambiental y Ordenamiento Territorial en los municipios, AES Chivor que maneja el embalse La Esmeralda, Universidad Nacional con inventarios de fauna y flora, empresa de Energía de Bogotá y Empresa de Energía de Boyacá.

5.1.11. Respecto a los mecanismos de participación ciudadana creen que si los utilizan pero han sido manipulados hacia fines políticos, la rendición de cuentas se realiza pero participan poco porque consideran que no es importante, se destaca que el nivel de escolaridad de los habitantes del área rural es muy bajo, máximo la básica primaria, el interés por la lectura y escritura no es prioritario. Confían en los entes de Control como la Personería, Inspector de policía y Juzgados, los cuales pueden reciben cualquier denuncia.

5.1.12. Reconocen que existe una veeduría para la vía principal el Sisga - Secreto, encargada de realizar seguimiento a los proyectos, en la región son pocas las veedurías conformadas.

5.1.13. En el tema de Responsabilidad social empresarial, le dan importancia a la compra de predios de interés hídrico, realizar reforestación y para la declaratoria de zonas protegidas. Manifiestan que la empresa Chivor S.A. (AES Chivor), ha realizado pequeñas inversiones en las comunidades, entregando elementos escolares, ayudas tecnológicas, arreglo de caminos, mantenimiento de puentes y patrocinan eventos 
culturales, realiza transferencias del sector eléctrico a CORPOCHIVOR y a los municipios.

5.2. Resultados del taller de cartografía social.

5.2.1. Al revisar los documentos de trabajo del taller de cartografía social, se puede concluir que lo que más les preocupa a los habitantes del municipio de Santa María, si se ejecuta el proyecto petrolero es:

- Generación de nuevos riesgos.

- Contaminación en los recursos naturales (suelo, agua, flora, fauna y aire).

- Abandono de las actividades productivas tradicionales. (Agrícola, en menor proporción la Ganadería).

- Afectación negativa por el desarrollo del turismo (presión a recursos naturales renovables).

- Daño en la malla vial por el incremento del transporte pesado.

- Afectación a las especies vivientes por el derrame de crudo y gas.

- Realizar el diagnóstico ambiental de alternativas completo y de manera oportuna.

- Aumento en la generación de residuos sólidos.

5.2.2. Impactos Negativos identificados si es adjudicado el bloque petrolero COR -60

\begin{tabular}{|c|c|c|}
\hline \multirow{5}{*}{ 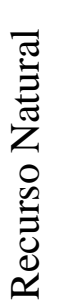 } & \multirow{5}{*}{ 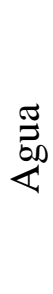 } & Desviación de fuentes hídricas. \\
\hline & & Alteración de la calidad del recurso hídrico. (Subterráneo y superficial). \\
\hline & & Contaminación de aguas subterráneas. \\
\hline & & Daño irreversible a ecosistemas por la generación de vertimientos. \\
\hline & & Contaminación de fuentes hídricas por los vertimientos líquidos y particulados. \\
\hline
\end{tabular}




\begin{tabular}{|c|c|c|}
\hline \multirow{5}{*}{ 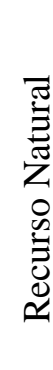 } & \multirow{5}{*}{$\frac{0}{\stackrel{Q}{\Xi}}$} & Cambio del uso del suelo. \\
\hline & & Fragmentación de capas geológicas. \\
\hline & & $\begin{array}{l}\text { Presencia de más deslizamientos por la utilización de infraestructura o maquinaria } \\
\text { pesada. }\end{array}$ \\
\hline & & Influencia de la Falla Santa María. \\
\hline & & Incremento del conflicto de uso del suelo. \\
\hline
\end{tabular}

\begin{tabular}{|c|c|c|}
\hline \multirow{2}{*}{\multicolumn{2}{|c|}{ 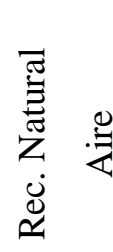 }} & Generación de ruido \\
\hline & & Aumento de emisiones atmosféricas. \\
\hline
\end{tabular}

\begin{tabular}{|c|c|c|}
\hline \multirow{2}{*}{\multicolumn{2}{|c|}{ 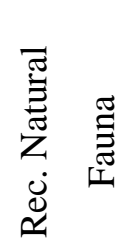 }} & Migración obligada de especies. \\
\hline & & Extinción de especies vulnerables. \\
\hline
\end{tabular}

\begin{tabular}{|c|c|}
\hline \multirow{4}{*}{ 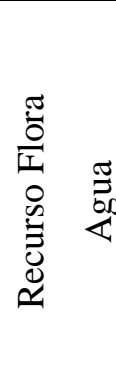 } & Fragmentación del hábitat (Incluida la tala). \\
\hline & Cambio del paisaje (alteración). \\
\hline & $\begin{array}{l}\text { Incremento de la explotación de madera. } \\
\text { Ocurrencia de incendios por fenómenos antrópicos. }\end{array}$ \\
\hline & $\begin{array}{l}\text { Afectación de los bosques por la ampliación de la frontera para la realización del } \\
\text { proyecto. }\end{array}$ \\
\hline
\end{tabular}

\section{Cartografía social generada en el taller:}




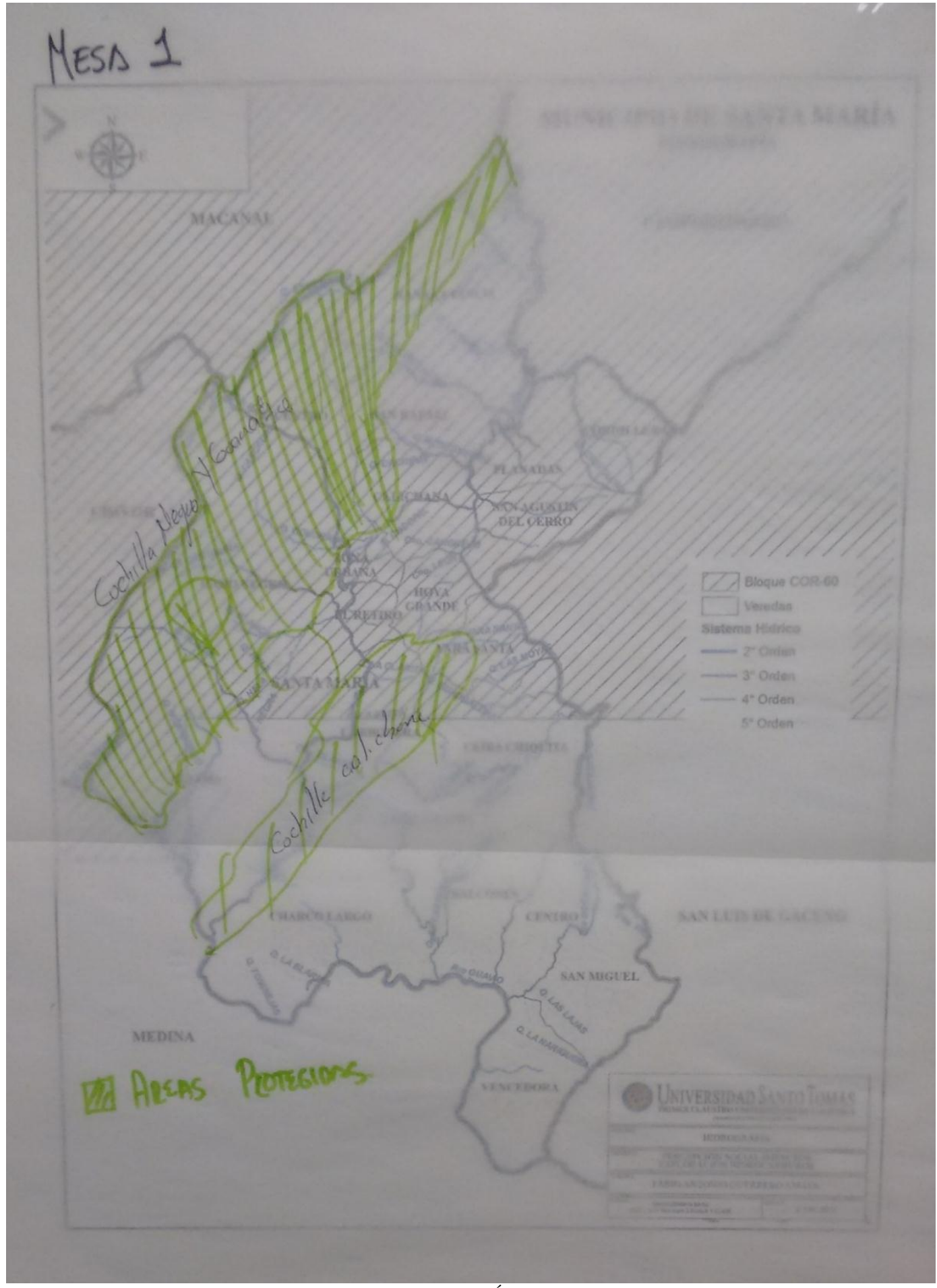

Mapa No. 4: Áreas Protegidas.

Mesa Biodiversidad, Ecosistemas y Recurso Hídrico, identificaron las áreas protegidas en el Municipio de Santa María. 


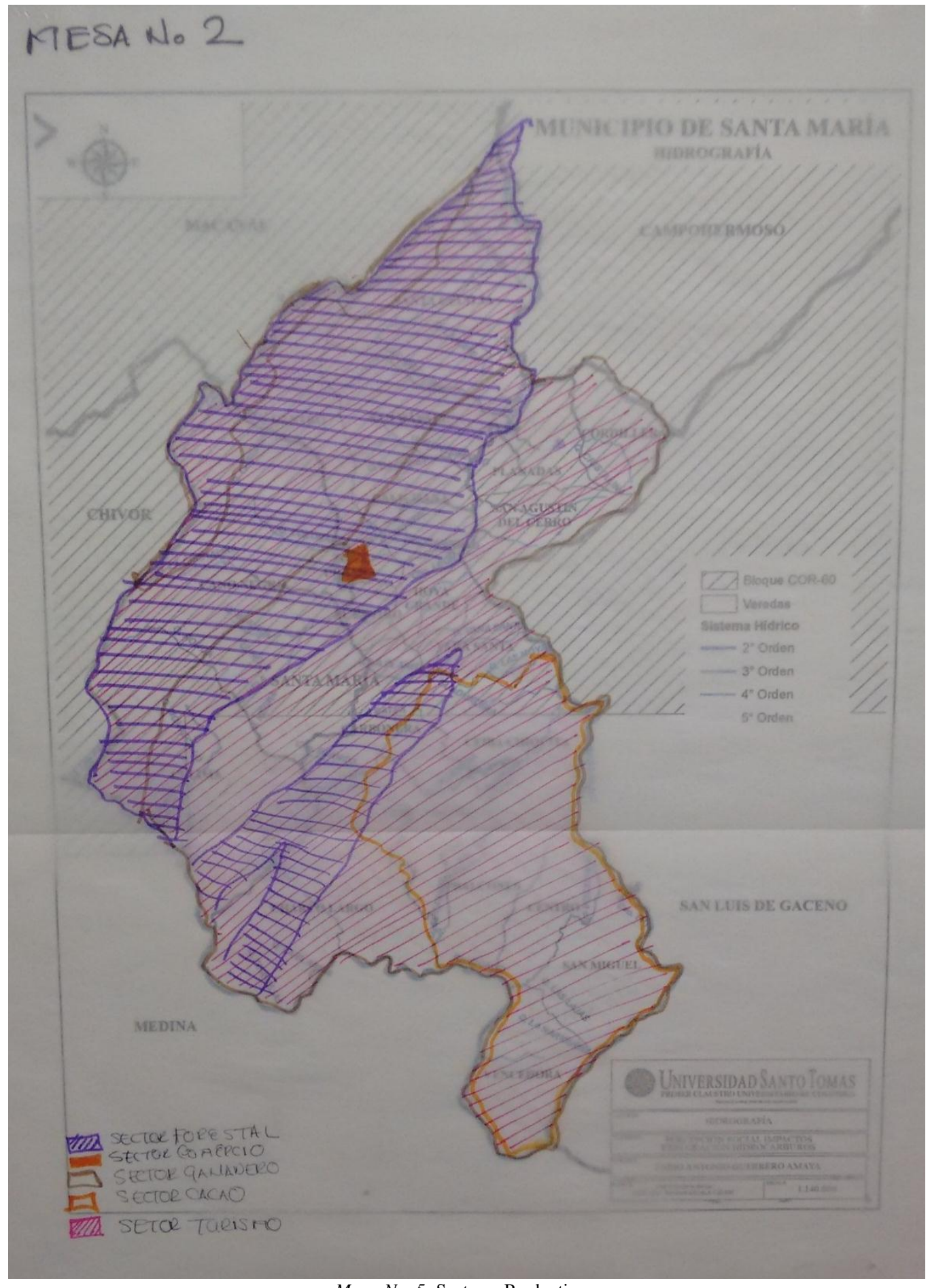

Mapa No. 5: Sectores Productivos.

Mesa de Sectores Productivos, identificaron la ubicación espacial de cada uno de los sectores existentes en el municipio de Santa María, el sector forestal se traslapa con las áreas protegidas. 


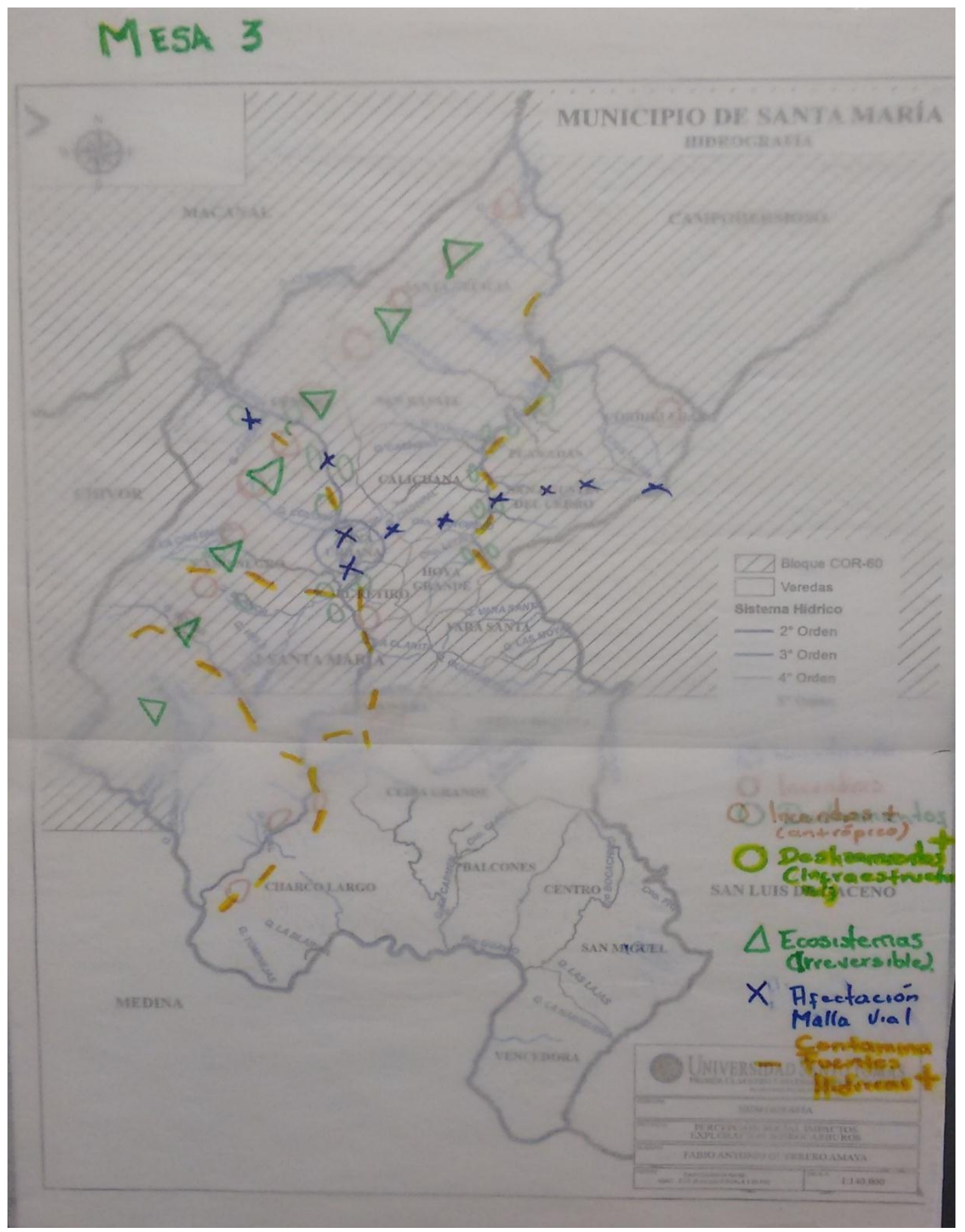

Mapa No. 6: Gestión del riesgo.

Mesa Gestión del Riesgo, identificaron zonas potenciales vulnerables a incendios forestales, deslizamientos, inundación, afectación malla vial y contaminación. 


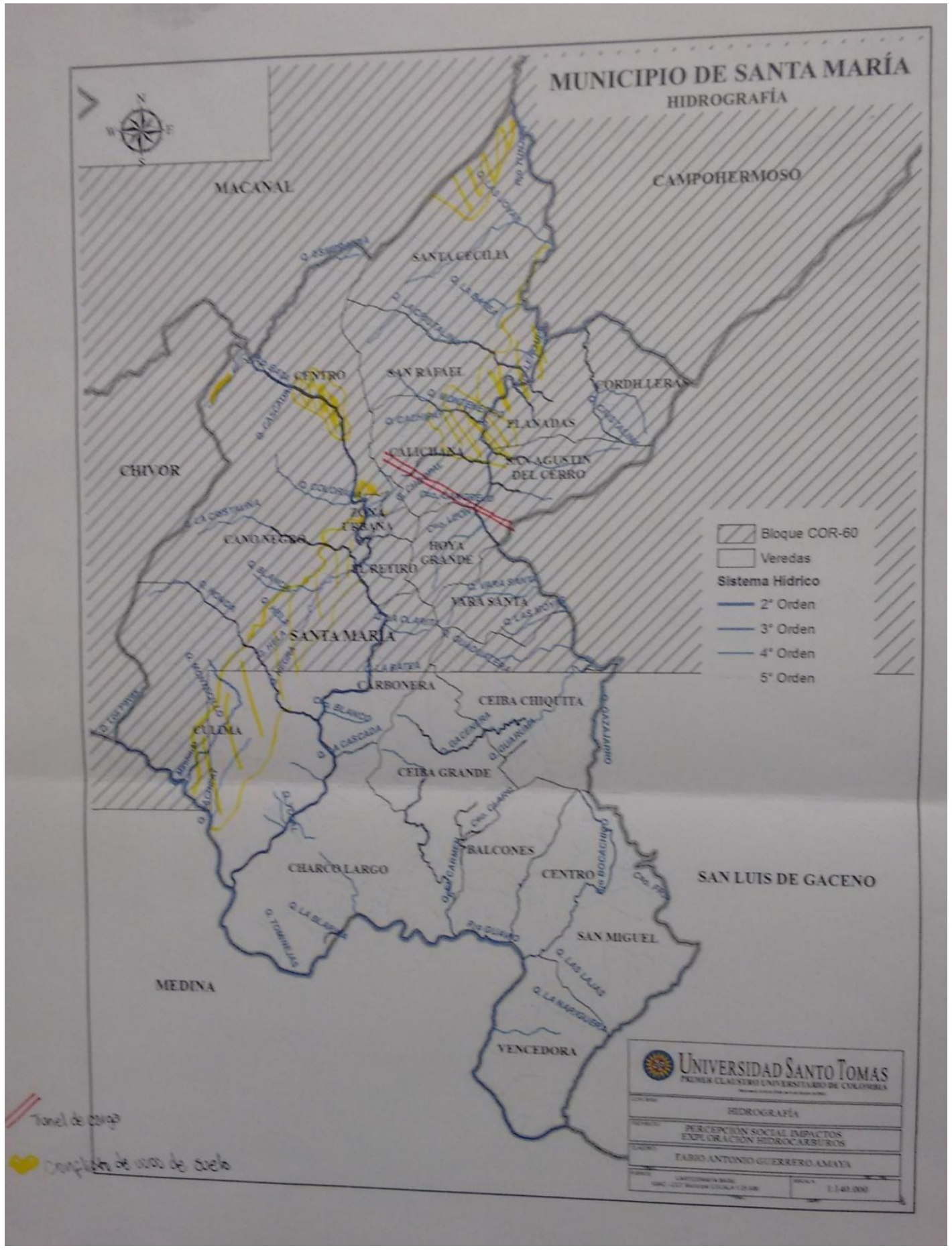

Mapa No. 7: Conflictos uso del suelo

Mesa Conflictos socio-ambientales, identificaron la presencia de conflictos por el uso del suelo y tenencia de la tierra. 
Los participantes de las diferentes mesas identificaron la mayoría impactos ambientales sobre la zona del bloque petrolero COR-60, están relacionados con áreas protegidas, que se deben sustraer al momento de licenciar por parte de las autoridades ambientales.

Al revisar las fuentes secundarias de investigación, se encontraron estudios realizados por diferentes fuentes en los cuales incluían al municipio de Santa María pero no se había realizado un análisis de fondo o cruce de aspectos ambientales estudiados, se tomó como referente geográfico el área que cubre el bloque petrolero COR60 del municipio de Santa María.

Se identifica a nivel nacional, las áreas disponibles para adjudicar, encontrando el bloque petrolero COR - 60, la cartografía permite ver claramente las veredas objeto de estudio, las diferentes zonificaciones que se han declarado como reserva, el potencial hídrico existente, las zonas vulnerables, los riesgos, el uso actual y potencial del suelo y la susceptibilidad a fenómenos sísmicos.

5.3. Cartografía de estudios relacionada con la investigación.

A continuación se encuentra la cartografía con diferentes aspectos que permiten contextualizar e interpretar la importancia ecológica y ambiental del municipio de Santa María, lo cual es muy importante para que sea valorada por las autoridades ambientales al momento de adjudicar el bloque petrolero COR-60. 


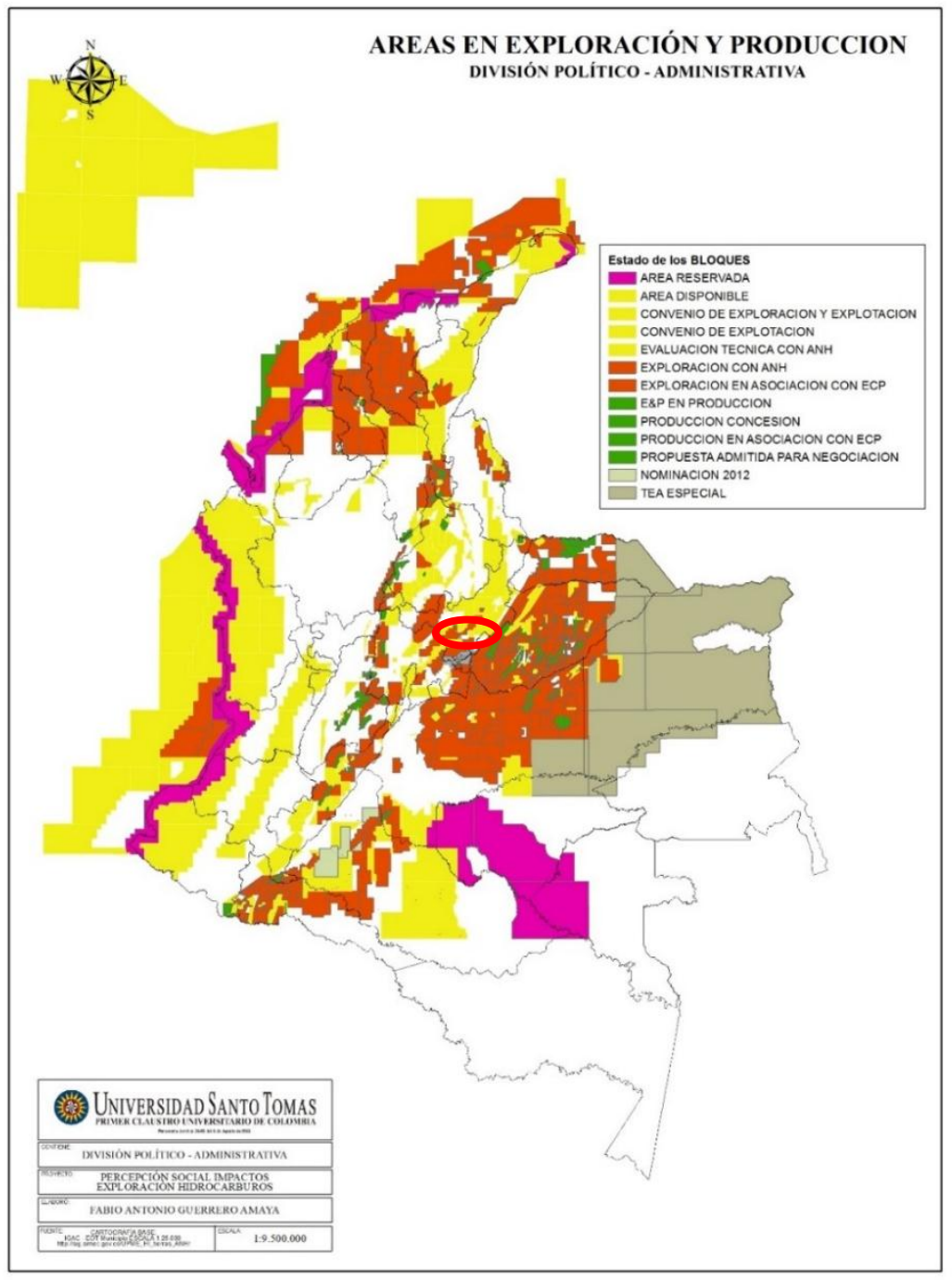

Mapa No. 8: Áreas en exploración y producción de petróleos / ANH 2014.

El Bloque petrolero COR-60, está clasificado por la Agencia Nacional de Hidrocarburos como área disponible. 


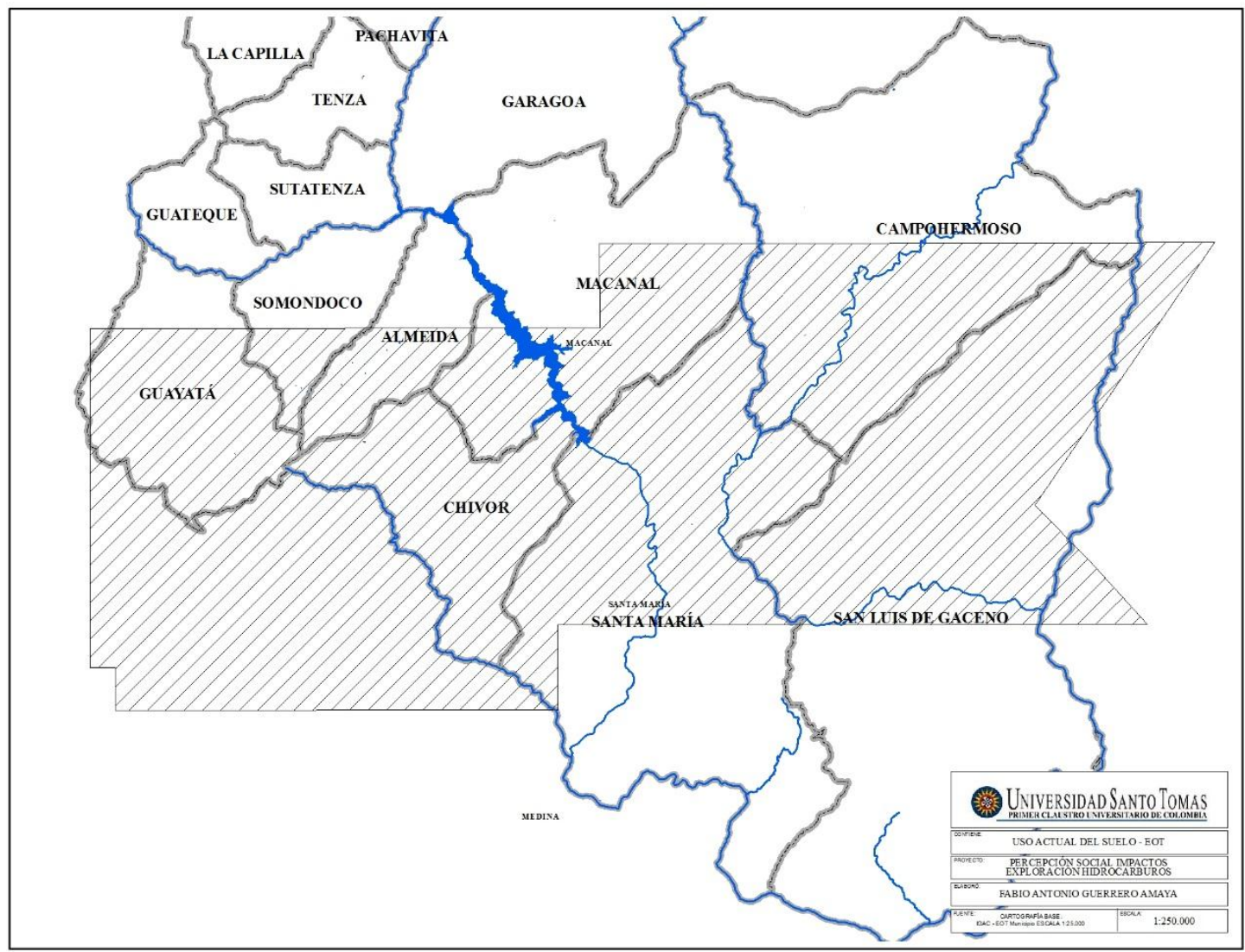

Mapa No. 9: Jurisdicción Bloque COR-60 / SIG - CORPOCHIVOR, 2015.

El bloque petrolero abarca el Centro y parte alta del municipio de Santa María. 


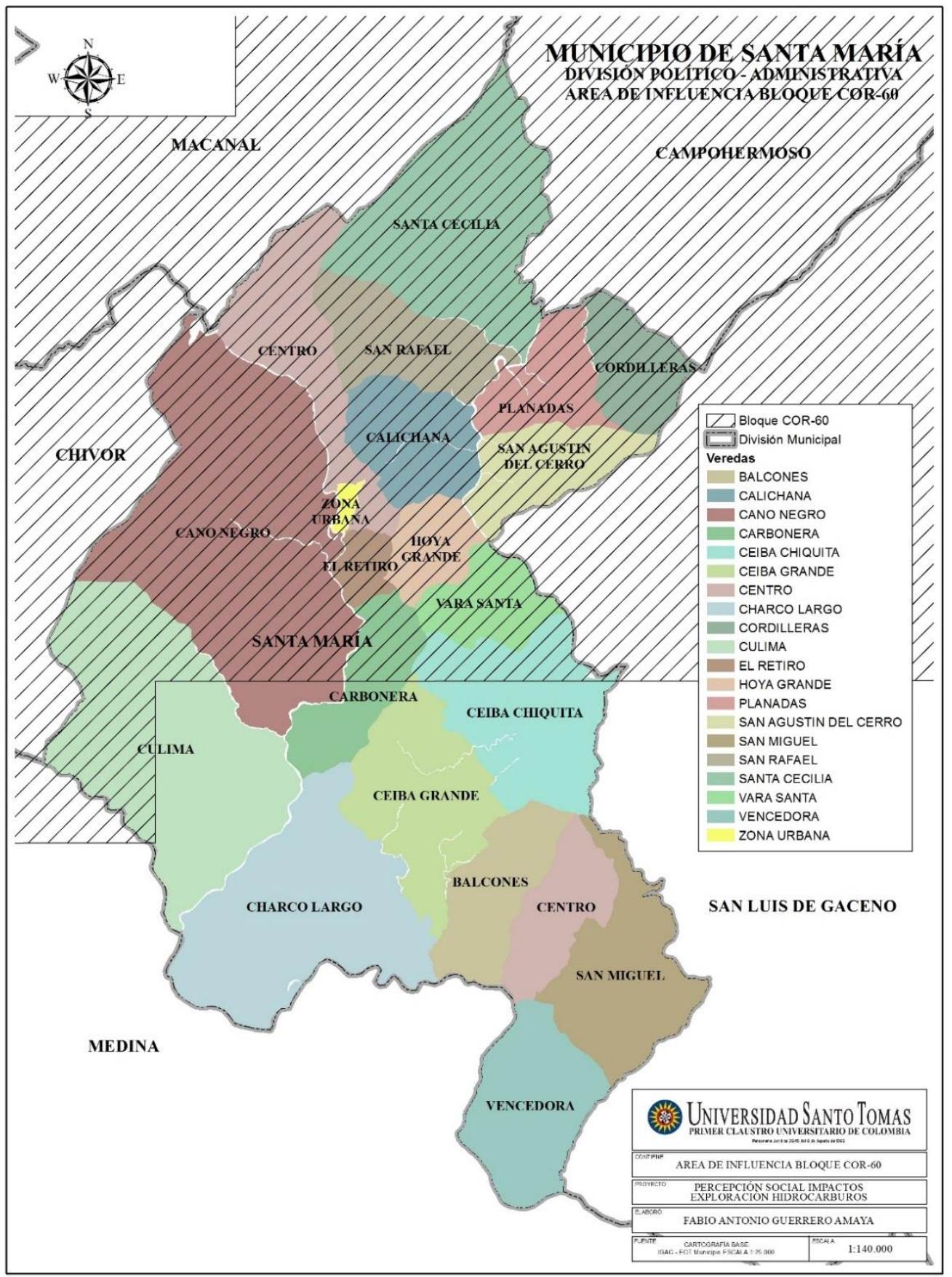

Mapa No. 10: Área de influencia del bloque COR-60 en el municipio de Santa María / SIG - CORPOCHIVOR, 2015.

Dentro del bloque petrolero se encuentran 13 veredas de las 19 y se incluye la también la zona urbana. 


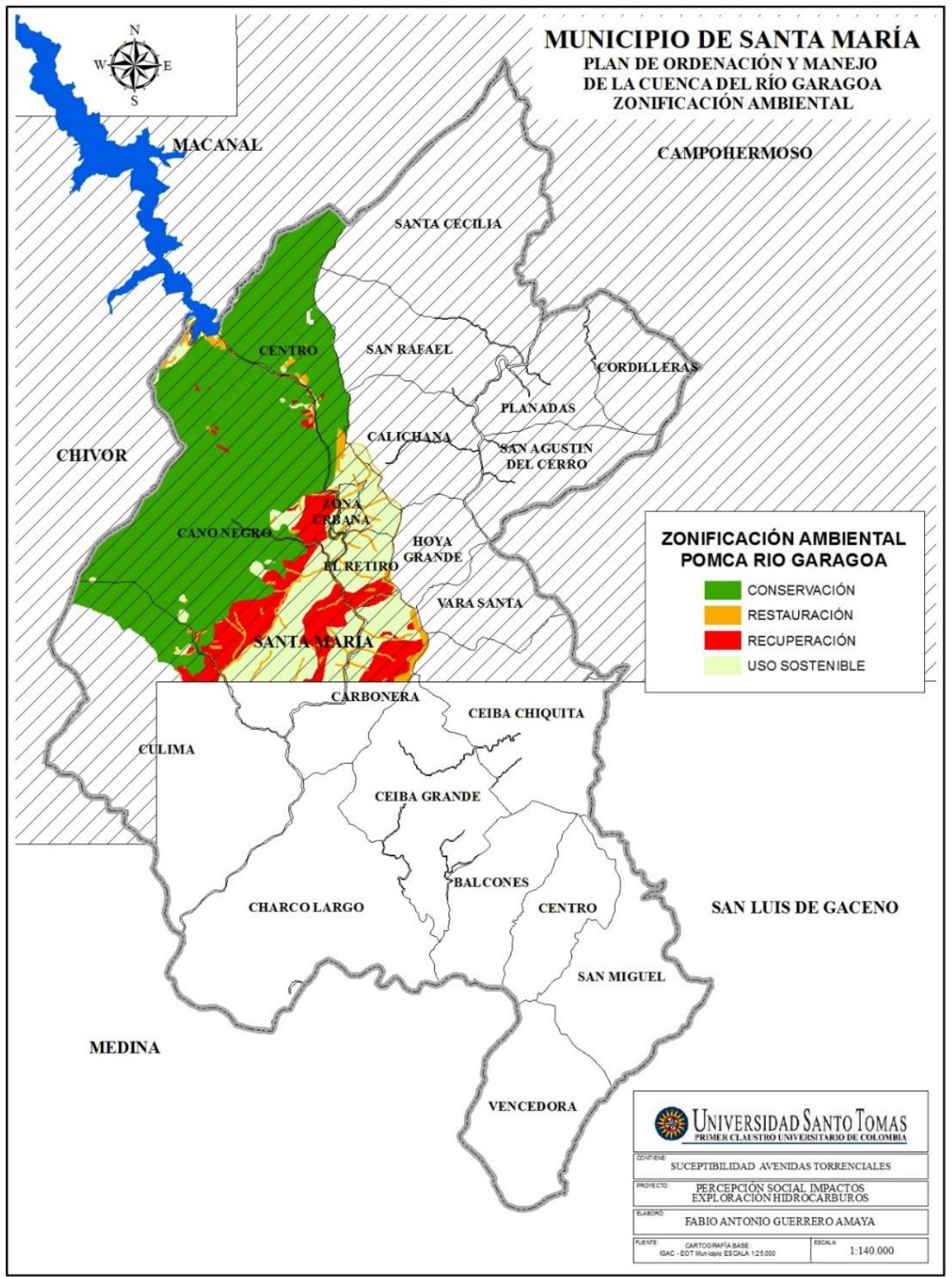

Mapa No. 11: Plan de ordenación y manejo de la cuenca del río Garagoa / Zonificación Ambiental / SIG - CORPOCHIVOR, 2015.

Se observa que toda la zona catalogada de conservación del POMCA, está incluida en jurisdicción del Bloque petrolero COR-60, la cual tiene restricciones ambientales. 


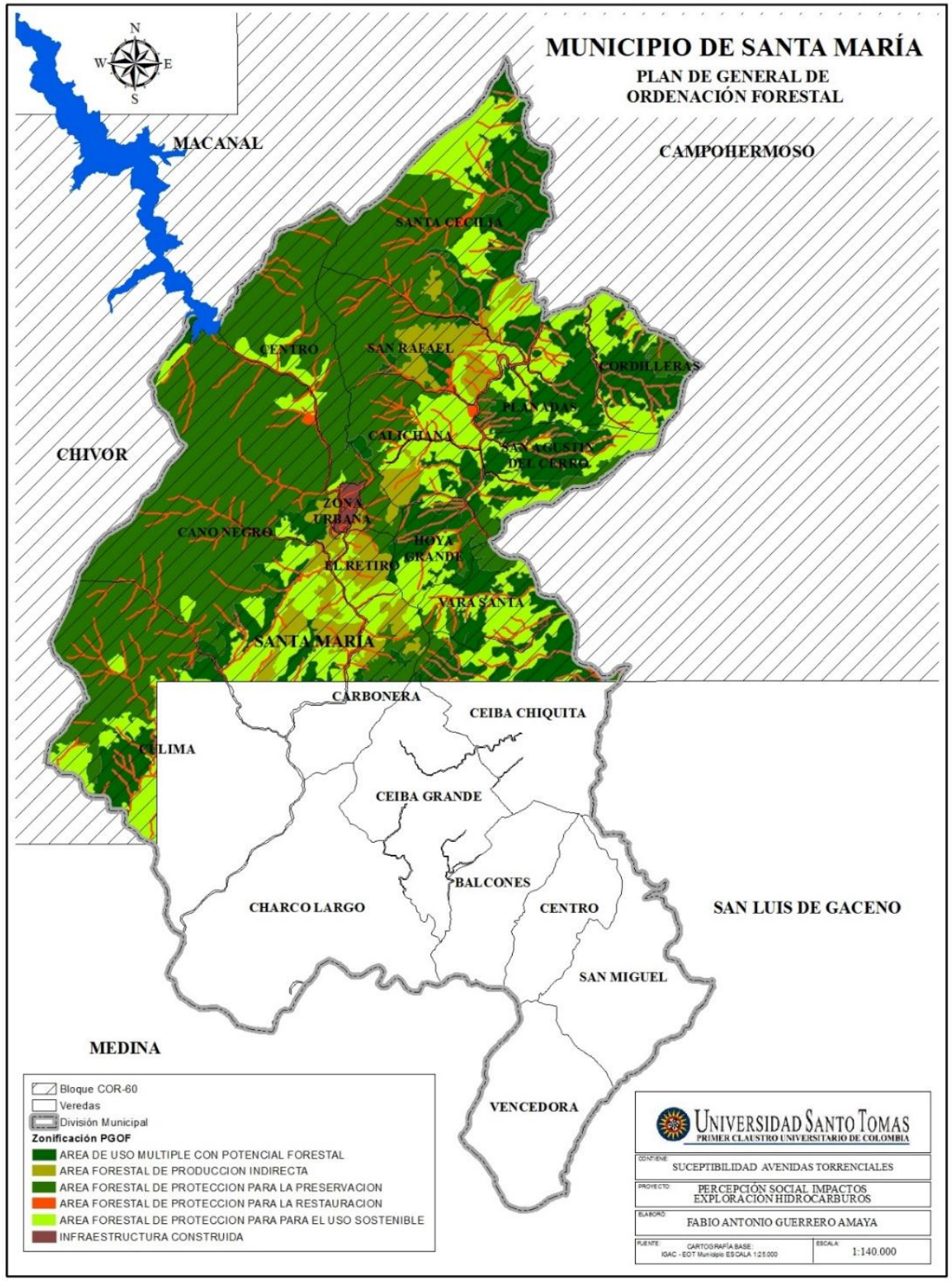

Mapa No. 12: Plan general de ordenación forestal / SIG - CORPOCHIVOR, 2015.

Se aprecia que gran parte del territorio del municipio de Santa María, está zonificada por el PGOF, como área forestal de protección para la restauración o área de uso múltiple con potencial forestal 


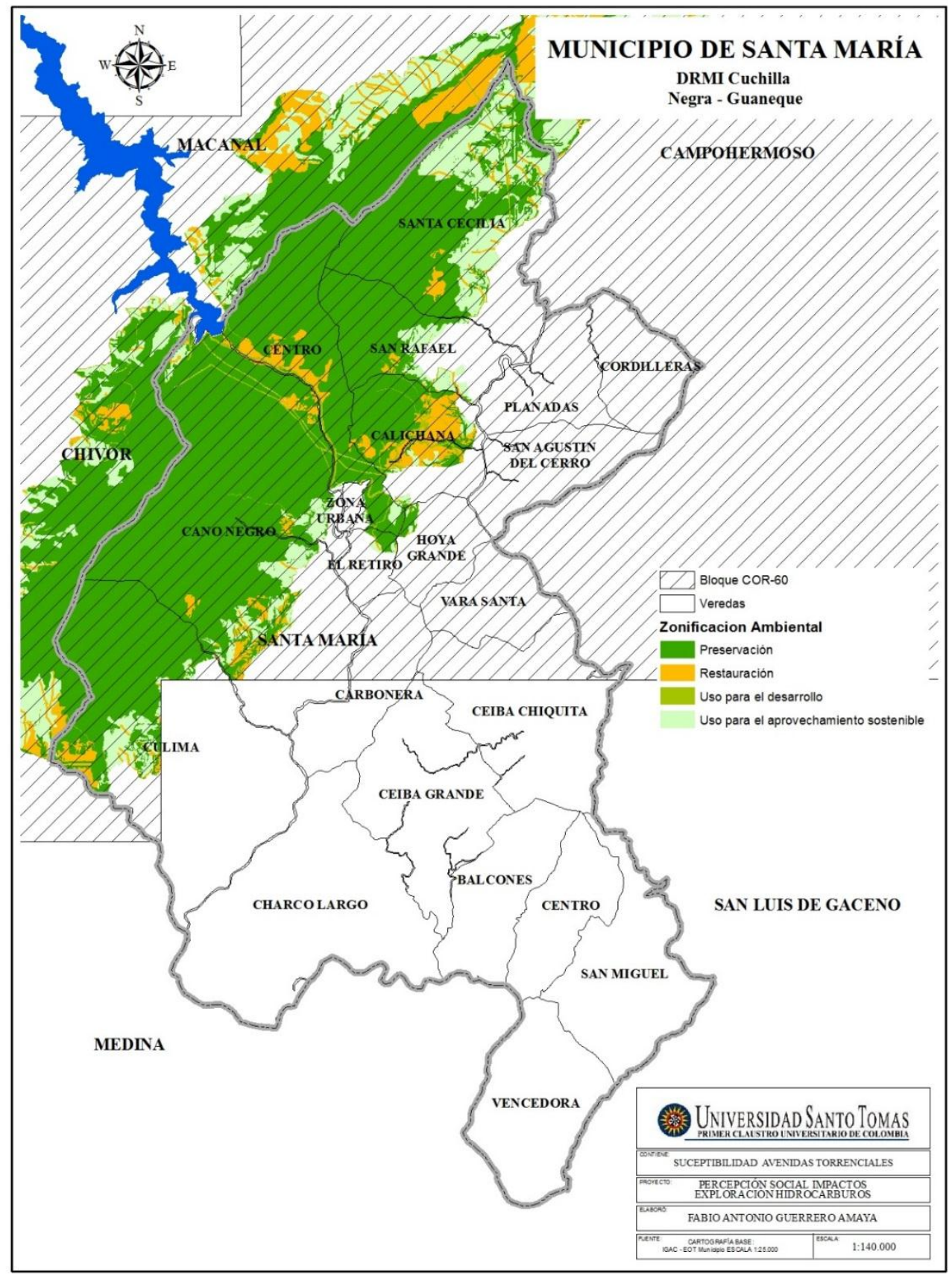

Mapa No. 13: Distrito regional de manejo integrado - DRMI / SIG - CORPOCHIVOR, 2015.

Se observa que gran extensión del municipio está clasificada de preservación por el DRMI Cuchilla Negra - Guanaque, la cual tiene restricciones ambientales. 


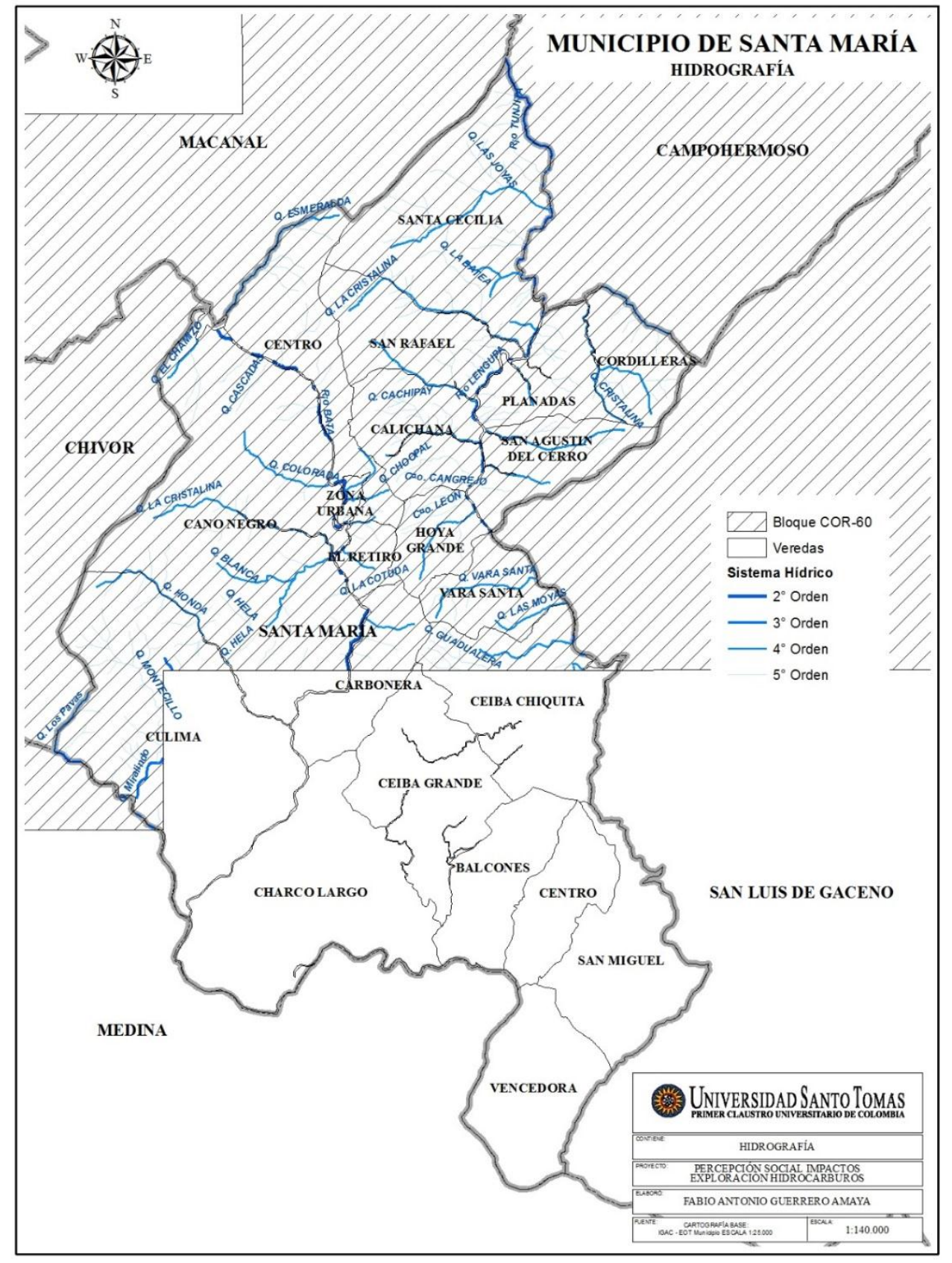

Mapa No. 14: Hidrografía / SIG - CORPOCHIVOR, 2015.

Se aprecia la red hídrica existente, importante por la oferta y sostenibilidad por la existencia de bosques y biodiversidad. 


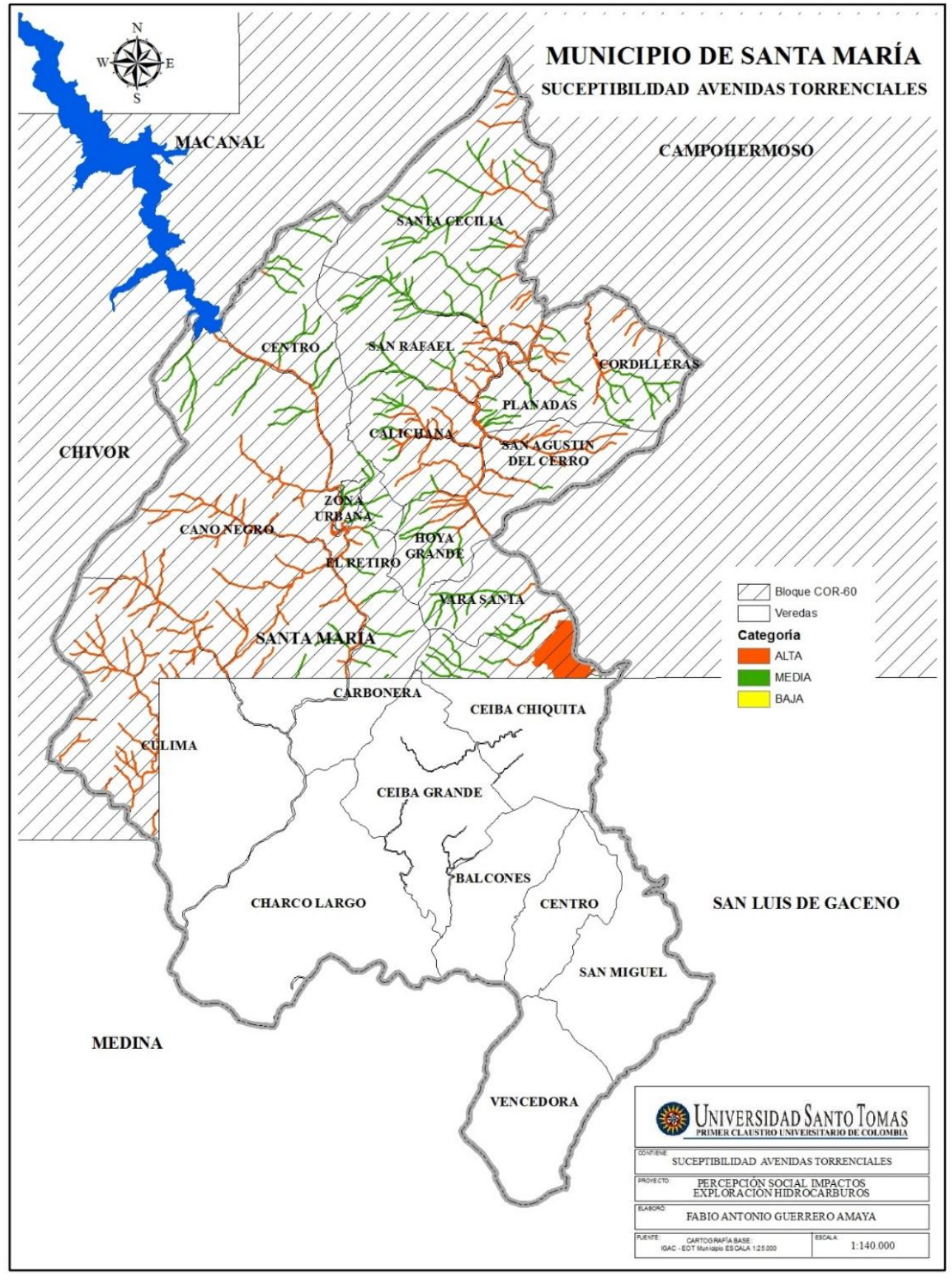

Mapa No. 15: Susceptibilidad avenidas torrenciales / SIG - CORPOCHIVOR, 2015.

Por la topografía del territorio, la susceptibilidad de avenidas torrenciales es clasificada como alta. 


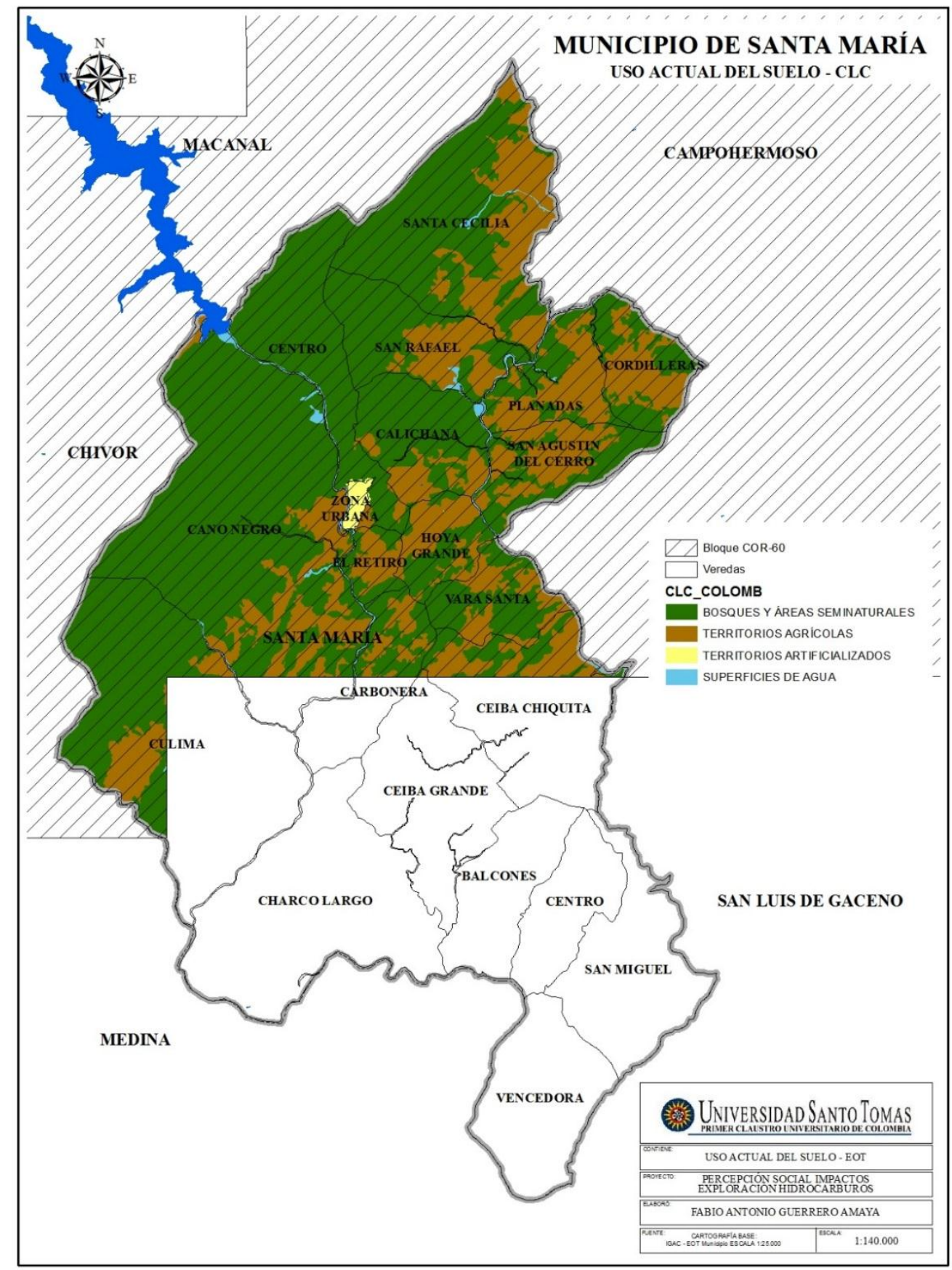

Mapa No. 16: Uso actual del suelo EOT / SIG - CORPOCHIVOR, 2015.

Se puede ver, que gran extensión del municipio de Santa María, está clasificada como Bosques y áreas siminaturales según el uso actual del suelo. 


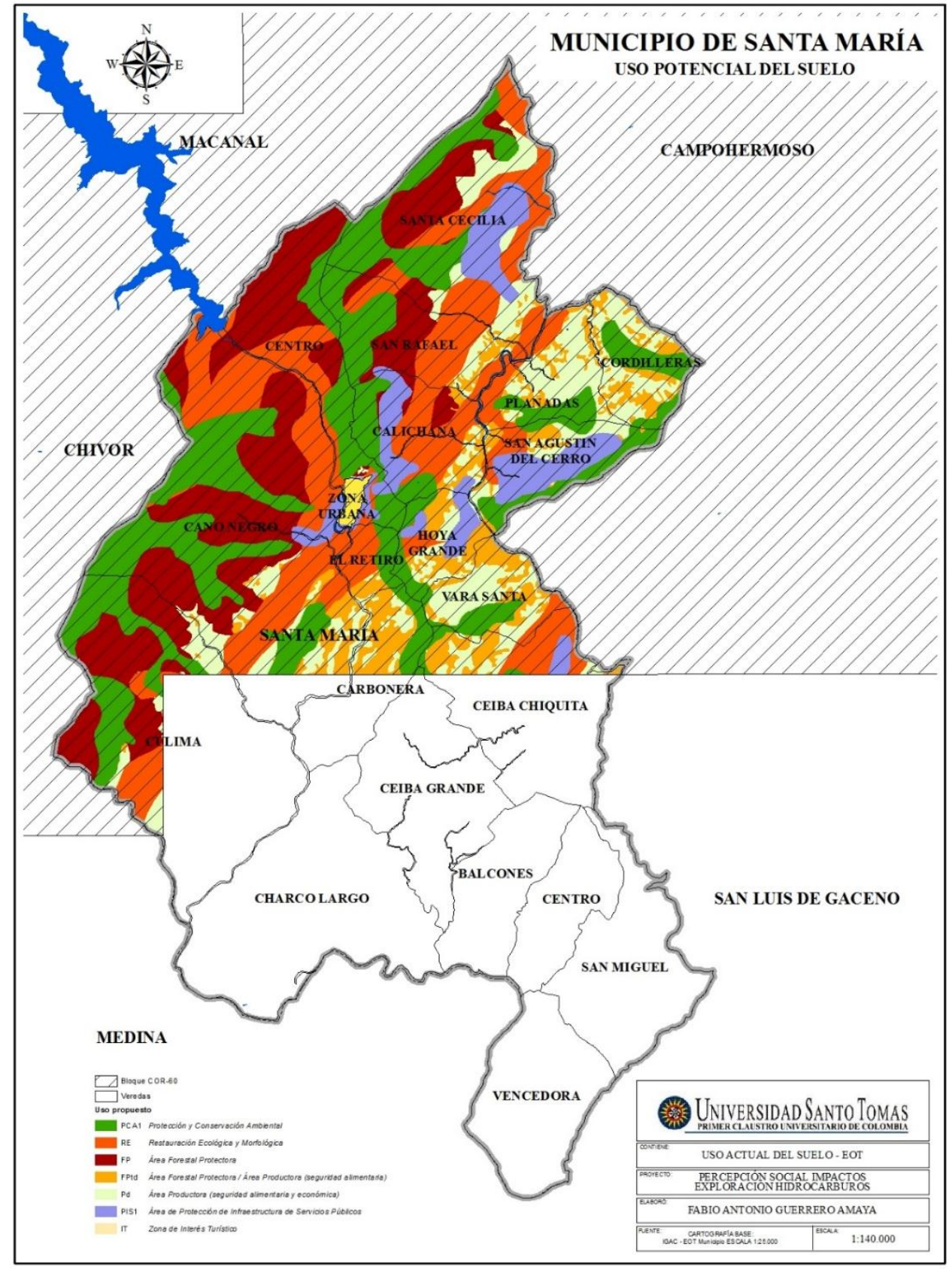

Mapa No. 17: Uso propuesto del suelo - EOT / Zonificación ambiental / SIG - CORPOCHIVOR, 2015.

Respecto al uso potencial del suelo, el área del municipio correspondiente al bloque petrolero COR-60, está clasificada a la protección y conservación ambiental, a Restauración ecológica y morfológica o área forestal protectora. 


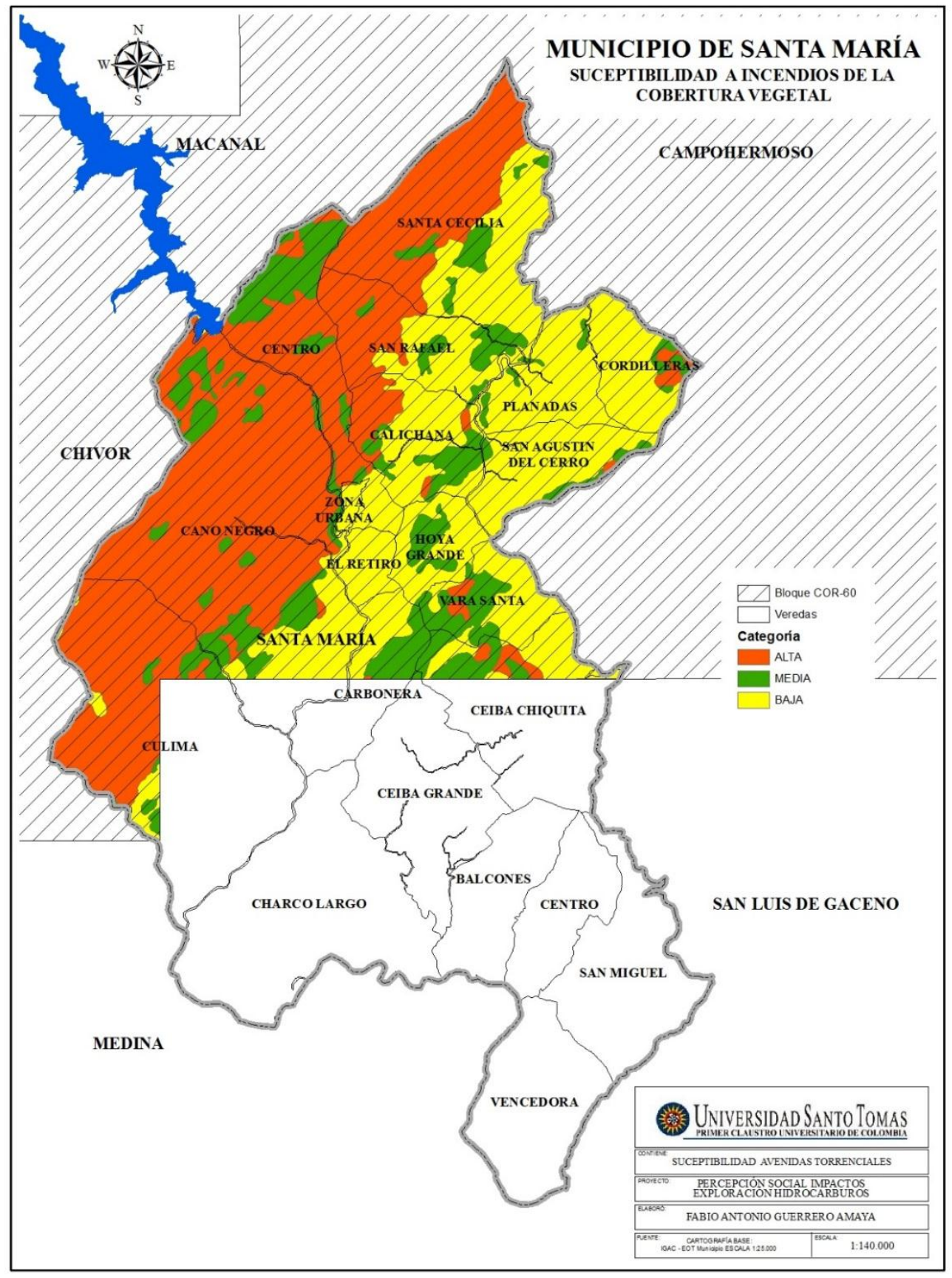

Mapa No. 18: Susceptibilidad a incendios forestales de la cobertura vegetal / SIG - CORPOCHIVOR, 2015.

Se aprecia que la susceptibilidad a la ocurrencia de incendios forestales es Alta debido a la existencia de bosques maduros. 


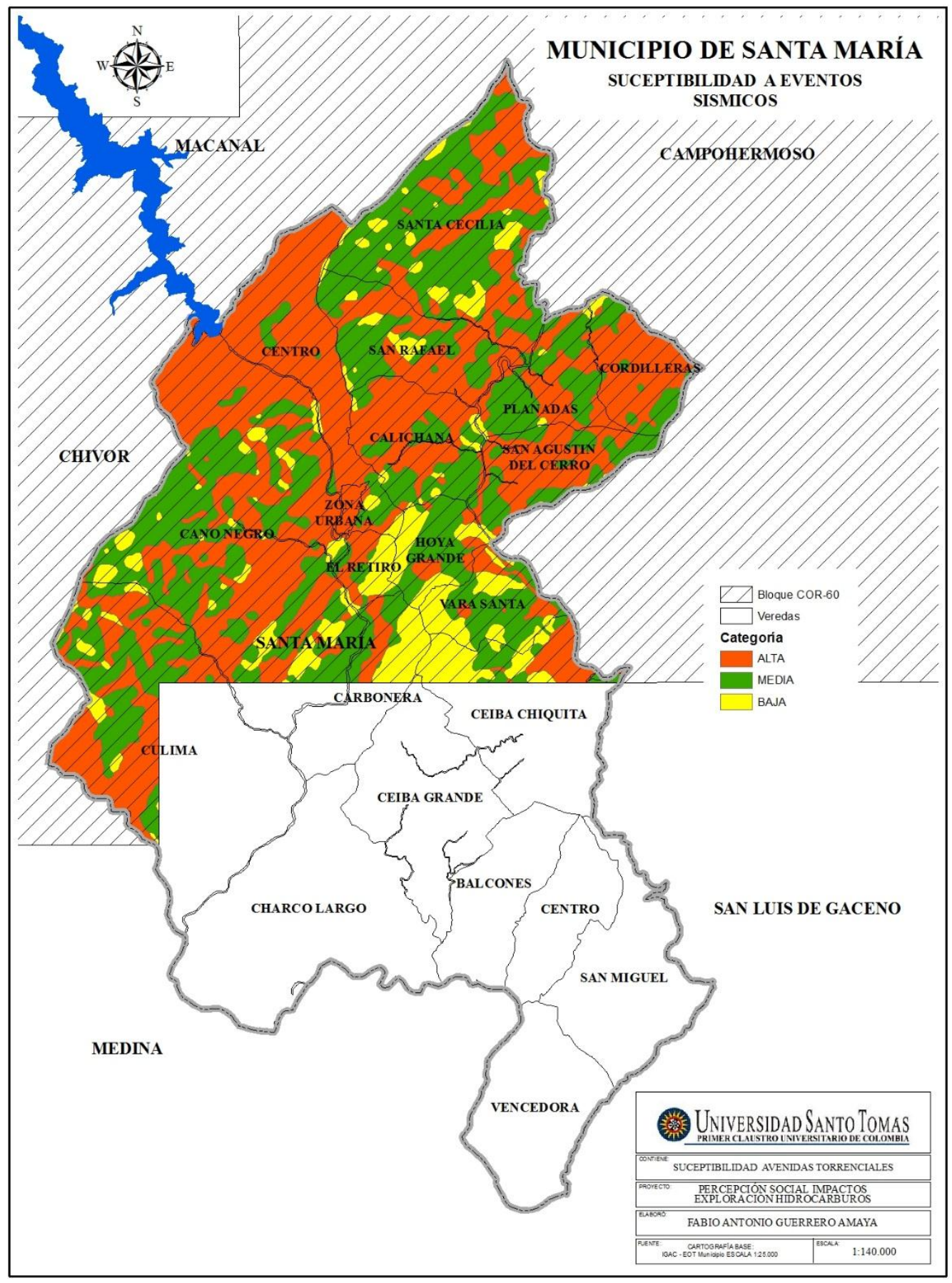

Mapa No. 19: Susceptibilidad Sísmica / SIG - CORPOCHIVOR, 2015.

La Susceptibilidad sísmica corresponde mayormente a las categorías Alta y Media. 
Como se puede observar en la cartografía, el municipio de Santa María es muy biodiverso, se han realizado estudios con zonificación y declarado áreas de protección y conservación ambiental, restauración ecológica y morfológica o área forestal protectora, que ante una posibilidad de solicitud de licenciamiento debe sustraerse dichas áreas, pero no se desconoce que también se han identifico áreas de uso para el desarrollo y uso para el desarrollo sostenible donde existe la posibilidad de implementar proyectos productivos con las exigencias de las autoridades ambientales al aplicar las normas vigentes.

Se concluye que el área objeto de estudio posee ecosistemas estratégicos, variedad de especies vegetales y animales que han sido estudiadas y valoradas por los entes territoriales, ambientales y sector privado.

\subsection{Priorización de categorías.}

Al cruzar la información que se recolectó en la entrevista semi estructurada y el taller de cartografía social, se identificaron unas temáticas y se ordenaron de acuerdo a la afinidad del aspecto que se estuviera analizando. En la tabla 1 se presenta la síntesis de las temáticas identificadas.

\section{Tabla 1}

Aspectos y categorías identificadas.

\begin{tabular}{|c|c|c|c|}
\hline Orden & Preocupación & Impactos Positivos & Impactos Negativos \\
\hline 1 & Recursos Naturales & Institucional & Comunidad \\
\hline 2 & Aspecto Social & Económico. & Agua \\
\hline 3 & Instrumentos & Social & Flora \\
& Planificación & & Aire \\
\hline 4 & Riesgos & Tecnológico & Fauna \\
\hline 5 & & & Suelo \\
\hline 6 & & & \\
\hline
\end{tabular}


Observando el primer orden de la Tabla 1, se interpreta que si el bloque petrolero COR60 es implementado, la problemática identificada se relaciona con el manejo adecuado de los recursos naturales, enfocados en el desarrollo sostenible, donde lo institucional es preponderante por el tema de autoridad ambiental, para mitigar los impactos que la comunidad ha identificado.

En segundo orden, el aspecto social se enfoca a los temores porque la población no está preparada si el proyecto es llevado a cabo, sin embargo el tema económico relacionado con transferencias, compensaciones y generación de empleo les llama la atención, les preocupa el tema del recurso hídrico si llegase a contaminarlo.

5.5. Síntesis de los resultados de la aplicación de la entrevista semi estructurada y cartografía social a integrantes de la población objetivo para determinar la percepción respecto a la eventual aprobación del bloque petrolero COR - 60:

\section{Tabla 2}

Niveles de la problemática.

\begin{tabular}{|c|c|c|}
\hline Nivel & Problemática identificada & $\%$ \\
\hline 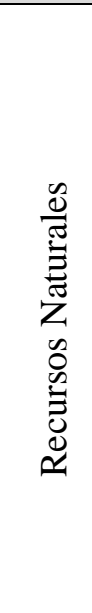 & $\begin{array}{l}\text { Manejo inadecuado el agua. } \\
\text { Falta de control en los métodos de explotación. } \\
\text { Cambio en el uso del suelo para los sitios de operación. } \\
\text { Generación riesgos y procesos erosivos o geodinámicos por la tala del } \\
\text { bosque y la gran precipitación en la zona. } \\
\text { Tala indiscriminada a bosques jóvenes. } \\
\text { Presencia de contaminación. } \\
\text { Afectación negativa a las especies vivientes. }\end{array}$ & 46.8 \\
\hline
\end{tabular}




\begin{tabular}{|c|c|c|}
\hline $\begin{array}{l}\bar{\pi} \\
\overline{0} \\
\text { is }\end{array}$ & $\begin{array}{l}\text { Abandono de las actividades productivas tradicionales. } \\
\text { Presencia de burbuja dentro de la economía del municipio. } \\
\text { Intensificación de intervención antrópica. } \\
\text { Aumento en la generación de residuos sólidos. }\end{array}$ & 26.6 \\
\hline 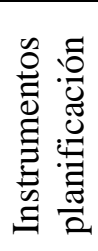 & $\begin{array}{l}\text { Intereses nacionales (políticas) primen más sobre los intereses regionales. } \\
\text { No realización técnica del diagnóstico ambiental de alternativas. } \\
\text { Afectación negativa por el desarrollo del turismo. }\end{array}$ & 20 \\
\hline $\begin{array}{l}\mathscr{0} \\
8 \\
\stackrel{0}{0} \\
\stackrel{0}{\alpha}\end{array}$ & Existencia de fallas geológicas en el municipio. & 6.6 \\
\hline
\end{tabular}

Para los habitantes del municipio de Santa María es preponderante el tema de los recursos naturales, especialmente el manejo del agua porque el municipio posee una red fluvial amplia que se interconecta y si es contaminada afectaría a la población.

Respecto al tema social, identifica el abandono de actividades productivas para dedicarse a nuevas actividades que exigen de más esfuerzo físico y la remuneración es baja porque es mano de obra no calificada, le preocupa la especulación que se presente por la llegada de más personas que demandan de bienes y servicios y la oferta es mínima, haciendo que los costos se intensifiquen, piensan que se aumentaría la descomposición familiar. 


\section{Tabla 3}

Niveles de los impactos positivos identificados

\begin{tabular}{|c|c|c|}
\hline Nivel & Impacto identificado & $\%$ \\
\hline 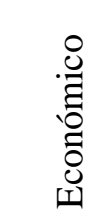 & $\begin{array}{l}\text { Dinamización del sector económico en el corto plazo. } \\
\text { Fortalecimiento del sector comercio. } \\
\text { Impulso del sector transporte y comunicaciones. }\end{array}$ & 33 \\
\hline 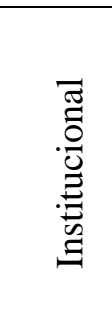 & $\begin{array}{l}\text { Implementación de política relacionada con el aprovechamiento de los } \\
\text { recursos naturales no renovables. } \\
\text { Las medidas de compensación ambiental mitigaran los efectos de la } \\
\text { intervención. } \\
\text { Realización de investigación en el área. }\end{array}$ & 33 \\
\hline $\begin{array}{l}\frac{\pi}{8} \\
0 \\
\mathscr{0}\end{array}$ & $\begin{array}{l}\text { Inversión en responsabilidad social empresarial. } \\
\text { Capacitación de la comunidad. }\end{array}$ & 22 \\
\hline 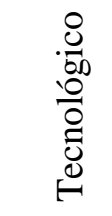 & Utilización de nuevas tecnologías. & 12 \\
\hline
\end{tabular}

Identifican aspectos que les favorecerían, como la dinamización y fortalecimiento del sector económico si el proyecto se llevase a cabo, beneficiándose el sector comercio por la demanda de bienes, servicios e infraestructura, creen que el transporte y las comunicaciones se impulsarían. 


\section{Tabla 4}

Niveles de los impactos negativos identificados

\begin{tabular}{|c|c|c|}
\hline $\begin{array}{c}\text { Rec. } \\
\text { Natural }\end{array}$ & Impactos & $\%$ \\
\hline 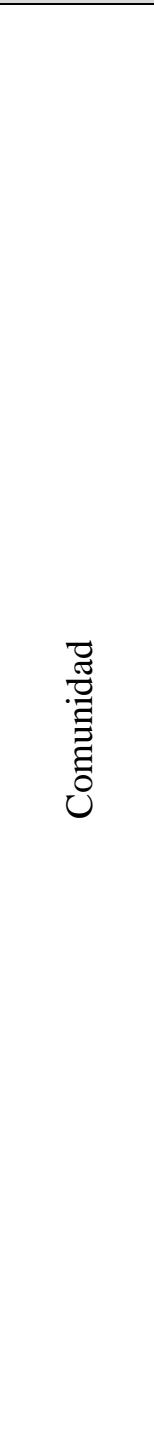 & $\begin{array}{l}\text { El proyecto es asumido por la comunidad como una imposición por } \\
\text { parte de ANH y Ministerio de Minas. } \\
\text { El comercio se ve como una oportunidad de trabajo, los demás como } \\
\text { una amenaza. } \\
\text { Desplazamiento de personas que habitan el lugar del proyecto. } \\
\text { Incremento en la descomposición familiar (generación de madres o } \\
\text { padres cabeza de familia). } \\
\text { La comunidad está interesada en el pago por servicios ambientales, } \\
\text { generen benéficos sociales. } \\
\text { Demanda de mano de obra no calificada únicamente. } \\
\text { Cambio en tradiciones y cultura. } \\
\text { Temor en la población urbana por la generación de riesgos } \\
\text { ambientales. } \\
\text { Incremento de la informalidad en cuanto a la tenencia de la tierra } \\
\text { (falsa tradición). } \\
\text { Incremento en la demanda de servicios básicos (salud, educación, } \\
\text { vivienda, infraestructura y seguridad) que puedan superar la capacidad } \\
\text { del municipio. } \\
\text { Conflicto social por la afectación de los ecosistemas (riqueza natural). } \\
\text { Ocurrencia de aculturación por los cambios paulatinos en los hábitos y } \\
\text { formas de vida. } \\
\text { Modificación del modelo económico actual. }\end{array}$ & 25 \\
\hline 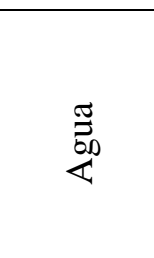 & $\begin{array}{l}\text { Incremento del consumo de agua. } \\
\text { Contaminación directa a nacimientos. } \\
\text { Agotamiento de los recursos naturales renovables y no renovables. } \\
\text { Contaminación aguas subterráneas que afloraran en el municipio. }\end{array}$ & 20.8 \\
\hline
\end{tabular}




\begin{tabular}{|c|c|c|}
\hline $\begin{array}{c}\text { Rec. } \\
\text { Natural }\end{array}$ & Impactos & $\%$ \\
\hline & $\begin{array}{l}\text { Contaminación con residuos químicos generados, metales pesados y } \\
\text { sustancias peligrosas, } \\
\text { Derrames de crudo, generación de aceites quemados por el uso de las } \\
\text { maquinarias. } \\
\text { Contaminación por vertimientos líquidos y particulados. } \\
\text { Daño irreversible a ecosistemas acuáticos por la generación de } \\
\text { vertimientos. } \\
\text { Descompensación en el ciclo hidrológico. } \\
\text { Desviación de fuentes hídricas. }\end{array}$ & \\
\hline$\frac{\pi}{\frac{\pi}{I}}$ & $\begin{array}{l}\text { La riqueza (especies promisorias, semillas, resinas, briofitas, líquenes } \\
\text { y musgos) del bosque se pierde por la ampliación de la frontera para la } \\
\text { realización del proyecto (descapotar la zona). } \\
\text { Afecta negativa a la vegetación aledaña que mantiene el agua. } \\
\text { Intervención de ecosistemas, donde la vegetación es diversa y } \\
\text { promisoria. } \\
\text { Incremento de explotación de madera a través del aprovechamiento } \\
\text { forestal, la deforestación y utilización de herbáceas. } \\
\text { Fragmentación del hábitat (Incluida la tala). } \\
\text { Cambio del paisaje (alteración). } \\
\text { Ocurrencia de más incendios por fenómenos antrópicos. }\end{array}$ & 16.6 \\
\hline 穵 & $\begin{array}{l}\text { Contaminación por fuentes fijas y móviles. } \\
\text { Generación de ruido, afecta la salud humana y produce estrés en los } \\
\text { animales. } \\
\text { Contaminación por altas temperaturas. } \\
\text { Emisión de gases no aprovechables. } \\
\text { Aumento de emisiones atmosféricas. } \\
\text { Manejo sustancias químicas, genera olores y polución. } \\
\text { Liberación de carbono al medio ambiente. }\end{array}$ & 14.6 \\
\hline
\end{tabular}




\begin{tabular}{|c|c|c|}
\hline $\begin{array}{c}\text { Rec. } \\
\text { Natural }\end{array}$ & Impactos & $\%$ \\
\hline 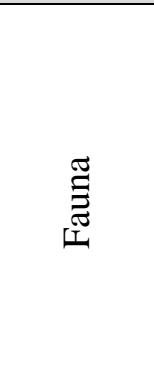 & $\begin{array}{l}\text { Ampliación de la frontera agrícola, pecuaria, industrial o habitacional. } \\
\text { Migración obligada de especies, } \\
\text { Amenaza de desaparición del entorno natural. } \\
\text { Ruptura en los ciclos de la reproducción vegetal. } \\
\text { Pérdida de dispersión de semillas. } \\
\text { Aumento de la caza. }\end{array}$ & 12.6 \\
\hline $\begin{array}{l}\frac{0}{0} \\
\stackrel{0}{=}\end{array}$ & $\begin{array}{l}\text { Cambio en el uso del suelo (pisoteo por personas, construcción de } \\
\text { infraestructura, uso de maquinaria pesada y vehículos). } \\
\text { Vertimientos líquidos alteran la composición. } \\
\text { Fragmentación de capas geológicas. } \\
\text { Incremento del conflicto de uso del suelo. } \\
\text { Desestabilización por falla Geológica Santa María. }\end{array}$ & 10.4 \\
\hline
\end{tabular}

Identifican que las comunidades serían las más afectadas porque llegarían otras culturas que influirían en aspectos como el vestuario, alimentación, lenguaje, costumbres y modos de vida, tienen temor de enfrentarse a situaciones nuevas por la experiencia vivida con el macro proyecto construcción y operación embalse La Esmeralda, entienden que la bonanza es por tiempo determinado y que al final los habitantes permanentes tienen que abordar toda la problemática que no se mitigó de manera oportuna.

\subsection{Recomendaciones o Sugerencias a Autoridades Ambientales}

Que exista coordinación interinstitucional entre las autoridades ambientales del orden local con las del orden nacional, de tal manera que compartan la información generada en investigaciones, estudios ambientales y actos administrativos, para que se sustraigan las áreas que han sido declaradas como reserva de las áreas identificadas como bloques petroleros para evitar conflictos socio-ambientales. 
Tener en cuenta los impactos ambientales negativos y positivos identificados por la comunidad de Santa María si el proyecto es aprobado e implementado para que se eviten o mitiguen en las diferentes fases del proyecto, en función de alcanzar el desarrollo humano sostenible.

Exigir el cumplimiento a cabalidad de la normatividad ambiental, para que se dé el manejo adecuado y oportuno a los componentes biótico, abiótico, social y económico, en función de mitigar los impactos que se generen.

Realizar acompañamiento y seguimiento a los ejecutores del proyecto desde la fase inicial hasta el abandono de la actividad de explotación de petróleo y exigir si es el caso la ejecución de los planes de contingencia, en función de mitigar los impactos generados.

Apoyar y fortalecer a las comunidades del municipio de Santa María, capacitándolas en aspectos ambientales, normativos y de participación ciudadana con el objeto de potencializar el recurso en la toma de decisiones.

Mantener contacto directo con las comunidades para que estén bien informadas de los avances del proyecto para evitar conflictos.

\subsection{Conclusiones:}

A la comunidad del municipio de Santa María le preocupa el manejo de los recursos naturales renovables, si el bloque petrolero COR-60 es adjudicado y no se tiene en cuenta las áreas declaradas como reserva. 
La áreas protegidas identificadas en el taller de cartografía Social, coinciden con los estudios e investigaciones realizados por parte de las autoridades ambientales regionales, como son: Plan de Ordenación y manejo la cuenca del río Garagoa, Plan General de Ordenamiento Forestal, Distrito Regional de Manejo Integrado de la cuchilla Negra y Guanaque y Esquema de Ordenamiento Territorial

Los habitantes del Municipio de Santa María - Boyacá reconocen que su territorio es rico en biodiversidad y se debe proteger y conservar, por las condiciones ambientales como el clima, la geomorfología, la existencia de bosques jóvenes naturales, que han sido valorados por la academia, las instituciones ambientalistas de la región y el sector privado.

La comunidad de Santa María - Boyacá, identifica como impactos positivos si se realiza el proyecto petrolero, la implementación de la política relacionada con el aprovechamiento sostenible de los recursos naturales, las medidas de compensación ambiental que mitigaran los efectos de la intervención, la realización de investigación en el área del proyecto, la inversión social de las transferencias y la generación de empleo.

Los impactos negativos clasificados en categorías, el de mayor magnitud en su orden es el de Comunidad por conflictos relacionados con el adecuado manejo del Agua, Flora, Aire, Fauna y Flora, ha influido la experiencia vivida con el desarrollo del macro proyecto de construcción y generación de energía hidráulica, denominado "Embalse la Esmeralda".

Si se llegase a ejecutar el proyecto petrolero, lo que más les preocupa a los habitantes del municipio de Santa María, es el manejo que se dé a los recursos naturales renovables, la contaminación, la generación de residuos sólidos y la presencia de riesgos con la intensificación de los fenómenos de remoción del suelo. 
Respecto al tema social, identifica el abandono de actividades productivas para dedicarse a nuevas actividades que exigen de más esfuerzo físico y la remuneración es baja porque es mano de obra no calificada, le preocupa la especulación que se presente por la llegada de más personas que demandan de bienes y servicios y la oferta es mínima, haciendo que los costos se intensifiquen, piensan que se aumentaría la descomposición familiar. 


\section{BIBLIOGRÁFICAS Y WEBGRAFÍA}

Alesina Et al. (2011). Metodología de la investigación en ciencias sociales, Universidad de la República.

Aguirre Ceballos, J. (2011) Guía de Campo de los mamíferos, anfibios y reptiles de Santa María (Boyacá), Instituto de Ciencias Naturales, Universidad Nacional de Colombia, AES Chivor, Bogotá D.C., Colombia.

Amat-García G. (2009) Biodiversidad Regional (Artrópodos: arácnidos, miriápodos, crustáceos e insectos: Santa María, Boyacá. Instituto de Ciencias Naturales, Universidad Nacional de Colombia. Bogotá D.C., Colombia.

Barkin, D. (2012) Superando el paradigma neoliberal: desarrollo popular sustentable. Cuadernos de Desarrollo Rural.

Batthyány, K. \& Cabrera, M. (Coord.) (2011). Metodología de la investigación en Ciencias Sociales. Apuntes para un curso inicial. Universidad de la República de Uruguay. Montevideo.

Betancur, Zuluaga, Clavijo, Cordero y Salinas. (2007) Santa María pintada de flores, Instituto de Ciencias Naturales, Universidad Nacional de Colombia. Bogotá D.C., Colombia.

Bonilla-Castro Ellsy. Rodríguez Penélope. (2005) Capítulo 5: Recolección de datos cualitativos. En: "Más allá del dilema de los métodos. La investigación en Ciencias Sociales". Grupo Editorial Norma. 
Campos S., Uribe M. y Aguirre C. (2008) Santa María, Líquenes, Hepáticas y Musgos. Instituto de Ciencias Naturales, Universidad Nacional de Colombia. Bogotá D.C., Colombia.

Corbetta, P. C. (2007). Metodología y técnicas de investigación social. McGraw-Hill,.

Correa, S., Puerta A. \& Restrepo, B. (2002) Investigación evaluativa. ICFES. Bogotá.

Corporación Autónoma Regional de Chivor, (2012) Aves de la región en peligro de extinción, Garagoa, Colombia.

Corporación Autónoma Regional de Chivor, (2015) Distrito de manejo integrado cuchilla Negra y Guanaque, Garagoa, Colombia.

DNP. (s/f). "Plan Nacional de Desarrollo. Resumen Ejecutivo". Bogotá: DNP. Recuperado de: https://www.dnp.gov.co/LinkClick.aspx?fileticket=4-J9VFE2pl\%3D\&tabid=1238.

ECOFONDO (2004) Resolución de conflictos ambientales, Bogotá - Colombia.

Espinoza, G. A. (2002) Gestión y fundamentos de evaluación de impacto ambiental (No. C056. 001). BID/CED.

Fernández, L. (2006). ¿Cómo analizar datos cualitativos? Butlletí La Recerca. Universitat de Barcelona. Institut de Ciències de l'Educació.

Fontaine, G. (2004). Enfoques conceptuales y metodológicos para una sociología de los conflictos ambientales. Guerra, Sociedad y Medio Ambiente. 
Fontaine, G. (2003). El Precio del petróleo. Conflictos socio-ambientales y gobernabilidad en la región amazónica. Flacso-Sede Ecuador.

Fontaine, G. (2004). Petróleo y desarrollo sostenible en Ecuador: Las apuestas (Vol. 2), Flacso-Sede Ecuador.

Giraldo Caro G. y Betancur J. (2011) Guía de campo de las orquídeas de Santa MaríaBoyacá. Instituto de Ciencias Naturales, Universidad Nacional de Colombia. Bogotá D.C., Colombia.

González F. M. y Betancur J. (2013) Un recorrido por la flora del sendero Hyca-Quye, Instituto de Ciencias Naturales, Universidad Nacional de Colombia, Bogotá D.C., Colombia.

González Serna, J., \& Cifuentes Ortega, M. A. (2014). Influencia de la exploración y el almacenamiento de petróleo y gas natural en la relación de las organizaciones con las comunidades.

Guimarães, J. A. C., de Moraes, J. B. E., \& Guarido, M. D. M. (2007). Análisis documental de contenido de textos narrativos: bases epistemológicas y perspectivas metodológicas. Ibersid: revista de sistemas de información y documentación.

Hueso González, A. \& Cascant, MJ. (2012). Metodología y técnicas cuantitativas de investigación. Universidad Politécnica de Valencia.

INDEPAZ, (2012), Documento Línea base, sector petróleos. Programa de las Naciones Unidas para el Desarrollo - PNUD, Agencia nacional de hidrocarburos - ANH, 
(2013). Línea base programas en beneficio de las comunidades implementados por el sector de hidrocarburos en Colombia, Editora 3 Ltda. Colombia.

Preciado, J.C.; Restrepo, G.M.; Velasco, A.C (1999). Cartografía social. Universidad Pedagógica y tecnológica de Colombia.

Programa de las Naciones Unidas para el Desarrollo - PNUD, Agencia nacional de hidrocarburos - ANH, (2014). Siete lecciones aprendidas para una inversión social exitosa en el sector de hidrocarburos, Bogotá D.C., Colombia.

Lavell, A. (1996). Degradación ambiental, riesgo y desastre urbano. Problemas y conceptos: hacia la definición de una agenda de investigación. Fernández, AM (comp.), Ciudades en Riesgo-Degradación Ambiental, Riesgos Urbanos y Desastres, La Red, Lima.

Maya, A. (1997) Desarrollo sostenible o cambio cultural, Imprenta departamental del valle del cuaca.

Millán J. (2005), Guía ambiental para evitar, corregir y compensar los impactos de las acciones de reducción y prevención de riesgos en el nivel municipal, Molde Gráficas Ltda.

Ministerio de ambiente y desarrollo sostenible, Corpochivor y U. Distrital (2013), Formulación plan general de ordenación forestal, Garagoa - Colombia.

Márquez Reyes, C. y Vanegas V. H. (2008) Guía de las aves rapaces diurnas de CORPOCHIVOR (Municipios de San Luis de Gaceno y Santa María), Instituto Alexander Von Humboldt, Bogotá D.C., Colombia. 
Méndez Arce C. M. y Murillo J. (2014) Helechos y Lycofitos de Santa María - Boyacá, Instituto de Ciencias Naturales, Universidad Nacional de Colombia, AES Chivor, Bogotá D.C., Colombia.

Llanos-Hernández, L. (2010). El concepto del territorio y la investigación en las ciencias sociales. Agricultura, sociedad y desarrollo.

PETRO-TECH, Peruana S.A., (2009). Estudio de impacto ambiental y social, prospección sísmica $2 d$ y $3 d$-lote z-48, Walsh Perú S.A.

Ramos Martínez, R. y Caicedo Rojas, Y. (2014). Adaptación de una herramienta de implementación de programas ambientales y sociales de Responsabilidad Social Empresarial para el sector de hidrocarburos en Colombia, Universidad San Buenaventura, Colombia.

Riveros H. y León L. (1997) Perspectiva constitucional de la gestión ambiental, Milenio.

Rodríguez, J. M. (2011). Métodos de investigación cualitativa. Revista de Investigación Silogismo, 1(08).

Sampieri, H. (1997) (1991). Metodología de la Investigación. McGrw-Hill. Capítulo 10.

Santos Calderón, Política nacional para la gestión integral de la biodiversidad y sus servicios ecosistémicos, Ministerio de Ambiente y Desarrollo Sostenible.

Sunkel, O. (1980). La interacción entre los estilos de desarrollo y el medio ambiente en América Latina. Revista de la Cepal. 
Wilches - Chaux, G. (2006). Brújula, Bastón y lámpara para trasegar por los caminos de la educación ambiental. Colombia, Panamericana formas e impresos. 
ANEXOS

ANEXO 1: Entrevista semi estructurada para comunidades de la cabecera municipal de Santa María.

FECHA:

LUGAR:

INSTITUCION U ORGANIZACIÓN:

SECTOR: HABITANTE DEL BARRIO:

ENTREVISTADOR:

Estamos realizando una investigación para determinar la percepción de la comunidad del municipio de Santa María (Boyacá) ante posibles impactos ambientales asociados a la adjudicación del bloque petrolero COR-60, por tal motivo le solicito su colaboración para que conteste una serie de preguntas, las cuales serán insumo para determinar los aspectos fundamentales que las autoridades competentes exigirán al momento de aprobar o licenciar el proyecto con el objeto de mitigar los impactos generados por la actividades de explotación del petróleo.

1. ¿Alguna institución ha determinado la importancia ambiental de Santa María? ¿Cuál? ¿Cómo?

2. ¿La Cuchilla Negra y Guaneque son ecosistemas estratégicos del municipio? ¿por qué?

3. ¿Tiene conocimiento de la existencia de la Agencia Nacional de Hidrocarburos?

4. ¿Las autoridades de hidrocarburos han realizado actividades en el municipio? ¿Cuáles?

5. ¿En el municipio se está desarrollando algún proyecto de hidrocarburos? ¿Dónde?

6. ¿Se ha enterado por algún medio de comunicación, de la existencia del bloque petrolero COR-60, el cual tiene incidencia en el municipio de Santa María? 
7. Si se ejecuta un proyecto petrolero en el municipio ¿qué le preocupa del componente ambiental?

8. Con las actividades del proyecto petrolero ¿cree que se generan impactos negativos? ¿Cuáles?

9. Con las actividades del proyecto petrolero ¿cree que se generaran impactos positivos? ¿Cuáles?

10. ¿Alguna entidad ha levantado cartografía ambiental para el municipio o la región? ¿Cuál?

11. Con las actividades del proyecto petrolero ¿cree que las fuentes hídricas serán afectadas? ¿por qué?

12. Con las actividades del proyecto petrolero ¿Cuáles recursos naturales serán afectados? ¿cómo?

13. ¿Considera que las comunidades de base se tienen en cuenta al momento de aprobar algún proyecto regional?

14. ¿Qué tipo de comunicación o interacción es utilizada por los ejecutores de los proyectos en el municipio?

15. ¿Las comunidades de base utiliza medios de participación ciudadana? ¿Cuáles?

16. ¿En el municipio se han llevado a cabo veedurías ciudadanas al desarrollar algún proyecto de carácter ambiental?

¿Cuál?

17. ¿Alguna empresa ha desarrollado actividades de responsabilidad social empresarial en el municipio?

¿Cuál?

Agradezco el tiempo dispuesto para el desarrollo de la entrevista, sus opiniones, sugerencias y propuestas constructivas son importantes para el manejo de los aspectos sociales y ambientales en la región. 
ANEXO 2: Guía para el desarrollo de cartografía social, para determinar la percepción de la comunidad del municipio de Santa María (Boyacá) ante posibles impactos ambientales asociados a la adjudicación del bloque petrolero COR-60.

La cartografía social como instrumento, es un ejercicio participativo que por medio de recorridos, talleres o grupos de discusión, utiliza el mapa como centro de motivación, reflexión y redescubrimiento del territorio en un proceso de conciencia relacional, invitando a los habitantes de un territorio a hablar sobre el mismo y las territorialidades, es decir, invitando a hacer visibles los micro poderes presentes y configuradores de la cotidianidad sobre los espacios comúnmente habitados y significados como sinónimos de gustos, encuentros, disgustos, desencuentros, miedos o prevenciones.

"En Términos Prácticos, el ejercicio de elaborar mapas no es otra que dibujar la realidad, empezando por lo más simple para poco a poco ir creando un campo estructurado de relaciones que posibilita la traducción, a un mismo lenguaje, de todas las distintas versiones de la realidad que empiezan a ser subjetivamente compartidas" (Preciado, J.C y otros, 1999, p. 35).

PÚBLICO OBJETIVO: Profesionales y técnicos de diferentes áreas del conocimiento ambiental y social con influencia en el municipio de Santa María.

\section{REALIZADORES:}

- ORIENTADOR, juega un papel de provocador, sin llegar a guiar forma de expresión, suscita el despliegue creativo de los elementos conceptuales que se arrojen, y de los elementos simbólicos implícitos en ejercicio. La importancia del orientador radica en la preparación misma del taller, no en su desarrollo. Es decir recoge los insumos cartográficos, prepara la guía del taller, formula preguntas 
pertinentes que generen información insumo para determinar la Línea Base ambiental del municipio de Santa María.

- FACILITADOR, es el encargado de observar y tomar nota, debe estar atento durante el desarrollo de la actividad a las conversaciones de los participantes, observar en detalle los gestos porque también son parte de la información sobre las preguntas orientadoras (disgustada, irónica, alegre, prevenida, conciliadora, etc.)

- RELATOR, es el encargado de tomar nota de los aspectos relevantes del ejercicio, expondrá en representación de la mesa temática las conclusiones sobre los impactos identificados y sus posibles soluciones, es una persona del público objetivo.

- MATERIALES, cada mesa estará ubicada estratégicamente e identificada, en la mesa se ubicará un croquis del área del bloque petrolero COR-60 con la división política para que ubiquen los impactos actuales y un pliego de papel calco, para ubicar los impactos futuros si es adjudicado el bloque petrolero COR-60, se superpondrán para análisis, plumasters, marcadores y lápiz.

\section{TALLER CARTOGRAFÍA SOCIAL}

Temática: Percepción de la comunidad del municipio de Santa María (Boyacá), ante posibles impactos ambientales asociados a la adjudicación del bloque petrolero COR-60.

\section{Tabla 5}

Planilla asistencia taller cartografía social

\begin{tabular}{|l|l|l|l|l|l|}
\hline No. & Nombres y Apellidos & Cédula & Profesión & $\begin{array}{c}\text { Mesa en la que } \\
\text { participó }\end{array}$ & $\begin{array}{c}\text { Desarrollo } \\
\text { Profesional }\end{array}$ \\
\hline & & & & & \\
\hline & & & & & \\
\hline
\end{tabular}




\begin{tabular}{|l|l|l|l|l|l|}
\hline & & & & & \\
\hline & & & & & \\
\hline & & & & & \\
\hline
\end{tabular}

ETAPAS DEL TALLER

MOTIVACIÓN, se hará en plenaria, con el objeto de sensibilizar a los participantes en torno a los mecanismos de participación ciudadana y en la definición de impactos ambientales.

\section{VISIBILIZACIÓN Y CONSTRUCCIÓN COLECTIVA DEL CONOCIMIENTO} SOBRE EL TERRITORIO. En este momento, cada grupo recibe las indicaciones sobre el trabajo a desarrollar y el suministro de los materiales a utilizar. El orientador y Facilitador desarrollaran sus roles al interior de cada grupo. Todos los integrantes del grupo serán guías, están encargados de conversar sobre las preguntas entregadas de la guía estructurada previamente de acuerdo a la temática desarrollada.

Si van a señalar en el mapa áreas que considere prioritarias, puede utilizar el siguiente formato:

\section{Tabla 6}

Identificación de convenciones

\begin{tabular}{|c|c|}
\hline \multicolumn{2}{|c|}{ Taller Cartografía Social / Municipio de Santa María - Boyacá } \\
\hline Número/Convención & Identificación, ubicación y sugerencias. \\
\hline 1 & \\
\hline 2 & \\
\hline 3 & \\
\hline 4 & \\
\hline
\end{tabular}


Para el desarrollo se harán grupos de máximo 10 personas, para abordar las siguientes temáticas:

\section{MESAS TEMATICAS Y ASPECTOS A TRABAJAR.}

Mesa 1: Biodiversidad, Ecosistemas y Recurso Hídrico / Orientador / Facilitador / Relator.

- Identifique y plasme las fortalezas en los aspectos de fauna, flora y recurso hídrico del municipio de Santa María.

- Identifique y plasme las áreas estratégicas ambientales declaradas en el municipio.

- Identifique y plasme los Impactos ambientales positivos,

- Identifique y plasme los impactos negativos del proyecto petrolero.

Mesa 2: Sectores Productivos / Orientador / Facilitador / Relator.

- Identifique y ubique los sectores productivos existentes en el municipio.

- Identifique y ubique la vocación productiva del municipio.

- Identifique y ubique las afectaciones a los sectores productivos si es adjudicado el bloque petrolero COR-60.

Mesa 3: Gestión del Riesgo / Orientador / Facilitador / Relator.

- Identifique y ubique los riesgos naturales actuales.

- Identifique y ubique los riesgos naturales post a la adjudicación del bloque.

Mesa 4: Conflictos socio-ambientales Orientador / Facilitador / Relator.

- Identifique y plasme los conflictos socio-ambientales Actuales. 
- Identifique y plasme los conflictos socio-ambientales después de adjudicado el bloque.

TIEMPO: En la construcción de cada mapa el grupo dispondrá de 30 minutos, se dejaran 10 minutos adicionales para que los relatores organicen los datos para la plenaria, con el objeto de socializar de la información generada.

SOCIALIZACIÓN DEL CONOCIMIENTO. En plenaria, cada relator de grupo expone en orden prioritario los principales impactos actuales y los futuros si es adjudicado el bloque perolero COR-60, se espera que las conclusiones de cada grupo generen en el resto de participantes reacciones que permitan recoger otra información no contemplada en las preguntas guías. El taller se cierra con una evaluación de la actividad por parte de los participantes, una vez terminadas todas las socializaciones y las reflexiones.

Posteriormente, con los mapas generados, se hará el ejercicio de relacionarlos entre sí, es decir, ganar una mirada integral del territorio, con sus actores, relaciones y escenarios, hasta la determinación de conclusiones. 
ANEXO 3: Estructuración del Normograma.

Se identificaron las normas que son aplicables al tema porque la claridad en la existencia y aplicabilidad permiten que las acciones del proyecto fluyan de manera ordenada, acorde a lo definido por las autoridades ambientales y locales.

\section{Tabla 7}

Normograma tema petróleo

\begin{tabular}{|c|c|c|c|}
\hline TEMA & $\begin{array}{l}\text { TIPO DE } \\
\text { NORMA }\end{array}$ & $\begin{array}{l}\text { NÚMERO / } \\
\text { FECHA }\end{array}$ & TITULO \\
\hline \multirow{4}{*}{ AMBIENTAL } & $\begin{array}{l}\text { Constitución } \\
\text { Política }\end{array}$ & 1991 & Constitución política de Colombia. \\
\hline & Decreto & 2811 de 1974 & $\begin{array}{l}\text { Código Nacional de Recursos Naturales } \\
\text { Renovables y el Medio Ambiente. }\end{array}$ \\
\hline & Ley & 99 de 1993 & $\begin{array}{l}\text { Se crea el Ministerio del Medio Ambiente, se } \\
\text { reordena el Sector Público encargado de la } \\
\text { gestión y conservación del medio ambiente y } \\
\text { los recursos naturales renovables, se organiza } \\
\text { el Sistema Nacional Ambiental, SINA, y se } \\
\text { dictan otras disposiciones. }\end{array}$ \\
\hline & Decreto & 1076 de 2015 & $\begin{array}{l}\text { Por medio del cual se expide el Decreto } \\
\text { Único Reglamentario del Sector Ambiente y } \\
\text { Desarrollo Sostenible }\end{array}$ \\
\hline \multirow[b]{3}{*}{ RECURSO AGUA } & Ley & 09 de 1979 & Código Sanitario. \\
\hline & Ley & 373 de 1991 & $\begin{array}{l}\text { Establece el programa para el uso eficiente y } \\
\text { ahorro del agua }\end{array}$ \\
\hline & Decreto & 3930 de 2010 & $\begin{array}{l}\text { Se reglamenta parcialmente el Título I de la } \\
\text { Ley } 9^{a} \text { de } 1979 \text {, así como el Capítulo II del } \\
\text { Título VI -Parte III- Libro II del Decreto-ley } \\
2811 \text { de } 1974 \text { en cuanto a usos del agua y } \\
\text { residuos líquidos y se dictan otras } \\
\text { disposiciones }\end{array}$ \\
\hline RECURSO AIRE & Decreto & 02 de 1982 & Se reglamentan parcialmente el Título I de la \\
\hline
\end{tabular}




\begin{tabular}{|c|c|c|c|}
\hline & & & $\begin{array}{l}\text { Ley } 09 \text { de } 1979 \text { y el Decreto Ley } 2811 \text { de } \\
1974 \text {, en cuanto a emisiones atmosféricas }\end{array}$ \\
\hline & Decreto & 948 de 1995 & $\begin{array}{l}\text { Se reglamentan, parcialmente la Ley } 23 \text { de } \\
\text { 1973, los artículos } 33,73,74,75 \text { y } 76 \text { del } \\
\text { Decreto-ley } 2811 \text { de 1974; los artículos } 41 \text {, } \\
42,43,44,45,48 \text { y } 49 \text { de la Ley } 9^{a} \text { de } 1979 ; \\
\text { y la Ley } 99 \text { de } 1993 \text {, en relación con la } \\
\text { prevención y control de la contaminación } \\
\text { atmosférica y la protección de la calidad del } \\
\text { aire. }\end{array}$ \\
\hline & Resolución & 627 de 2006 & $\begin{array}{l}\text { Se establece la norma nacional de emisión de } \\
\text { ruido y ruido ambiental. }\end{array}$ \\
\hline & Resolución & 601 de 2006 & $\begin{array}{l}\text { Se establece la Norma de Calidad del Aire o } \\
\text { Nivel de Inmisión, para todo el territorio } \\
\text { nacional en condiciones de referencia }\end{array}$ \\
\hline \multirow{5}{*}{ RESIDUOS } & & 1998 & $\begin{array}{l}\text { Política para la Gestión Integral de Residuos } \\
\text { (GIRS) }\end{array}$ \\
\hline & Ley & 1252 de 2008 & $\begin{array}{l}\text { Por la cual se dictan normas prohibitivas en } \\
\text { materia ambiental referentes a los residuos y } \\
\text { desechos peligrosos y se dictan otras } \\
\text { disposiciones. }\end{array}$ \\
\hline & Decreto & 4741 de 2005 & $\begin{array}{l}\text { Se reglamenta parcialmente la prevención y } \\
\text { el manejo de los residuos o desechos } \\
\text { peligrosos generados en el marco de la } \\
\text { gestión integral. }\end{array}$ \\
\hline & Resolución & 1362 de 2007 & $\begin{array}{l}\text { Expedida por el Ministerio de Ambiente, } \\
\text { Vivienda y Desarrollo Territorial, por la cual } \\
\text { se establece los requisitos y el procedimiento } \\
\text { para el registro de generadores de residuos o } \\
\text { desechos peligrosos, a que hacen referencia } \\
\text { los artículos } 27^{\circ} \text { y } 28^{\circ} \text { del decreto } 4741 \text { del } \\
30 \text { de diciembre de } 2005 \text {. }\end{array}$ \\
\hline & Ley & 1252 de 2008 & $\begin{array}{l}\text { Se dictan normas prohibitivas en material } \\
\text { ambiental referente a los residuos y desechos }\end{array}$ \\
\hline
\end{tabular}




\begin{tabular}{|c|c|c|c|}
\hline & & & peligrosos y se dictan otras disposiciones. \\
\hline \multirow{9}{*}{ HIDROCARBUROS } & Resolución & 1506 de 2008 & $\begin{array}{l}\text { Se señalan los criterios para delimitar los } \\
\text { campos de producción de hidrocarburos } \\
\text { existentes, para efectos de la aplicación de } \\
\text { los instrumentos ambientales, se modifican } \\
\text { las Resoluciones } 1137 \text { de } 1996 \text { y } 482 \text { de } \\
2003 \text { y se adoptan otras disposiciones }\end{array}$ \\
\hline & Decreto & 2020 de 2010 & $\begin{array}{l}\text { Se reglamenta el Título VIII de la Ley } 99 \text { de } \\
1993 \text { sobre licencias ambientales. }\end{array}$ \\
\hline & Decreto & 330 de 2010 & $\begin{array}{l}\text { Se reglamentan las audiencias públicas } \\
\text { ambientales y se deroga el Decreto } 2762 \text { de } \\
2005\end{array}$ \\
\hline & Decreto & 500 de 2006 & $\begin{array}{l}\text { Se modifica el Decreto } 1220 \text { del } 21 \text { de abril } \\
\text { de } 2005 \text {, reglamentario del Título VIII de la } \\
\text { Ley } 99 \text { de } 1993 \text { sobre licencias ambientales. }\end{array}$ \\
\hline & Decreto & 1900 de 2006 & $\begin{array}{l}\text { Se reglamenta el parágrafo del artículo } 43 \text { de } \\
\text { la Ley } 99 \text { de } 1993 \text { y se dictan otras } \\
\text { disposiciones. }\end{array}$ \\
\hline & Decreto & 1220 de 2005 & $\begin{array}{l}\text { Se reglamenta el parágrafo del artículo } 43 \text { de } \\
\text { la Ley } 99 \text { de } 1993 \text { y se dictan otras } \\
\text { disposiciones. }\end{array}$ \\
\hline & Decreto & 321 de 1999 & $\begin{array}{l}\text { Se adopta el Plan Nacional de Contingencia } \\
\text { contra derrames de Hidrocarburos, Derivados } \\
\text { y Sustancias Nocivas. }\end{array}$ \\
\hline & Resolución & 655 de 1995 & $\begin{array}{l}\text { Se establecen los requisitos y condiciones } \\
\text { para la solicitud y obtención de la Licencia } \\
\text { Ambiental establecida por el artículo } 132 \text { del } \\
\text { Decreto Ley } 2150 \text { de } 1995 \text {. }\end{array}$ \\
\hline & Decreto & 1056 de 1953 & Por el cual se expide el Código de Petróleos. \\
\hline $\begin{array}{l}\text { ESPECIES } \\
\text { SILVESTRES. }\end{array}$ & Resolución & 584 de 2002 & $\begin{array}{l}\text { Se declaran las especies silvestres que se } \\
\text { encuentran amenazadas en el territorio } \\
\text { nacional y se adoptan otras disposiciones. }\end{array}$ \\
\hline $\begin{array}{l}\text { AREAS } \\
\text { PROTEGIDAS }\end{array}$ & Decreto & 2372 de 2010 & $\begin{array}{l}\text { Se reglamenta el Decreto-ley } 2811 \text { de } 1974 \text {, } \\
\text { la Ley } 99 \text { de } 1993 \text {, la Ley } 165 \text { de } 1994 \text { y el } \\
\text { Decreto-ley } 216 \text { de } 2003 \text {, en relación con el } \\
\text { Sistema Nacional de Áreas Protegidas, las }\end{array}$ \\
\hline
\end{tabular}




\begin{tabular}{|c|c|c|c|}
\hline & & & $\begin{array}{l}\text { categorías de manejo que lo conforman y se } \\
\text { dictan otras disposiciones. }\end{array}$ \\
\hline DRMI & Acuerdo & 20 de 2014 & $\begin{array}{l}\text { Por el cual se declara, reserva, delimita y } \\
\text { alindera el Distrito Regional de Manejo } \\
\text { Integrado DRMI cuchilla Negra y Guanaque, } \\
\text { en los municipios de Santa María, Chivor, } \\
\text { Macanal y Campohermoso, en jurisdicción } \\
\text { de la Corporación Autónoma Regional de } \\
\text { Chivor CORPOCHIVOR. }\end{array}$ \\
\hline POMCAS & Decreto & 1640 de 2012 & $\begin{array}{l}\text { Se reglamentan los instrumentos para la } \\
\text { planificación, ordenación y manejo de las } \\
\text { cuencas hidrográficas y acuíferos, y se dictan } \\
\text { otras disposiciones. }\end{array}$ \\
\hline \multirow{7}{*}{$\begin{array}{l}\text { ORDENAMIENTO } \\
\text { TERRITORIAL }\end{array}$} & Ley & 388 de 1997. & $\begin{array}{l}\text { Se modifica la ley } 9 \text { de } 1989 \text { y la ley } 2 \text { de } \\
1991 \text { y se dictan otras disposiciones. }\end{array}$ \\
\hline & Ley & 507 de 1999 & Se modifica la ley 388 de 1997 \\
\hline & Decreto & 097 de 2006 & $\begin{array}{l}\text { Se reglamenta la expedición de licencias } \\
\text { urbanísticas en suelo rural y se expiden otras } \\
\text { disposiciones }\end{array}$ \\
\hline & Decreto & 3600 de 2007 & $\begin{array}{l}\text { Se reglamentan las disposiciones de las } \\
\text { Leyes } 99 \text { de } 1993 \text { y } 388 \text { de } 1997 \text { relativas a } \\
\text { las determinantes de ordenamiento del suelo } \\
\text { rural y al desarrollo de actuaciones } \\
\text { urbanísticas de parcelación y edificación en } \\
\text { este tipo de suelo y se adoptan otras } \\
\text { disposiciones. }\end{array}$ \\
\hline & Decreto & 4066 de 2007 & $\begin{array}{l}\text { Por el cual se modifican los artículos } 1^{\circ}, 9^{\circ} \text {, } \\
10,11,14,17,18 \text { y } 19 \text { del Decreto } 3600 \text { de } \\
2007 \text { y se dictan otras disposiciones. }\end{array}$ \\
\hline & Decreto & 1478 de 2013 & $\begin{array}{l}\text { Se modifica parcialmente el Decreto } 2181 \text { de } \\
2006\end{array}$ \\
\hline & Decreto & 306 de 1999 & $\begin{array}{l}\text { Se expiden los determinantes ambientales } \\
\text { para la elaboración de planes básicos y } \\
\text { esquemas de ordenamiento territorial. }\end{array}$ \\
\hline
\end{tabular}




\begin{tabular}{|c|c|c|c|}
\hline & Resolución & 221 de 2014 & $\begin{array}{l}\text { Se compilan las Determinantes Ambientales } \\
\text { para la formulación, revisión y/o ajuste de los } \\
\text { Planes de Ordenamiento Territorial de los } \\
\text { municipios de la jurisdicción de } \\
\text { CORPOCHIVOR }\end{array}$ \\
\hline \multirow{5}{*}{$\begin{array}{l}\text { LICENCIAS } \\
\text { AMBIENTALES }\end{array}$} & Decreto & 1753 de 1994 & $\begin{array}{l}\text { Establece las disposiciones de un plan de } \\
\text { manejo ambiental, en donde, de manera } \\
\text { detallada, establece las acciones que se } \\
\text { requieren para prevenir, mitigar, controlar, } \\
\text { compensar, y corregir los posibles efectos o } \\
\text { impactos ambientales negativos causados por } \\
\text { un proyecto, obra o actividad }\end{array}$ \\
\hline & Decreto & 1751 de 1996. & $\begin{array}{l}\text { Reglamentación sobre aprovechamiento } \\
\text { forestal. }\end{array}$ \\
\hline & Decreto & 2041 de 2014 & $\begin{array}{l}\text { Se reglamenta el Título VIII de la Ley } 99 \text { del } \\
93 \text { sobre licencias ambientales. }\end{array}$ \\
\hline & Decreto & 783 de 2015 & $\begin{array}{l}\text { "Por el cual se deroga el numeral } 10 \text { del } \\
\text { artículo } 24 \text { del Decreto } 2041 \text { de } 2014 " \text {. }\end{array}$ \\
\hline & Decreto & 1076 de 2015 & $\begin{array}{l}\text { "Por medio del cual se expide el Decreto } \\
\text { Único Reglamentario del Sector Ambiente y } \\
\text { Desarrollo Sostenible". }\end{array}$ \\
\hline $\begin{array}{l}\text { PLANIFICACIÓN } \\
\text { AMBIENTAL }\end{array}$ & Ley & 1753 de 2015 & $\begin{array}{l}\text { Por la cual se expide el Plan Nacional de } \\
\text { Desarrollo 2014-2018 "Todos por un nuevo } \\
\text { país" }\end{array}$ \\
\hline
\end{tabular}




\section{ANEXO No. 4 Fases de la investigación Cualitativa.}

\section{Tabla 8}

Fases investigación cualitativa

\begin{tabular}{|c|c|}
\hline FASE INVESTIGACIÓN & INVESTIGACIÓN CUALITATIVA \\
\hline \multicolumn{2}{|c|}{ PLANTEAMIENTO DE LA INVESTIGACIÓN } \\
\hline \multirow{2}{*}{ Relación teoría -investigación } & Abierta, interactiva. \\
\hline & Método inductivo (la teoría surge de la observación) \\
\hline Función de la literatura & Auxiliar \\
\hline Conceptos & Orientativos, abiertos, en construcción. \\
\hline Relación con el entorno. & Naturalista. \\
\hline $\begin{array}{l}\text { Interacción psicológica entre el estudioso y el } \\
\text { objeto estudiado. }\end{array}$ & Interacción empática con el objeto estudiado. \\
\hline Interacción física estudioso - estudiado & Proximidad, contacto. \\
\hline Papel del sujeto estudiado & Activo. \\
\hline \multicolumn{2}{|c|}{ RECOPILACIÓN DE DATOS } \\
\hline Diseño de la investigación & $\begin{array}{l}\text { Desestructurado, abierto, se construye en el curso de la } \\
\text { investigación. }\end{array}$ \\
\hline Representatividad / Inferencia. & Casos individuales no representativos estadísticamente. \\
\hline Instrumentos de investigación. & $\begin{array}{l}\text { Varía según el interés de los sujetos. No se tiende a la } \\
\text { estandarización. }\end{array}$ \\
\hline Naturaleza de los datos. & Soft, Subjetivos y flexibles. \\
\hline \multicolumn{2}{|c|}{ ANÁLISIS DE LOS DATOS. } \\
\hline Objeto de análisis. & El individuo (análisis por sujetos). \\
\hline Objetivo del análisis. & Comprender a los sujetos. \\
\hline Usos de técnicas matemáticas y estadísticas. & Ninguno. \\
\hline \multicolumn{2}{|r|}{ RESULTADOS } \\
\hline Presentación de datos. & Fragmentos de entrevistas, textos (enfoque narrativo) \\
\hline Generalizaciones. & $\begin{array}{l}\text { Clasificaciones y tipologías. Tipos ideales. Lógica de la } \\
\text { clasificación. }\end{array}$ \\
\hline Alcance de los resultados & Especificidad. \\
\hline
\end{tabular}


ANEXO 5: Participantes herramientas de investigación.

\section{Tabla 9}

Participantes taller de cartografía social

\begin{tabular}{|c|l|l|l|l|}
\hline No. & \multicolumn{1}{|c|}{ Nombres y Apellidos } & \multicolumn{1}{|c|}{ Profesión } & Mesa en la que participó & \multicolumn{1}{|c|}{ Desarrollo Profesional } \\
\hline 1 & Claudia Catalina Rodríguez L. & Bióloga & Conflictos sociambientales & Ordenamiento Territorial. \\
\hline 2 & Cristian F. Martin & Periodista & Conflictos sociambientales & Comunicación Social. \\
\hline 3 & Omar Forero & Adm. Empresas & Conflictos sociambientales & Administración Empresas \\
\hline 4 & Larissa Aragón & Ing. Ambiental & Conflictos sociambientales & Extensión Comunitaria. \\
\hline 5 & Briyith Sacristán & Adm. Ambiental & Biodiversidad y Ecosistemas & Áreas Estratégicas. \\
\hline 6 & Néstor A. Valero. & Ing. Forestal. & Biodiversidad y Ecosistemas & Forestal. \\
\hline 7 & Natanael Morales. & Ing. Civil. & Biodiversidad y Ecosistemas & Obras Recurso Hídrico. \\
\hline 8 & Sofía Ávila Camelo. & Bióloga. & Biodiversidad y Ecosistemas & Áreas Protegidas. \\
\hline 9 & Mauricio Otálora. & Biólogo. & Biodiversidad y Ecosistemas & Declaratoria DRMl. \\
\hline 10 & Ana Celia Salinas. & Ing. Forestal & Sector Productivo. & Gestión Ambiental. \\
\hline 11 & Jorge E. Castillo Duarte. & Ing. Sanitario. & Sector Productivo. & Manejo integral de residuos. \\
\hline 12 & Diana Milena Jiménez. & Zootecnista & Sector Productivo. & Cadenas productivas. \\
\hline 13 & Jhon Fredy Vallejo. & Administrador. & Sector Productivo. & Mercados Verdes. \\
\hline 14 & Norfa Yilen Cárdenas. & Ing. Civil. & Gestión del Riesgo. & Manejo riesgo ambiental. \\
\hline 15 & Nelson Leguizamón & Ing. Minas. & Gestión del Riesgo. & Extensión Comunitaria riesgos. \\
\hline 16 & Jorge E. Guachetá C. & Adm. Ambiental. & Gestión del Riesgo. & Instrumentos de planificación. \\
\hline
\end{tabular}

\section{Tabla 10}

\section{Participantes entrevista semi estructurada}

\begin{tabular}{|c|l|l|l|}
\hline No. & \multicolumn{1}{|c|}{ Nombres y Apellidos } & \multicolumn{1}{|c|}{ Profesión } & \multicolumn{1}{|c|}{ Desarrollo Profesional } \\
\hline 1 & Néstor Alexander Valero Fonseca & Ing. Forestal. & Coordinador PGOF. \\
\hline 2 & Mauricio Otálora. & Biólogo. & Coordinador Declaratoria DRMI. \\
\hline 3 & Omar Forero & Adm. Empresas & Ex alcalde de Santa María. \\
\hline 4 & Ruby Esperanza Barrero. & Técnica Ambiental & Extensión a comunidades. \\
\hline 5 & Wilson Aurelio Lozano. & Ing. Ambiental. & Residente municipio Santa María \\
\hline 6 & Edwin Yesid Ortega Castro & Ing. Forestal. & Comunidades - PGOF. \\
\hline 14 & Norfa Yilen Cárdenas. & Ing. Civil. & Manejo riesgo ambiental. \\
\hline 15 & Nelson Leguizamón & Ing. Minas. & Extensión Comunitaria riesgos. \\
\hline 16 & Jorge E. Guachetá C. & Adm. Ambiental. & Instrumentos de planificación. \\
\hline
\end{tabular}


ANEXO 6: Evidencias realización del taller de Cartografía Social.

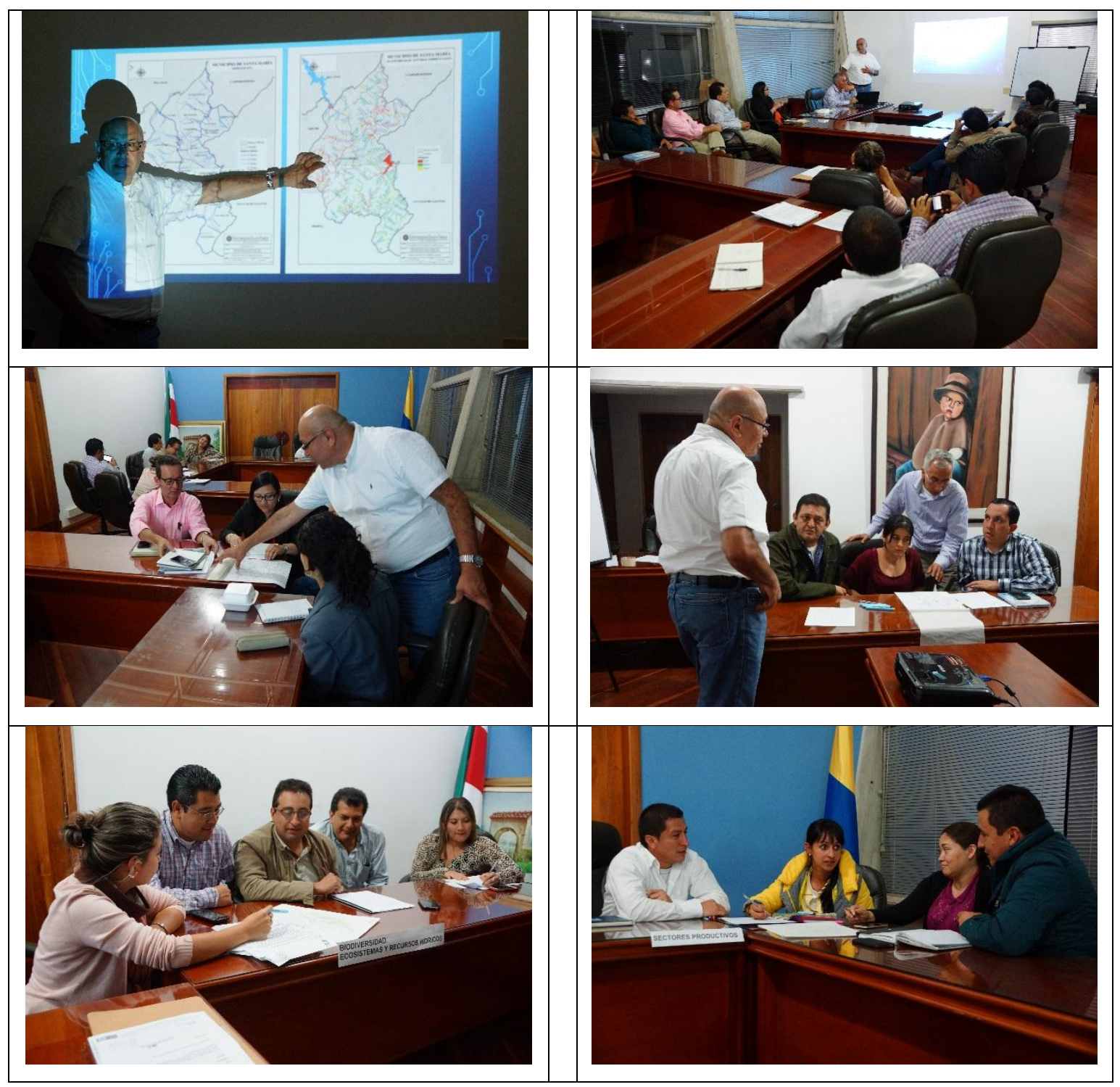




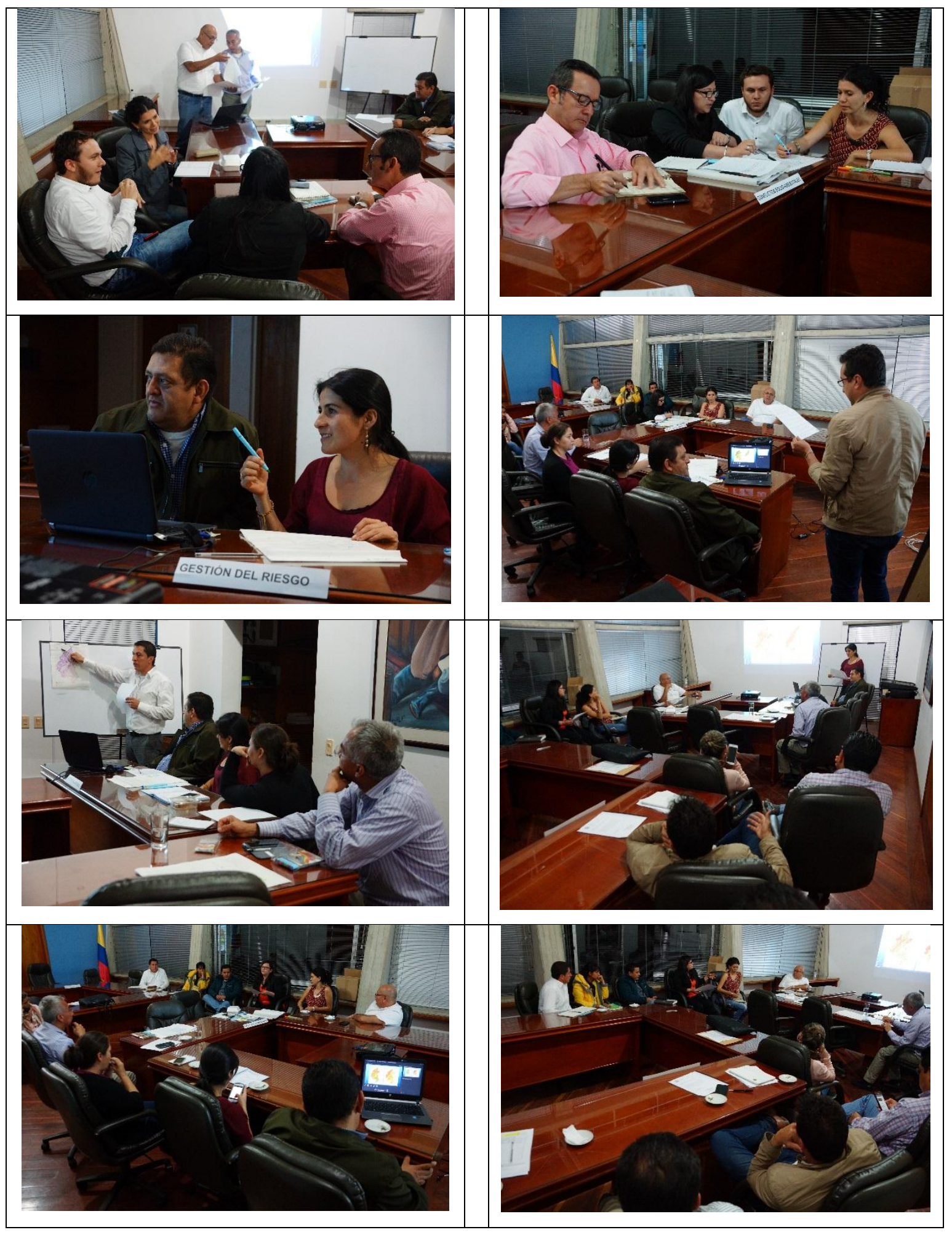


ANEXO 7: Fotografías del territorio.

“Características ecológicas estructurales de los bosque existentes en el municipio de Santa María-Boyacá” (Ministerio de Ambiente y desarrollo sostenible - Corpochivor U. Distrital, 2013, p. 102)

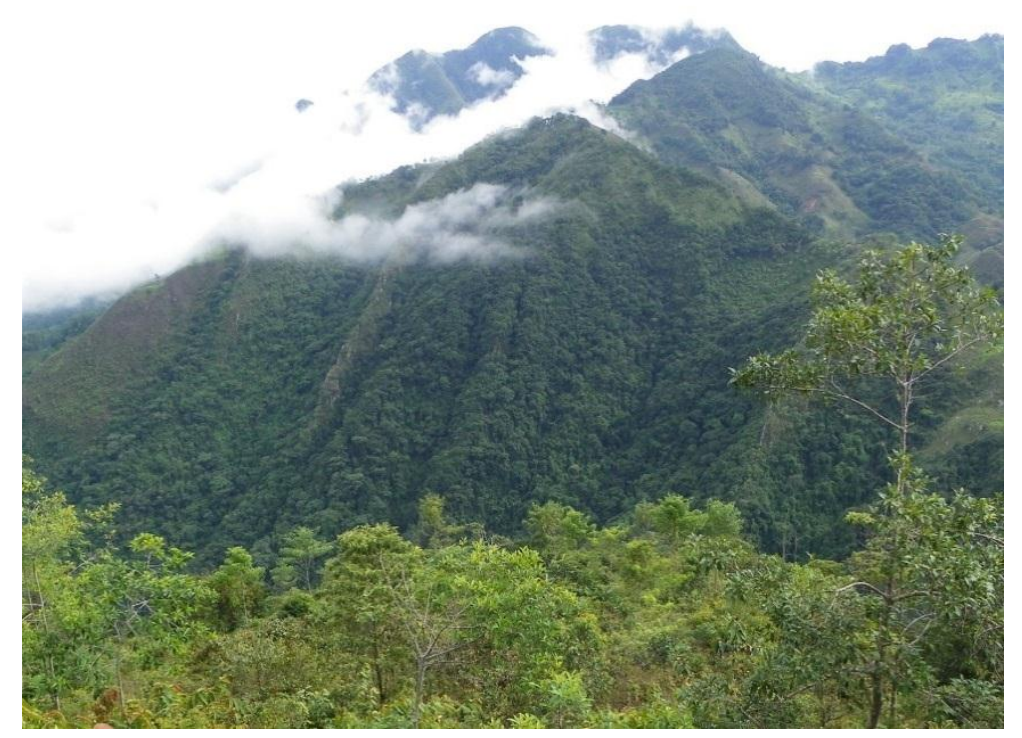

"Foto 3. Bosque de cordillera y serranía, $935 \mathrm{msnm}$. Vereda Calichana, Municipio de Santa María".

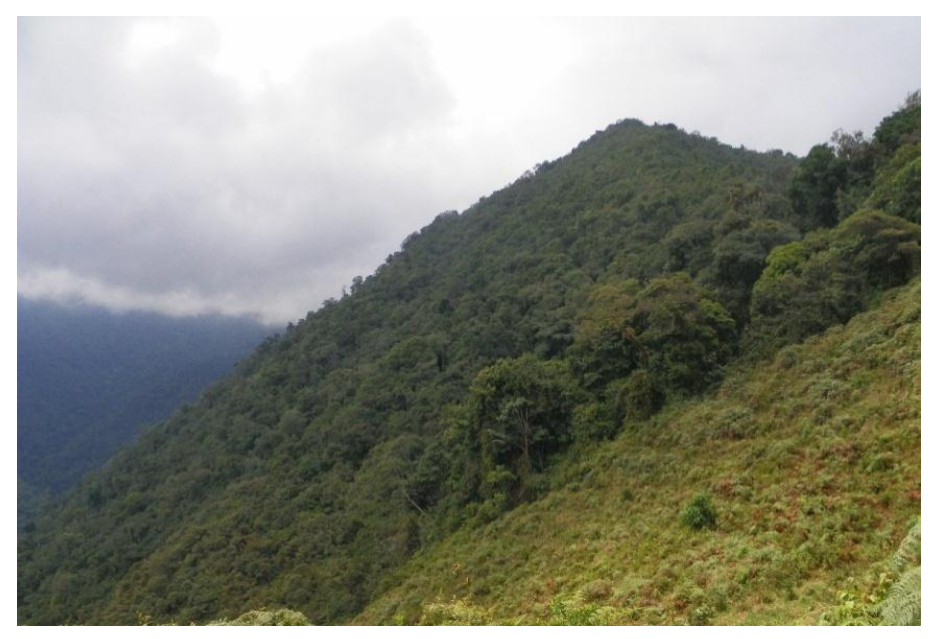


"Foto 21. Bosque Denso que crece en Lomas Bajas (BDDb), vereda Caño Negro, municipio de Santa María, zona de vida bp-PM. Se observa la pérdida de bosques por ampliación de frontera ganadera".

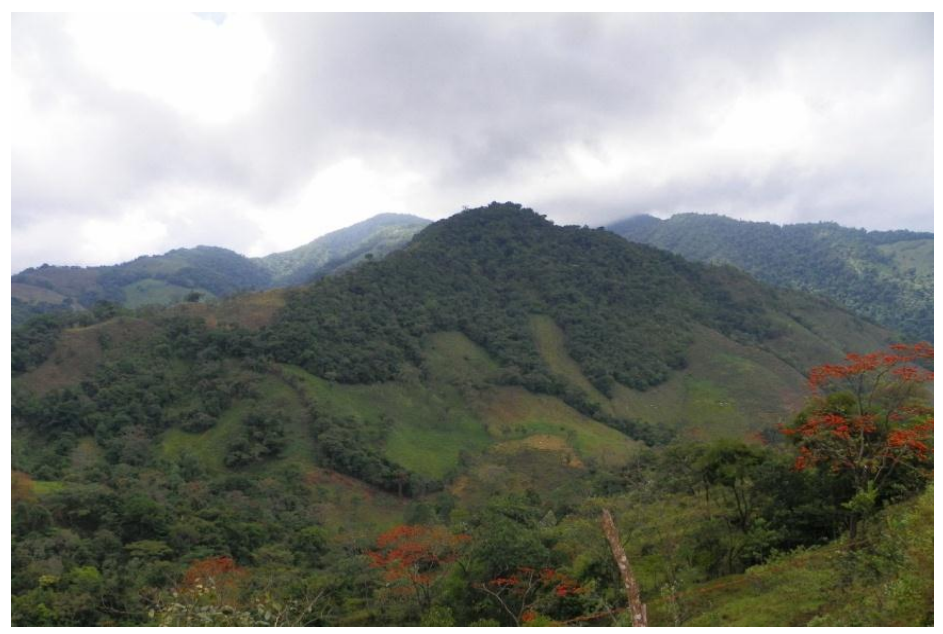

"Foto 22. Bosque Fragmentado de Lomas Bajas (BFrAMDb), vereda Caño Negro, municipio de Santa María, zona de vida bp-PM. Se observa la pérdida de bosques por ampliación de frontera ganadera".

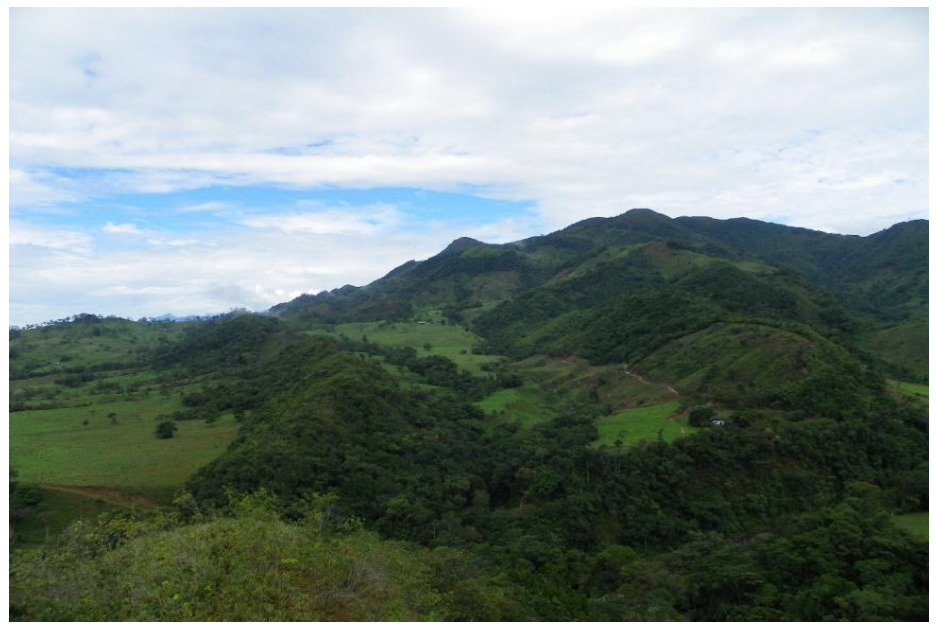

"Foto 23. Relictos de Bosque Fragmentado que se desarrolla en Lomas Bajas (BFrAMDb), alrededor se observan pasturas de ganadería extensiva sobre la geoforma de Depósito Aluvial (Fa), vereda Ceiba Chiquita, municipio de Santa María, zona de vida bmh-T"'. 


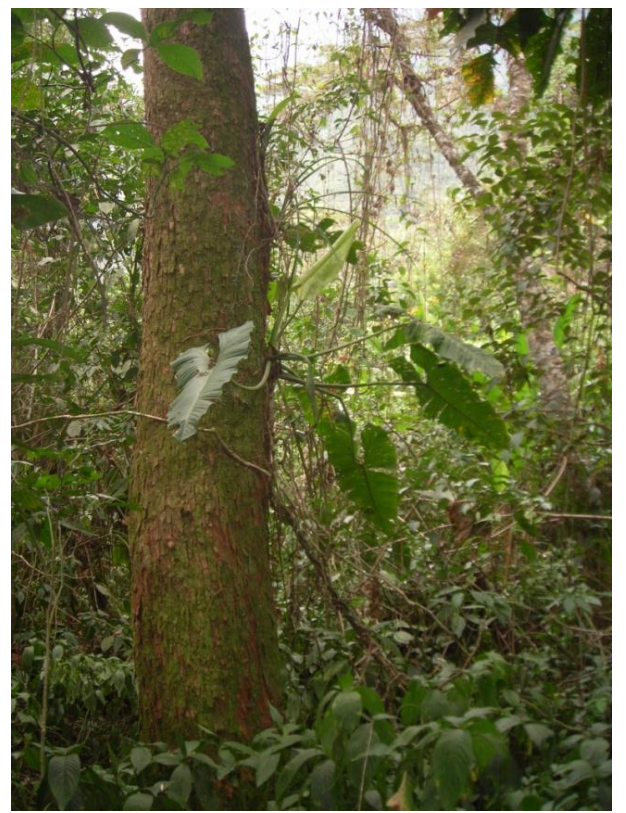

"Foto 24. En el Bosque Fragmentado de Lomas Bajas (BFrAMDb) la composición florística está determinada por el uso previo del suelo, en algunas parcelas se registraron árboles de Yopo (Anadenanthera peregrina) de gran porte como el observado en la foto. Vereda Calichana, municipio de Santa María, zona de vida bmh-T". 


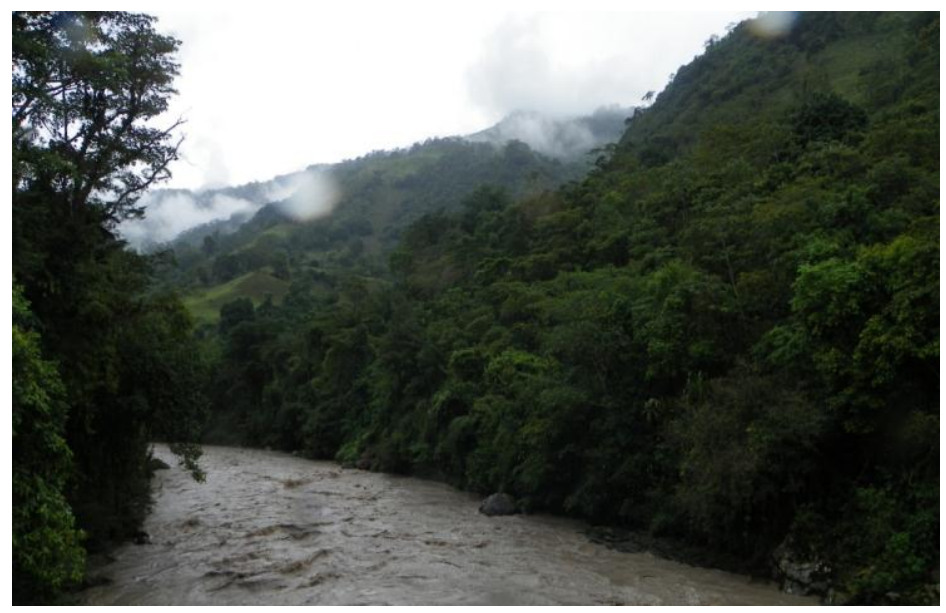

"Foto 25. Bosque Denso de Taludes Erosivos (BDDe), vereda San Agustín, municipio de Santa María, zona de vida bmh-T. La extensión de bosques pertenecientes a esta tipología son escasos en el municipio de Santa María. La permanencia de este relicto está asegurada por tratarse de una zona de protección estricta del Río Lengupá”.

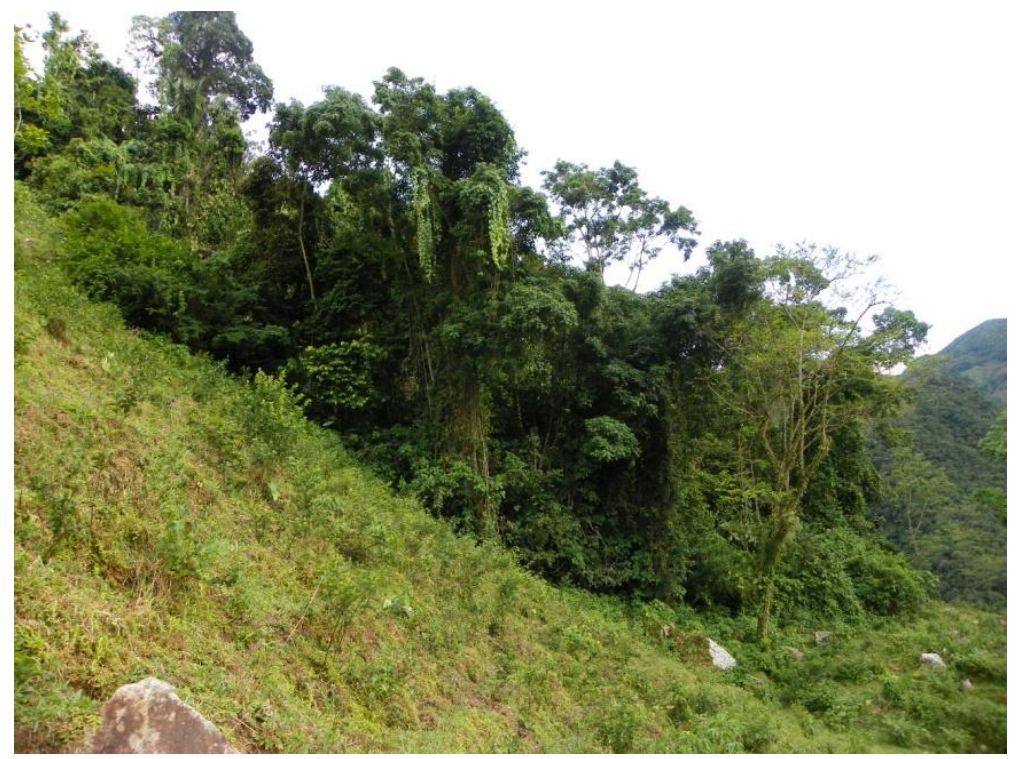

"Foto 26. Bosque Fragmentado que se desarrolla en Taludes Erosivos (BFrAMDe), vereda San Agustín, municipio de Santa María, zona de vida bmh-T”. 


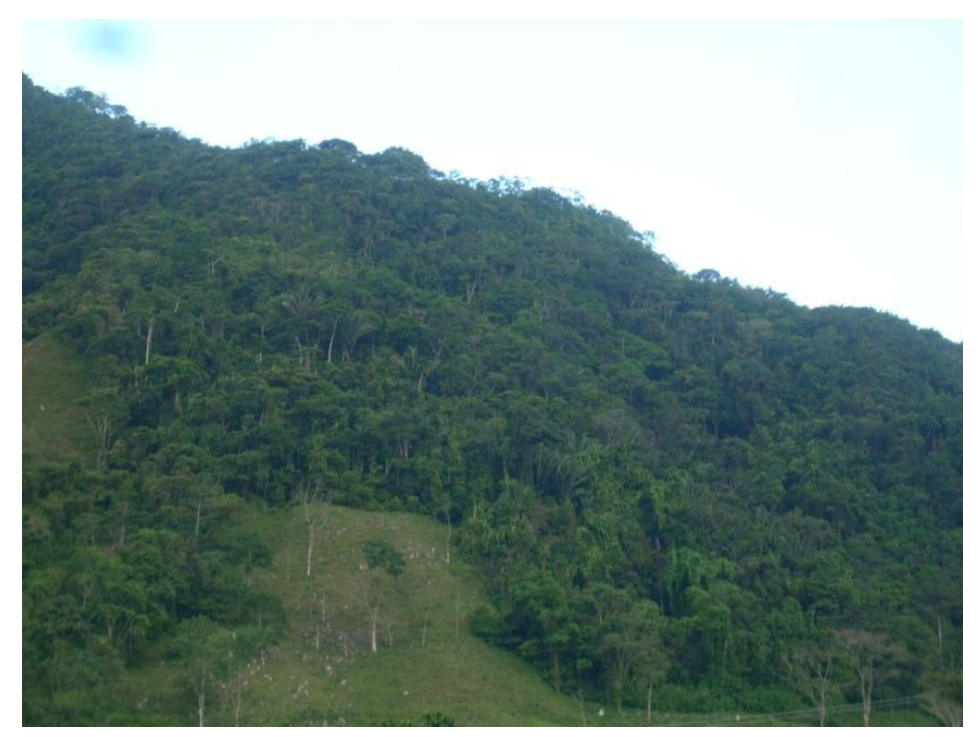

"Foto 27. Bosque Denso que crece en Laderas Estructurales (BDEl), vereda San Agustín, municipio de Santa María, zona de vida bmh-T. Se observa la pérdida de bosques por ampliación de frontera ganadera".

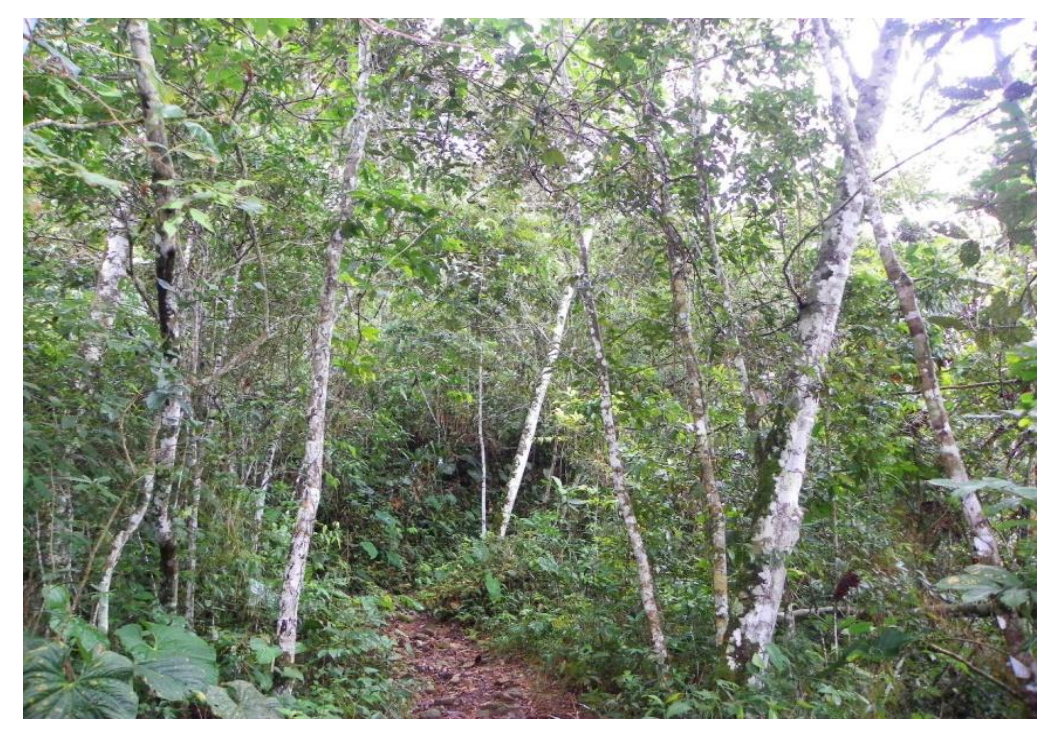

"Foto 28. Bosque Fragmentado que medra sobre Laderas Estructurales (BFrAMEl), vereda San Agustín, municipio de Santa María, zona de vida bmh-T. Se presenta gran disturbación en la estructura y la composición florística del bosque por corta selectiva de especies valiosas. En la foto, camino de extracción con animales abandonado". 